\title{
Transport impacts on atmosphere and climate: Land transport
}

\author{
Elmar Uherek $^{\mathrm{a}, *}$, Tomas Halenka ${ }^{\mathrm{b}}$, Jens Borken-Kleefeld ${ }^{\mathrm{c}, 1}$, Yves Balkanski ${ }^{\mathrm{d}}$, Terje Berntsen ${ }^{\mathrm{e}}$, \\ Carlos Borrego ${ }^{f}$, Michael Gauss ${ }^{g}$, Peter Hoor ${ }^{a}$, Katarzyna Juda-Rezler ${ }^{\text {h }}$, Jos Lelieveld ${ }^{\mathrm{a}}$, \\ Dimitrios Melas $^{\mathrm{i}}$, Kristin Rypdal ${ }^{\mathrm{e}}$, Stephan Schmid ${ }^{\mathrm{j}}$
}

\footnotetext{
${ }^{a}$ Max Planck Institute for Chemistry, Atmospheric Chemistry Department, P.O. Box 3060, D-55020 Mainz, Germany

${ }^{\mathrm{b}}$ Charles University in Prague, Department of Meteorology and Environment Protection, 18000 Prague, Czech Republic

${ }^{\mathrm{c}}$ DLR, Transportation Studies, D-12489 Berlin, Germany

${ }^{\mathrm{d}}$ LSCE/IPSL, Laboratoire CEA-CNRS-UVSQ 91191 Gif-sur-Yvette, France

${ }^{\mathrm{e}}$ CICERO - Center for International Climate and Environmental Research Oslo, 0318 Oslo, Norway

${ }^{\mathrm{f}}$ University of Aveiro, CESAM \& Department of Environment and Planning, 3810-193 Aveiro, Portugal

${ }^{g}$ University of Oslo, Department of Geosciences, 0315 Oslo, Norway

${ }^{\mathrm{h}}$ Warsaw University of Technology, Faculty of Environmental Engineering, Nowowiejska 20, 00-653 Warsaw, Poland

${ }^{\mathrm{i}}$ Aristotle University of Thessaloniki, Physics Department, Thessaloniki, Greece

${ }^{\mathrm{j}}$ DLR, Institute of Vehicle Concepts, D-70569 Stuttgart, Germany
}

\section{A R T I C L E I N F O}

\section{Article history:}

Received 18 July 2008

Received in revised form

29 December 2009

Accepted 8 January 2010

\section{Keywords:}

Transport: road, rail, inland shipping

Emissions

Climate impacts

Radiative forcing

Air pollution

Health impacts

Mobile air conditioners

Vehicle technologies

Emission scenarios

Mitigation scenarios

\begin{abstract}
A B S T R A C T
Emissions from land transport, and from road transport in particular, have significant impacts on the atmosphere and on climate change. This assessment gives an overview of past, present and future emissions from land transport, of their impacts on the atmospheric composition and air quality, on human health and climate change and on options for mitigation.

In the past vehicle exhaust emission control has successfully reduced emissions of nitrogen oxides, carbon monoxide, volatile organic compounds and particulate matter. This contributed to improved air quality and reduced health impacts in industrialised countries. In developing countries however, pollutant emissions have been growing strongly, adversely affecting many populations. In addition, ozone and particulate matter change the radiative balance and hence contribute to global warming on shorter time scales. Latest knowledge on the magnitude of land transport's impact on global warming is reviewed here.

In the future, road transport's emissions of these pollutants are expected to stagnate and then decrease globally. This will then help to improve the air quality notably in developing countries. On the contrary, emissions of carbon dioxide and of halocarbons from mobile air conditioners have been globally increasing and are further expected to grow. Consequently, road transport's impact on climate is gaining in importance. The expected efficiency improvements of vehicles and the introduction of biofuels will not be sufficient to offset the expected strong growth in both, passenger and freight transportation. Technical measures could offer a significant reduction potential, but strong interventions would be needed as markets do not initiate the necessary changes. Further reductions would need a resolute expansion of low-carbon fuels, a tripling of vehicle fuel efficiency and a stagnation in absolute transport volumes. Land transport will remain a key sector in climate change mitigation during the next decades.
\end{abstract}

(c) 2010 Elsevier Ltd. All rights reserved.

\section{Introduction}

\subsection{Scope and structure of this publication}

This is an international assessment of the impacts of land transport on climate and atmospheric composition within the

\footnotetext{
* Corresponding author. Tel.: +49 6131305 310; fax: +49 6131305577.

E-mail address: elmar.uherek@mpic.de (E. Uherek).

1 Now at: IIASA - International Institute for Applied Systems Analysis, Atmospheric Pollution and Economic Development Program, A-2361 Laxenburg, Austria.
}

European 6th Framework project 'ATTICA' publication series (Transport Impacts on Atmosphere and Climate). Further assessments give an overview of Metrics for estimating emission impacts at different time scales (Fuglestvedt et al., 2010), aviation impacts on atmosphere and climate (Lee et al., 2010) and shipping impacts on atmosphere and climate (Eyring et al., 2010).

Emissions from land transport, coming primarily from road vehicles and to a smaller extent from rail and inland shipping, dominate the release of long-lived greenhouse gases from transportation. They make a major and increasing contribution to the total anthropogenic greenhouse effect. Furthermore, many 
short-lived gases and particles are emitted by land transport, which have an impact on atmospheric composition and air quality. This report relies on peer-reviewed literature, selected studies of the recent years and research carried out in the European Quantify project in order to assess what we know about this increasingly important role of land transport. According to the concept of this publication, we give answers to the questions: What is emitted? What are the impacts on the atmosphere? What are the impacts on the radiation budget and climate change? Which responses and future developments are likely?

After an introduction and view back in chapter 1, we give in chapter 2 an overview of the different types of direct and indirect emissions. This includes long-lived as well as short-lived emissions, released by land transport vehicles on a global scale and partially in comparison of industrialised and developing regions. The briefly discussed chemistry of active species such as ozone $\left(\mathrm{O}_{3}\right)$ nitrogen oxides $\left(\mathrm{NO}_{\mathrm{x}}\right)$, carbon monoxide $(\mathrm{CO})$ or non-methane volatile organic compounds (NMVOC) have an impact on atmospheric composition which is presented as a result of global models in chapter 3. These species or particles or both together have also an impact on air quality and health which is summarised in the same section. In particular carbon dioxide and ozone, but to a nonnegligible extent also halocarbons have an influence on radiative forcing and the climate system. This is discussed in chapter 4 . Finally, we present in chapter 5 (future developments) evolving trends in vehicle technology, alternative fuels and mobility management and assess their potential to reduce emissions. In different emission scenarios we give an outlook to the future, although the respective calculations of future climate impacts are still part of ongoing research.

\subsection{Land transport from the past to the present}

Many people associate an increase in their personal mobility with an increase in life quality. From the time of ancient civilizations up to about 250 years ago, the power to overcome long distances came from horses, donkeys, cattle, camels or human muscles. Nowadays climate science considers the period of the development of steam engines allowing to convert the energy of fossil fuels into the movement of a wheel (e.g. by James Watt in 1769) as the end of the pre-industrial time and as the start of a significant human alteration of the natural greenhouse effect. These engines, based on fossil fuels, did not only initialise the start of the industrial revolution but also of modern transport. First they were applied in ships and trains. Between 1900 and 1930 it is likely that shipping was still the largest source of $\mathrm{CO}_{2}$ emissions from the transport sector (Fuglestvedt et al., 2008).

Since ships and rail were first the dominating emitters they still have a relatively higher relevance in cumulative $\mathrm{CO}_{2}$ than in present emissions as shown in Table 1. But after 1910 road traffic gained soon more and more importance, overtaking all other transport modes. Fig. 1 demonstrates the enormous increase in road vehicles, which are now responsible for typically $75-80 \%$ of all $\mathrm{CO}_{2}$ emissions from transport.

The car fleet in the United States grew from about 140,000 vehicles in 1907 to more than 20 million in 1927. A similar development took place in Europe with a delay of about 30 years, i.e. after the second world war. Still in 1960, there were less than 10 cars per 1000 inhabitants in United Kingdom, growing up to about 400 and more within 40 years and boosting the usage of oil. Now, again with a shift of 30 years, a similar evolution starts in East Asia. The permanently increasing fuel consumption in road transport will soon generate more than one fifth of the global $\mathrm{CO}_{2}$ emissions.

Shorter-lived exhaust gases from dense road traffic had and have negative impacts on air quality. Road vehicles are a major
Table 1

Emissions of $\mathrm{CO}_{2}$ from transport in year 2000 and cumulative emissions $1900-2000$. Derived from calculations condensed in Fuglestvedt et al. (2008).

\begin{tabular}{lllllll}
\hline & \multicolumn{2}{l}{2000} & & \multicolumn{2}{l}{ Cumulative 1900-2000 } \\
\cline { 2 - 3 } \cline { 5 - 6 } \cline { 5 - 6 } & Emissions $\mathrm{Tg} \mathrm{CO}_{2}$ & Share [\%] & & Emissions $\mathrm{Tg} \mathrm{CO}_{2}$ & Share [\%] \\
\hline Road & 4282 & 72.3 & & 114,494 & 55.1 \\
Rail & 124 & 2.1 & & 20,913 & 10.1 \\
Maritime shipping & 626 & 10.6 & & 31,940 & 15.4 \\
Aviation & 688 & 11.6 & & 16,890 & 8.1 \\
\hline
\end{tabular}

source of nitrogen oxides over land. The induced photochemical smog is often mixed with particle emissions and was called 'ozone smog' or Los Angeles smog. It was first discovered in Los Angeles and soon attributed to the dense road traffic in the 1940th and 1950th. Maximum concentration observed in L.A. was 580 ppb $\left(1160 \mu \mathrm{g} \mathrm{m}^{-3}\right)$ of ozone. An answer to the problem was the regulation of car emissions which began with the U.S. Clean Air Act of 1970. Mass production of catalytic converters started for the 1975 car generation in the U.S. About one decade later it was introduced also in Europe.

Road transport became more and more important not only for private passenger vehicles, but also in the cargo business. Vans were more flexible than trains or ships and the continuously improving state of the road infrastructure increased their mobility. The share of road transport in the European inland freight transport markets in tonne kilometres of freight reached 78\% in 2004 (EEA member countries). The total freight volume increased by $43 \%$ between 1992 and 2005 (EEA report No. 1/2007).

Gradually, increasing attention has been paid to road transport as a health problem. Due to stricter legislation and improved reduction technologies emissions could be reduced in the recent two decades. Following near stagnation during the 1970s and 1980s, the emissions of carbon monoxide (CO) and non-methane volatile organic compounds (NMVOC) fell by a factor of two to three in 10 years in many European countries. Also nitrogen oxide $\left(\mathrm{NO}_{\mathrm{x}}\right)$ and particulate matter (PM) emissions fell after a peak around 1990, although the problem of increasing $\mathrm{NO}_{2}$ emissions from diesel vehicles with particle filters still requires improved technologies in order to achieve continued reductions.

Carbon dioxide emissions continued to increase despite improved fuel efficiency. Increasing mileage and comfort (e.g. air conditioners) as well as larger and more powerful vehicles more

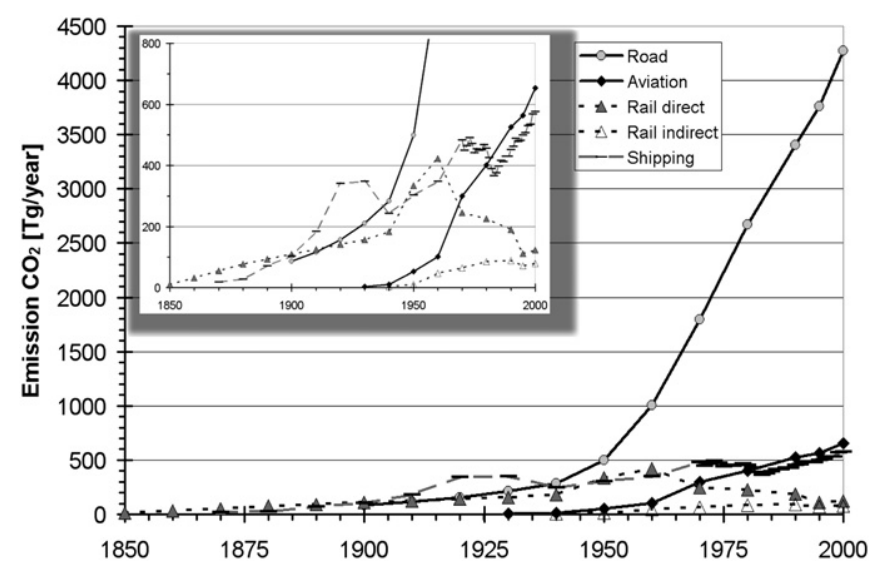

Fig. 1. $\mathrm{CO}_{2}$ emissions from the transport sector 1900-2000 (from Fuglestvedt et al., 2008). The inset shows the lower values with a higher resolution of the $y$-axis. 
than outweighed the progress made in engine technologies. The example in Fig. 2 of the development in France, representative of many countries in Western Europe, illustrates this trend.

The situation is slightly different for the United States, where large cars were already common in the past. Due to higher engine efficiency and smaller vehicles the fuel used per vehicle does not increase anymore. But the number of registered vehicles and the total amount of motor fuel consumed did not yet reach a saturation point.

While the so far dominating European and North American regions could not yet achieve a reduction of their fuel consumption, a very strong growth is observed in many developing countries. Therefore land transport emissions continue to be a major burden for the environment. The analysis of the present situation and the estimation of future developments are subject of numerous scientific publications and several assessments. An overview of major studies and recent research is also given in Appendix A.

\section{Land transport emissions}

\subsection{Exhaust emissions of road transport}

There are few recent estimates of road transport's global fuel consumption and related $\mathrm{CO}_{2}$ emissions (IEA, 2004, 2005a,b; IEA/ OECD, 2006; Turton, 2006) and a few estimates include non- $\mathrm{CO}_{2}$ exhaust emissions (Aardenne et al., 2005; Borken et al., 2007; Fulton and Eads, 2004). At the level of regions and countries more emission inventories are available and the level of detail in both, approach and results, usually increases strongly. Here, we first discuss the global emission totals and then briefly analyse emissions in North America, Western Europe and developing Asia as the most relevant regions.

All global emission estimates take the road fuel consumption as given by the International Energy Agency as a reference (e.g. IEA, 2004, 2005a,b): Aardenne et al. (2005) have taken the amount of fuel consumed as starting point and multiplied with fuel specific emission factors (Tier 1 approach, cf. IPCC, 2006). Fulton and Eads (2004) and Borken et al. (2007) have calibrated their vehicle mileage to the year 2000 fuel consumption (Tier 2 approach). Borken et al. (2007) cross-checked with national data and calculated the fuel consumption bottom-up notably for China, Iran, SaudiArabia, Russia and India as well as many smaller countries in Africa and Latin America. They conclude on misallocation of the statistical entries, under- or non-reporting notably of the diesel fuel consumption and derive a global diesel fuel consumption of

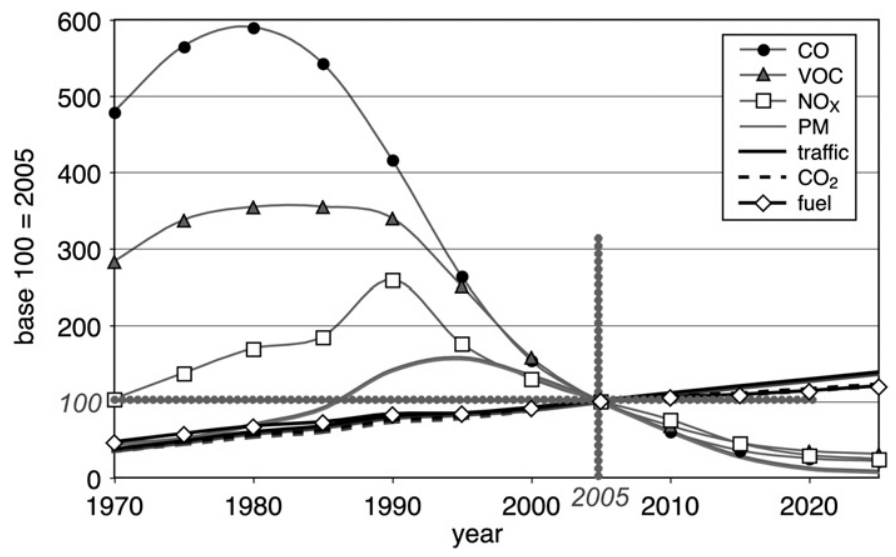

Fig. 2. Relative evolution of mileage and emissions of French road-traffic emissions from 1973 to 2020. Base 100 = year 2005 (Joumard, 2005).
550 Mtoe, about $6 \%$ higher than reported by IEA energy statistics for that year. About $38 \%$ of the 1450 Mtoe total fuel consumed is diesel, $60 \%$ is gasoline, gaseous fuels and liquid biofuels account for about $1 \%$ and $0.7 \%$ respectively. In consequence, all global emission estimates assume about the same amount of fossil fuel and calculate about the same global $\mathrm{CO}_{2}$ emissions.

Differences are much stronger for the non- $\mathrm{CO}_{2}$ emissions because of the different assumptions how the mileage is distributed among the different vehicle categories and what the average exhaust emission factors are. Both, Borken et al. (2007) and Fulton and Eads (2004) have differentiated by 5 vehicle categories and several fuel types and the emission factors refer to the transport activity of each vehicle fuel combination. All authors have aggregated countries to about 11-13 world regions. Thus, the emission factors are assumed as regional averages and differences between countries within one region are neglected.

More than two thirds of the total global fuel is consumed in OECD countries, most of which in the US. Hence, the much higher data uncertainties in non-OECD regions and eventual corrections applied have not influenced much the global balance. However they will be important for the total exhaust emissions in the respective regions, as the emission level strongly depends on the vehicle technology.

\subsubsection{Emissions of road transportation worldwide in the year 2000}

Total exhaust emissions by road transportation worldwide are summarised in Table 2 . As there is largely agreement on the fuel types and their total amounts, the assumptions about emission factors determine the overall results. They concur for $\mathrm{CO}_{2}$ and $\mathrm{NO}_{\mathrm{x}}$ emissions, but there are large differences for all other compounds. To understand them, and hence to judge on the plausibility of one or the other figure, we need to analyse results and emission factors on the regional level; otherwise all will be dominated by the emissions of the OECD region. Emission factors from Aardenne et al. (2005) are based on estimates for 1995 or 1990 in OECD or nonOECD regions. Fulton and Eads (2004) underscore that their data for non-OECD regions are rough estimates only.

\subsubsection{Emissions of road transportation in various world regions in the year 2000}

The different world regions contribute in variable amounts to the global exhaust emissions. Usually, North America, Europe and the highly populated Asian region contribute significant amounts. However, vice versa, how well the road transport in the important regions has been modelled determines how reliable the resulting global estimate can be considered. Therefore an analysis of the regional emissions is mandatory and there are also further regional inventory data to compare with, often produced with a much more detailed method (e.g. Amann et al., 2008; Baidya and BorkenKleefeld, 2009; Cai and Xie, 2007; EEA, 2006; Ohara et al., 2007; Streets et al., 2003; US-EPA, 2005). For the purpose of this review

Table 2

Road transportation's exhaust emissions worldwide in the year 2000.

\begin{tabular}{|c|c|c|c|c|c|c|c|}
\hline \multirow[t]{2}{*}{ Ref. } & $\mathrm{CO}_{2}$ & $\mathrm{SO}_{2}$ & $\mathrm{CO}$ & NMVOC & $\mathrm{CH}_{4}$ & $\mathrm{NO}_{\mathrm{x}}$ & PM \\
\hline & $\mathrm{Tg}$ & $\operatorname{Tg~S}$ & $\mathrm{Tg}$ & $\mathrm{Tg}$ & $\mathrm{Tg}$ & $\operatorname{Tg} \mathrm{N}$ & $\mathrm{Tg}$ \\
\hline 1 & 4276 & 1.83 & 186 & 33.8 & n.a. & 8.7 & n.a. \\
\hline 2 & 4282 & 0.95 & 110 & $20.4^{\mathrm{a}}$ & 0.8 & 9.1 & $\begin{array}{l}1.37, \mathrm{BC}: 0.72 \text {, } \\
\text { OC: } 0.31\end{array}$ \\
\hline 3 & 4037 & n.a. & 272 & $42.3^{b}$ & n.a. & 9 & 2.7 \\
\hline
\end{tabular}

References: (1) Aardenne et al. (2005), (2) Borken et al. (2007), (3) Fulton and Eads (2004).

a Evaporative emissions estimate included.

b Total VOC emissions. 
we cannot go into the details of each approach, but already the comparison of the final results (Table 3 ) is revealing.

\subsubsection{Carbon dioxide emissions}

All inventories concur for carbon dioxide emissions both globally and in the OECD regions. The slightly higher value of Aardenne et al. (2005) for North America cannot be confirmed by national (US-DoT, 2006) or international fuel data (IEA, 2004). The higher values of Borken et al. (2007) for Asia and the Reforming Region are due to their corrections of the fuel data as explained above.

\subsubsection{Non-carbon dioxide gaseous emissions}

Estimates for nitrogen oxide emissions agree within 30 percent across the different inventories, both globally and in the regions. Emission factors of Borken et al. (2007) for OECD regions are slightly higher: It has recently been found that real world emissions from heavy-duty vehicles in Western Europe are by about 30\% higher than the mandatory exhaust emission limit values (Hausberger et al., 2003). For carbon monoxide the emission estimates concur for the relative distribution among regions. However,

Table 3

Road transportation's exhaust emissions by region in the year 2000 .

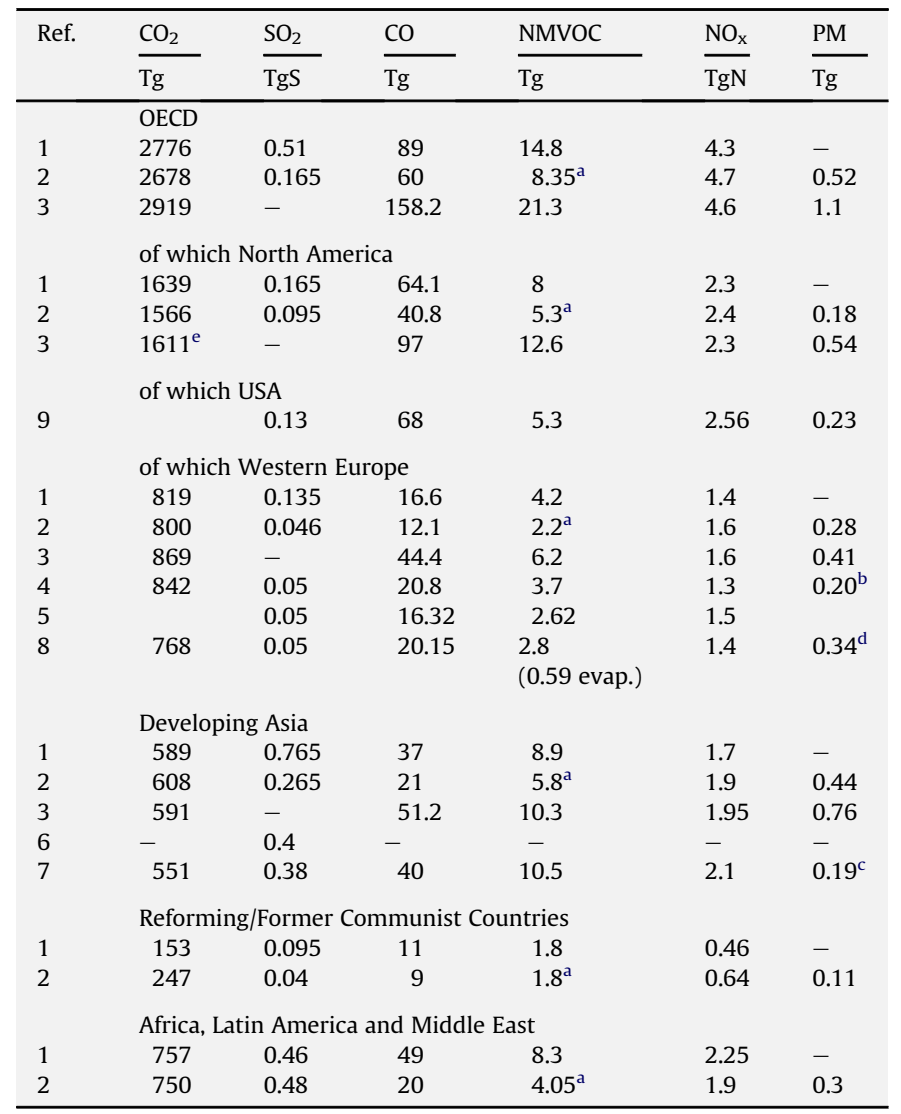

References: (1) Aardenne et al. (2005), (2) Borken et al. (2007), (3) Fulton and Eads (2004), (4) EEA (2006), (5) IIASA (2001): RAINS-ASIA, (6) Ohara et al. (2007), (7) IIASA (2007): GAINS Europe, C\&E CL, NEC6 scenarios (retrieved 07/09/2009), (8) US-EPA (2005).

-: No data.

a Evaporative emissions estimate included.

b From diesel fuelled vehicles only.

c Derived from fuel consumption.

d $\mathrm{PM}_{10}\left(\mathrm{PM}_{2.5}: 0.28 \mathrm{Tg}\right)$.

e About $1514 \mathrm{Tg} \mathrm{CO}_{2}$ without MEX, that accounts for about $6 \%$ of the total road fuel consumption in NAM + MEX.
Table 4

Total and road transportation emissions for $\mathrm{BC}, \mathrm{POM}$ and $\mathrm{SO}_{2}$.

\begin{tabular}{clll}
\hline & $\mathrm{BC}\left[\mathrm{Tg} \mathrm{yr}^{-1}\right]$ & $\mathrm{POM}\left[\mathrm{Tg} \mathrm{yr}^{-1}\right]$ & $\mathrm{SO}_{2}\left[\mathrm{TgS} \mathrm{yr}^{-1}\right]$ \\
\hline $\begin{array}{c}\text { Emission total for } \\
\text { reference year 1996 }\end{array}$ & $\begin{array}{l}\text { (Bond et al., } \\
\text { 2004) }\end{array}$ & $\begin{array}{l}\text { (Bond et al., } \\
\text { 2004) }\end{array}$ & $\begin{array}{l}\text { (Boucher et al., } \\
\text { 2002) }\end{array}$ \\
$\begin{array}{c}\text { Emission from road } \\
\text { transportation for }\end{array}$ & 0.72 & 0.31 & 0.95 \\
$\quad \begin{array}{l}\text { reference year 2000 } \\
\text { Fraction (\%) of emissions }\end{array}$ & 9.0 & 0.9 & \\
\hline
\end{tabular}

absolute differences are large: Borken et al. (2007) use the lowest emission factors, the more detailed emission inventories for the US and Western Europe (US-DoT, 2006; US-EPA, 2005) have higher ones, while the emission factors assumed by Fulton and Eads (2004) appear rather high. For sulphur dioxide emissions the lower totals of Borken et al. (2007) reflect the reductions in the fuel sulphur contents since 1995, the base year of Aardenne et al. (2005). The emissions of volatile organic compounds, including evaporative emissions, vary strongly. Values by Aardenne et al. (2005) and Fulton and Eads (2004) appear on the high side, while the values from Borken et al. (2007) are significantly lower and thus much closer to the official emission estimates for the US and Europe, respectively (US-EPA, 2005; EEA, 2006). The global estimate of $20.4 \mathrm{Tg}$ NMVOC for the year 2000 in Table 2 includes $4.6 \mathrm{Tg}$ (23\%) of evaporative emissions.

\subsubsection{Emissions of particulate matter}

For PM emissions the large differences can be traced back to the emission factors assumed for gasoline vehicles. Emissions factors broadly concur for diesel vehicles between Borken et al. (2007) and Fulton and Eads (2004). However for gasoline-powered vehicles Fulton and Eads (2004) assume as much as $40-50 \%$ of the respective value of diesel vehicles without giving a reference. Usually PM emissions of gasoline-powered vehicles are about two orders of magnitude smaller (Bond et al., 2004; US-EPA, 2003; Samaras et al., 2005). According to Quantify calculations about $9 \%$ of the total black carbon emitted is attributable to road transportation, from which $98.7 \%$ of the BC produced comes from diesel from road and freight traffic whereas only the remaining, 1.3\%, comes from gasoline. Fig. 3 illustrates the area with maximum BC atmospheric content which are contributing to the overall aerosol burden: Western Europe, Asia in particular over India and Eastern Asia, Northeastern United States.

Aging, mixing and changes in properties make it difficult to attribute atmospheric aerosol to certain sources. For example, $20 \%$ of the black carbon is considered as soluble whereas $80 \%$ is treated as insoluble upon emission. As the aerosol ages, the insoluble BC becomes soluble with an e-folding lifetime of 1.1 day. For organic carbon the soluble fraction even amounts to 50\% upon emission. Exchange processes with water droplets and aerosols from other sources take place.

Usually, inventories calculate mass emissions of primary $\mathrm{PM}_{10}$, though health evidence suggest that mass or number concentrations of fine and ultrafine particles $\left(\mathrm{PM}_{2.5}, \mathrm{PM}_{1}\right.$ and finer $)$ are more relevant (cf. chapter 3.3). However, reliable emission factors for these particle fractions are not yet available for the different vehicle technologies and world regions. As an indication, Bond et al. (2004) assume that more than $85 \%$ of all exhaust PM emitted from road vehicles belongs to the $\mathrm{PM}_{1}$ fraction. Size resolved measurement data reveal that about $90 \%$ of these particles have an aerodynamic diameter below $0.5 \mu \mathrm{m}$ (e.g. Birmili et al., 2009; Ketzel et al., 2004, 2007; Rose et al., 2006; Samaras et al., 2005) and hence are in the health relevant size segment. 

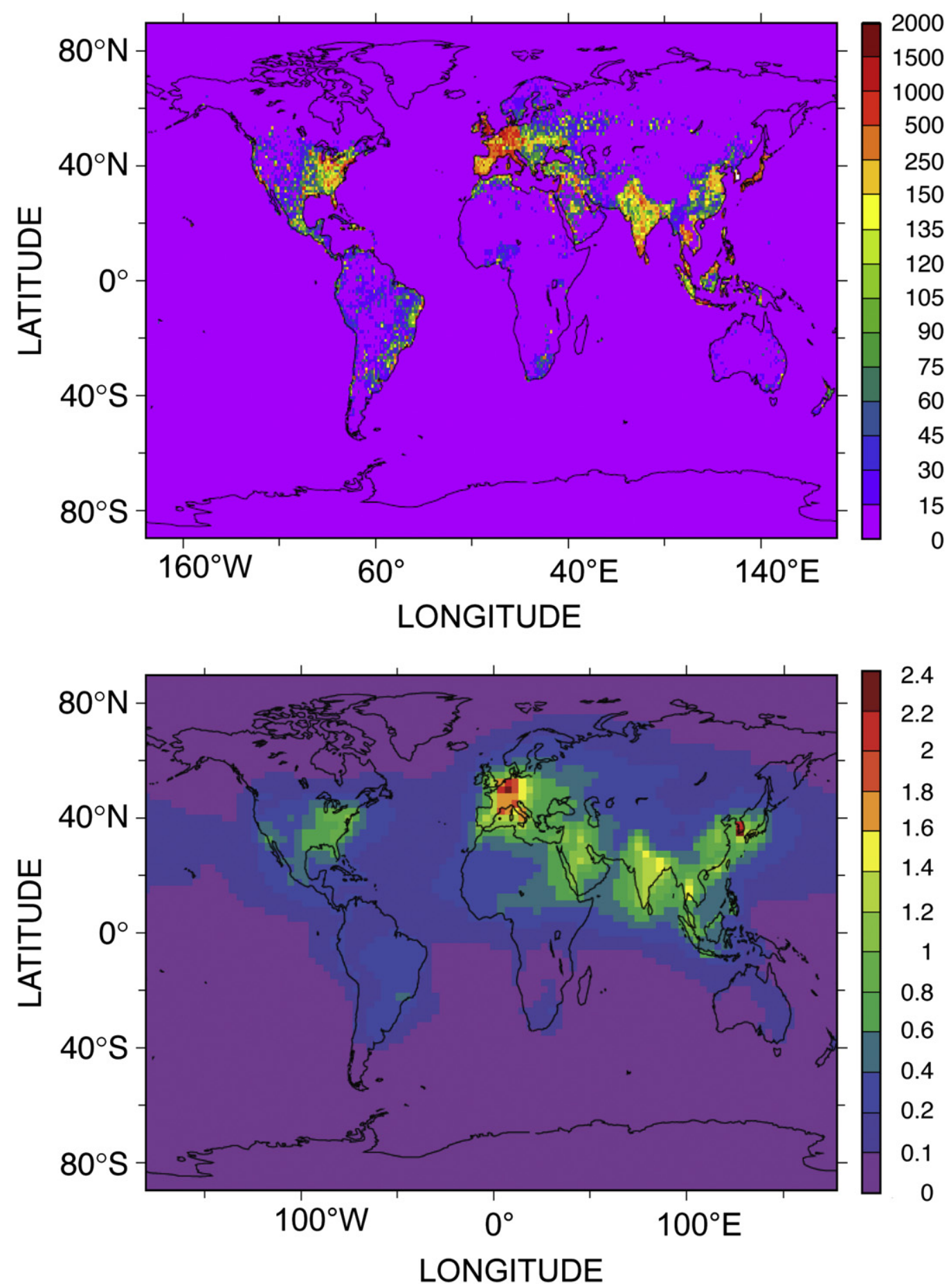

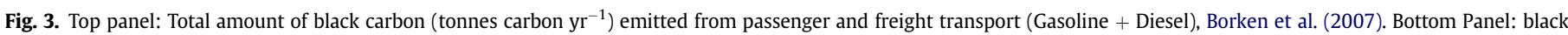
carbon optical depth $(\times 1000)$ from passenger and freight transport (gasoline + diesel) global mean, ecmwf winds for 2000.

Vehicle emissions of air pollutants strongly depend on the exhaust emission control devices and their operation efficiency in a given year. This needs a careful characterisation of the technical characteristics of the fleet in a given year. Therefore, a large part of the differences in the three global emission estimates reviewed here (Aardenne et al., 2005; Borken et al., 2007; Fulton and Eads, 2004) can be traced back to differences in technologies assumed. For instance, Aardenne et al. (2005) are bound to have high emission estimates as they use emission factors average for 1995 technologies. These do not capture the important tightening of emission controls in many industrialised countries.

\subsubsection{Uncertainties}

The biggest differences in values are for the region of developing Asia, comprising China, India and the growing South East Asian economies. This region has undergone a very rapid development in road transport volume and increase in vehicle stock. Therefore the state for the year 2000 is difficult to estimate. Furthermore, vehicle 
Table 5

Estimate of the uncertainty for road transport emission in the year 2000 (Borken et al., 2007).

\begin{tabular}{lrrrrrr}
\hline & $\mathrm{CO}_{2}$ & $\mathrm{SO}_{2}$ & $\mathrm{CO}$ & $\mathrm{NMVOC}$ & $\mathrm{NO}_{\mathrm{x}}$ & $\mathrm{PM}$ \\
\hline OECD & & & & & & \\
Emission share & $61 \%$ & $16 \%$ & $52 \%$ & $40 \%$ & $49 \%$ & $36 \%$ \\
Uncertainty & $5 \%$ & $13 \%$ & $30 \%$ & $30 \%$ & $30 \%$ & $50 \%$ \\
non-OECD & & & & & & \\
Emission share & $39 \%$ & $84 \%$ & $48 \%$ & $60 \%$ & $51 \%$ & $64 \%$ \\
Uncertainty & $20 \%$ & $30 \%$ & $60 \%$ & $60 \%$ & $40 \%$ & $75 \%$ \\
Cumulated uncertainty & $11 \%$ & $27 \%$ & $44 \%$ & $48 \%$ & $35 \%$ & $66 \%$ \\
\hline
\end{tabular}

exhaust emission control has not been as stringent as in OECD countries and hence their variability is bigger.

Moreover, the inventories differ in the sophistication of the approach and in the quality of their input data. Therefore the range of values rather reflects the outcome of various more or less well controlled simplifications not the range of uncertainty.

To estimate the potential uncertainty we give the following expert judgement for the year 2000 based on the differentiated results of Borken et al. (2007): The input data (vehicle stock composition and their mileage, the emission factors and the overall fuel balance) are more reliable and less variable in OECD countries. Our judgement goes for $5 \%$ uncertainty in the fuel balance and related $\mathrm{CO}_{2}$ emissions over an estimated $30 \%$ uncertainty for $\mathrm{CO}$, NMVOC and $\mathrm{NO}_{\mathrm{x}}$ to about $50 \%$ uncertainty for PM emissions. For non-OECD countries the available data are much less representative, less reliable and the variation in vehicle technology and operating conditions is much larger. Consequently we have assumed about a two to three times higher uncertainty for each species. Weighted with the respective region's share in emission we estimated a cumulated uncertainty in the order of $10 \%$ for $\mathrm{CO}_{2}$ emissions, about $30 \%$ for $\mathrm{SO}_{2}$ and $\mathrm{NO}_{\mathrm{x}}$ emissions, $40-50 \%$ for $\mathrm{CO}$ and NMVOC emissions and 66\% for PM (Table 5).

\subsection{Emissions of rail transport}

In many countries railway plays an important role in transport of goods and passengers. Globally rail transport's performance is $2.2( \pm 0.4)$ trillion passenger $\mathrm{km}$ and $8.6( \pm 1.7)$ trillion tonne $\mathrm{km}$ per year. Approximately one third of this transport takes place in Europe. Rail goods transport plays an important role in North America while $1 / 4$ of the global rail passenger transport takes place in India and China, respectively (Community of European Railway and Infrastructure Companies). In EU-25 rail contributes to 9\% of total passenger transport and 3\% of the goods transport (EEA, 2006). Approximately $30 \%$ of the global rail network is currently electrified; this share is 50\% in the European Union.
Table 7

Rail emission factors.

\begin{tabular}{lllllll}
\hline & $\mathrm{NO}_{\mathrm{x}}$ & $\mathrm{CO}$ & $\mathrm{NMVOC}$ & $\mathrm{PM}_{2.5}$ & $\mathrm{CH}_{4}$ & $\mathrm{~N}_{2} \mathrm{O}$ \\
\hline IPCC $\left(\mathrm{kg} \mathrm{TJ}^{-1}\right)$ & $1200(300)$ & $1000(150)$ & $100(20)$ & - & $5(10)$ & $0.6(1.4)$ \\
$\begin{array}{c}\text { EMEP } / \text { Corinair } \\
\left(\mathrm{kg} \mathrm{TJ}^{-1}\right)\end{array}$ & 915 & 247 & 107 & 112 & 4 & 29 \\
\hline()$=$ coal. & & & & & & \\
\hline
\end{tabular}

The remaining railway network is using fossil fuels, namely diesel oil for propulsion. Due to large coal resources of the country coal driven trains are still common in China (IEA).

\subsubsection{Fuel consumption and carbon dioxide emissions}

There is yet no global gridded rail inventory available. The global EDGAR inventory includes railways, but together with inland waterways and pipeline transport. EMEP prepares a gridded rail inventory for Europe based on data reported by the Parties to the Convention, which is however not fully complete (http:// www.emep.int/index_data.html).

European (EU-25) rail emissions have also been estimated by the EEA TERM (2003). This study shows that rail emissions in Europe make up for only $1-3 \%$ of the total transport emissions.

Rail fuel consumption data are available for all world regions at the country level from the IEA for all years since 1971. Selected years are presented in Table 6. The table shows a large decline in coal consumption, a 70\% increase in electricity consumption and stable diesel consumption from 1971 to 2004.

The energy consumption can be used to estimate global carbon dioxide emissions. We address only direct emissions here excluding electricity generation and other indirect emissions which are discussed in Section 2.4. Information about rail emission factors as also shown in Table 7 can be found in the EMEP/Corinair emission inventory guidebook EMEP/CORINAIR (2006), the IPCC (1995) inventory Guidelines and UIC/CER (2006).

\subsubsection{Emissions of short-lived pollutants}

European rail vehicles produced after 1990 emit substantially less $\mathrm{NO}_{\mathrm{x}}$ and $\mathrm{PM}$ compared to older vehicles. For example for mainline locomotives the reduction has been $30 \%$ in $\mathrm{NO}_{\mathrm{x}}$ and $70 \%$ in PM emission factors, while for railcars the reduction has been even larger (UIC/CER, 2006). We have estimated emissions using the EMEP/Corinair emission factors for diesel and the IPCC emission factors for coal. The UIC/CER emission factors are only applicable for Europe. The uncertainty margins are large for all emission data given the uncertainty in emission factors and fuel consumption and the fact that independent studies are not available for verification.

The estimates shown in Table 8 illustrate that rail emission are small compared to the emissions from road transport. Nevertheless, the mode is important as part of a transport inventory and

Table 6

Energy consumption in railways for selected years and per world region. Coal and diesel (kt) and electricity (GWh). (n.a. = no data available).

\begin{tabular}{|c|c|c|c|c|c|c|c|c|c|c|c|c|}
\hline & \multicolumn{3}{|l|}{1971} & \multicolumn{3}{|l|}{1980} & \multicolumn{3}{|l|}{1990} & \multicolumn{3}{|l|}{2004} \\
\hline & Coal & Diesel & Electricity & Coal & Diesel & Electricity & Coal & Diesel & Electricity & Coal & Diesel & Electricity \\
\hline World & - & 28,102 & 107,346 & 48,738 & 35,166 & 154,490 & 35,432 & 34,152 & 182,253 & 8328 & 33,076 & 184,950 \\
\hline EU-25 & - & n.a. & n.a. & n.a. & n.a. & n.a. & 181 & 3877 & 48,089 & 1 & 2518 & 58,403 \\
\hline Non-OECD Europe & - & n.a. & 567 & 20 & n.a. & 1936 & 14 & 103 & 2207 & n.a. & 308 & 2136 \\
\hline Africa & - & 187 & 2771 & 2217 & 299 & 4446 & 280 & 217 & 4370 & 7 & 343 & 3911 \\
\hline Latin America & - & 378 & 1126 & 80 & 612 & 1224 & 2 & 560 & 2015 & 1 & 596 & 2119 \\
\hline Asia Excl. China & - & 622 & 1663 & 11,950 & 979 & 2514 & 5265 & 1832 & 4700 & n.a. & 2907 & 12,622 \\
\hline China & - & n.a. & n.a. & 19,344 & n.a. & 2650 & 20,271 & 2047 & 5936 & 8194 & 7833 & 20,016 \\
\hline Former USSR & - & 8200 & 48,800 & 12,007 & 11,300 & 76,000 & 9423 & 11,600 & 87,000 & 125 & 4721 & 50,674 \\
\hline Middle East & - & 8 & n.a. & n.a. & 10 & n.a. & n.a. & 17 & n.a. & n.a. & n.a. & n.a. \\
\hline
\end{tabular}


Table 8

Emissions from rail (n.a. $=$ no data available).

\begin{tabular}{|c|c|c|c|c|c|c|c|c|}
\hline & \multicolumn{4}{|c|}{$\mathrm{CO}_{2}\left[\mathrm{Tg} \mathrm{yr}^{-1}\right]$} & \multicolumn{4}{|c|}{$\mathrm{NO}_{\mathrm{x}}\left[\mathrm{GgN} \mathrm{yr}^{-1}\right]$} \\
\hline & 1980 & 1990 & 2000 & 2004 & 1980 & 1990 & 2000 & 2004 \\
\hline World & 209.0 & 179.1 & 119.7 & 121.5 & 512.8 & 476.3 & 393.7 & 413.9 \\
\hline EU-25 & n.a. & 12.7 & 9.3 & 8.0 & n.a. & 47.1 & 35.5 & 30.3 \\
\hline Non-OECD Europe & n.a. & 0.4 & 1.3 & 1.0 & 0 & 1.3 & 4.9 & 3.7 \\
\hline Africa & 5.4 & 1.2 & 1.2 & 1.1 & 7.6 & 3.1 & 4.5 & 4.1 \\
\hline Latin America & 2.1 & 1.8 & 1.4 & 1.9 & 7.5 & 6.8 & 5.3 & 7.2 \\
\hline Asia excluding China & 27.0 & 16.3 & 6.1 & 9.2 & 33.6 & 31.7 & 23.1 & 35 \\
\hline China & 38.7 & 47.0 & 44.5 & 41.2 & 35.3 & 61.7 & 108.2 & 109.4 \\
\hline Former USSR & 59.8 & 55.6 & 13.7 & 15.2 & 158.1 & 157 & 52 & 57.1 \\
\hline Middle East & n.a. & 0.1 & n.a. & n.a. & 0.1 & 0.2 & n.a. & n.a. \\
\hline
\end{tabular}

assessment due to rails important role in current, and expected future transport policies. From a climate perspective rail transport will compared to air and road transportation imply less emissions per passengers and freight transported (EEA TERM, 2003), since per passenger emissions from road transport are more than twice as high as those from rail, while emissions from air transport are 10-20\% higher than those from road (average figures for EU-15). For freight, on a tonne $\mathrm{km}$ basis, emissions from road are around five times as high as those from rail while they are more than 8 times as high as emissions from maritime shipping. These figures however mask differences in average distance travelled and capacity utilisation (EIONET, TRENDS, 2003).

\subsection{Emissions of inland shipping}

Inland shipping, defined as shipping on rivers and lakes, is not important in terms of emissions at the global level, but can play an important role for transport primarily of goods at the local level. Emission estimates are not always comparable in different studies, since the differentiation between ocean going ships and inland shipping is not always sharp. But emissions from shipping on inland waterways are below $1 \%$ of all emissions from transport. For the EU 27 region the IIASA Gains model (IIASA, 2007) reports $\mathrm{CO}_{2}$ emissions of $5.73 \mathrm{Tg}$ for 2000 and $7.41 \mathrm{Tg}$ for 2005 . This is $0.7 \%$ or $0.85 \%$ of the emissions from cars, trucks and buses. In Europe (EEA 30 ) inland shipping is estimated to have a share of $5 \%$ in freight transport (EEA Report No 1/2007), but there is no relevant passenger transport. Inland shipping will not affect the global climate to a measurable extent.

\subsection{Indirect emissions}

Transport generates direct emissions when fuel is combusted in the engine of the vehicle. However, when assessing the land transport impact on climate it is evidently relevant to consider all emissions generated as a result of transport activities. The use of transport infrastructure like roads, rail-lines and harbour facilities but also bridges, car parks, tunnels or filling stations requires energy for construction work, maintenance and production of materials (e.g. asphalt, concrete and steel). Production of the vehicles requires energy, in particular for primary products (e.g. steel, aluminium and plastic). Besides from these material related emissions, production of fuels generates emissions from extraction, refining and transportation which will be discussed as well-to-tank emissions.

\subsubsection{Material related emissions}

Although construction and maintenance of transport infrastructure are usually attributed to other emission sectors (mainly industry or construction) and adding them also to the transport emissions would mean a double counting, we need to be aware that many of these emissions grow with the respective transport mode. In particular for road and rail transport they are not negligible compared to the tailpipe emissions.

Chester and Horvath (2009) find in a total life-cycle assessment of transport modes in the United States, that considering infrastructure, fuel production and supply chains leads to greenhouse gas emissions, which are 1.4-1.6 times higher for onroad transport and 1.8-2.5 times higher for rail transport than emissions from the tailpipe only. $7-8 \%$ of the total life-cycle's GHG emissions are attributed to vehicle manufacturing, $3-5 \%$ to vehicle maintenance. This corresponds to about $12 \%$ and $6 \%$ of the tailpipe emissions. The Japanese institute for Lifecycle Environmental assessment (http:// www.ilea.org) estimates similar emissions from production of a gasoline conventional vehicle of about $1 / 8(12-13 \%)$ of the total $\mathrm{CO}_{2}$ emissions from tailpipe. Samaras and Meisterling (2008) attribute for a Toyota Corolla type vehicle $35 \mathrm{~g} \mathrm{CO}_{2}$-eq $\mathrm{km}^{-1}$ to the car manufacturing, $177 \mathrm{~g} \mathrm{CO}_{2}$-eq $\mathrm{km}^{-1}$ to the gasoline consumption on site and $57 \mathrm{~g} \mathrm{CO}_{2}$-eq km${ }^{-1}$ for gasoline upstream emissions (e.g. distribution and refining). Thus, production related emissions are $15 \%$ of the gasoline related emissions and $20 \%$ of the tailpipe emissions. In this study $102 \mathrm{GJ}$ or primary energy demand ( 8.5 tonnes of $\mathrm{CO}_{2}$-eq) are estimated for the production and the car life is assumed to be $240,000 \mathrm{~km}$. Schmid (2003) estimated twice as much, $69 \mathrm{~g} \mathrm{CO}_{2}$-eq $\mathrm{km}^{-1}$, for the total of manufacturing, maintenance and end-of-life emissions. This corresponds to Jancovici (2004), who reports that about $15 \%$ of the $\mathrm{CO}_{2}$ emissions can be attributed to the production and another $15 \%$ to the maintenance (Jancovici, 2004). Although values vary depending on the assumptions made a common range of $12-20 \%$ emissions for manufacturing compared to tailpipe emissions is assumed for conventional vehicles. In comparison, a life-cycle analysis for a ferry concluded that $97 \%$ of $\mathrm{CO}_{2}$ emissions are from operation, $1.4 \%$ from construction, $0.65 \%$ from maintenance and $1.1 \%$ from scrapping (Johnsen and Fet, 1999).

For construction, maintenance and end-of-life of a train with 3 wagons of 100 seats each and 30\% occupancy emissions of about $8 \mathrm{~g}$ $\mathrm{CO}_{2}$-eq per passenger kilometre travelled (PKT) can be deduced from data of Schmid (2003) for a German train. This is similar to values of about $11 \mathrm{~g} \mathrm{CO}_{2}$-eq per PKT (or $30 \%$ of vehicle operation) estimated by Chester and Horvath (2009) for CALTRAIN in California. A higher share of emissions, about $65 \%$ of those from vehicle operation, are estimated for rail's infrastructure construction and operation (Fig. 4).

Chester and Horvath (2009) allocate $9-13 \%$ of the life-cycle emissions (about $20 \%$ of the tailpipe emissions) to infrastructure construction. 200 tonnes of $\mathrm{CO}_{2}$-eq (2500 GJ energy) are estimated to be emitted during the construction of $1 \mathrm{~km}$ lane of an average US road. Such estimations have high uncertainties. For example, another study on an Australian continuously reinforced concrete road calculated nearly four times higher energy needs and emissions (Treloar et al., 2004; pers. comm. Robert Crawford).

\subsubsection{Well-to-tank emissions}

Well-to-tank emissions are relevant for all fuels used for transport and include emissions from extraction, processing and refining as well as evaporative emissions from fuel distribution. Combustion emissions from transportation of the fuels are already included in the datasets in Sections 2.1-2.3.

The indirect emissions are at present most important for electricity production (power plants) for use in railways and to a small extent for road transport. Indirect emissions from electricity provision will depend on the technology used for producing the electricity and abatement level. Due to increasing electrification of the railway network, indirect $\mathrm{CO}_{2}$ emissions for rail are nowadays 


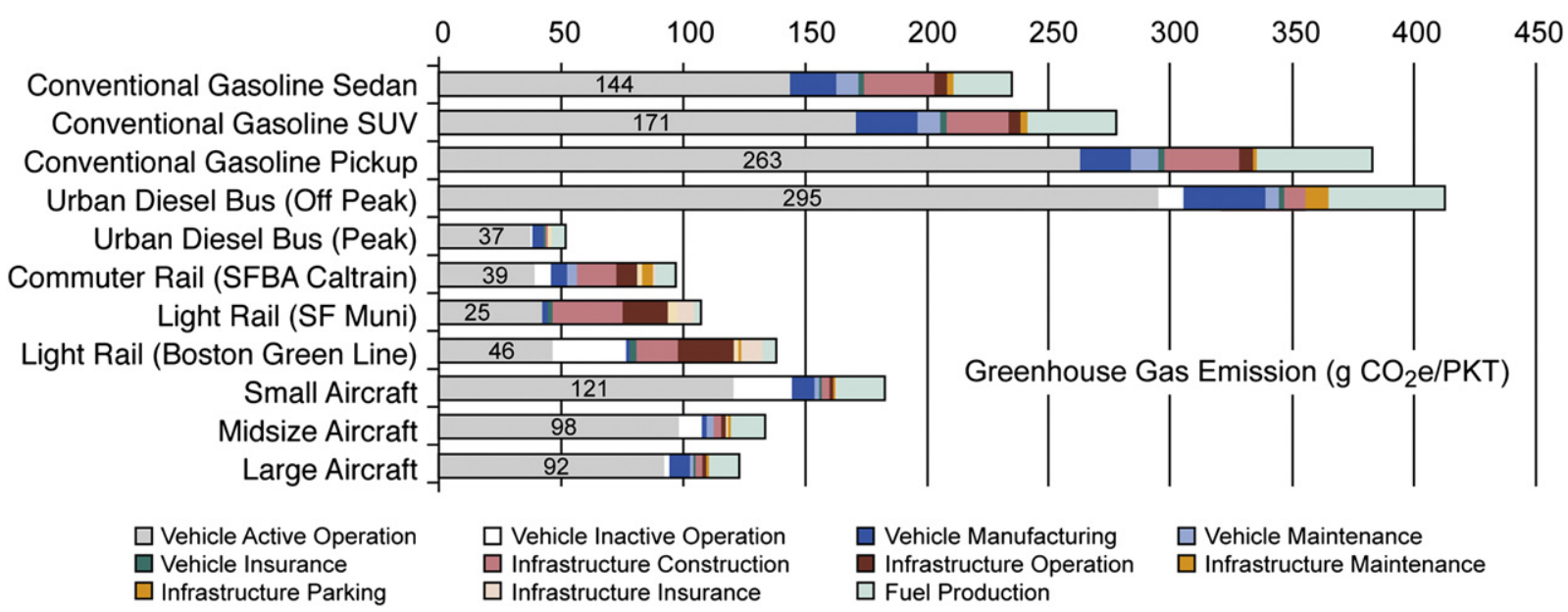

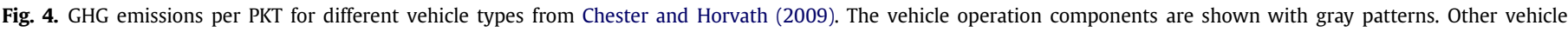
components are shown in shades of blue. Infrastructure components are shown in shades of red and orange. The fuel production component is shown in green.

approaching the same order of magnitude as direct emissions. It is important to include this component in an assessment of future emission where more of the transport system is being electrified, in rail and also in road transport. A life-cycle assessment of greenhouse gas emissions demonstrated for the present electricity mix in the United States that plug-in hybrid electric car are hardly beneficial compared to normal hybrids (Samaras and Meisterling, 2008). Future emissions per unit of electricity produced are, however, also expected to change. For example, use of carbon capture and storage and more use of solar and wind power will reduce emissions substantially. For such a low-carbon scenario life-cycle GHG reductions could be $51-63 \%$ for plug-in hybrids compared to conventional vehicles.

Also fossil fuels have a footprint from the extraction phase and refineries. Energy requirements for extraction and processing/ refining generate i.e. $\mathrm{CO}_{2}, \mathrm{NO}_{\mathrm{x}}$ and $\mathrm{SO}_{2}$ emissions. Due to low sulphur content in fuel, the total $\mathrm{SO}_{2}$ emissions from all indirect sources are estimated for the US to be 19-26 times larger than the operational emissions (Chester and Horvath, 2009). In addition there are fugitive emissions of methane and NMVOCs from the extraction, refining and transport of fuels. Typically $\mathrm{CO}_{2}$-equivalent emissions of direct greenhouse gases well-to-tank would constitute 14 and 16 percent of well-to-wheel emissions for conventional gasoline and diesel road vehicles, respectively (JRC/CONCAWE/ EUCAR, 2006). Chester and Horvath (2009) estimate a similar average ratio of $13-15 \%$ fuel production related emissions compared to operational emissions for the US passenger car fleet.

Gasoline used for road transport is a light and relatively volatile fuel. Therefore it is more easily evaporated during handling and use compared to diesel fuels and heavy fuel oil. Gasoline distribution and tanking is an important NMVOC source, depending on fuel properties, climate and technologies. In Europe tighter standards for emissions from gasoline stations have resulted in reduced emissions the last years. In addition to exhaust emissions, gasoline vehicles themselves will result in evaporative emissions (EMEP/CORINAIR, 2006). These emissions can be classified as running losses, hot soak and diurnal (daily) emissions (ibid). Diurnal emissions are associated with daily variations in ambient temperature that results in vapour expansion inside the gasoline tank and contraction during nights with lower temperature. Hot soak emissions occur when a hot engine is turned off and heat from the engine and the exhaust system increases the temperature of the fuel in the system. Running losses are the result of vapour generated in gasoline tanks during vehicle operations. Modern vehicles control these emissions by $90 \%$
(EMEP/Corinair, 2006) compared to older vehicles. Some quantitative estimations are given in Section 2.1.

In recent years and likely in the near future biofuels are increasing in importance for use in road transportation and perhaps also in shipping. Emissions from the production of biofuels must be added to the indirect emissions. This will include emissions from fertilization and fertilizer production $\left(\mathrm{N}_{2} \mathrm{O}\right.$ and $\left.\mathrm{CO}_{2}\right)$, fuel processing, transport of fuels and even $\mathrm{CO}_{2}$ emissions from land use change. Synthetic fuels, for example hydrogen, will shift most emissions to the production stage. An overview of these well-to-tank emissions from alternative fuels is given in the well-towheel analysis as described in Section 5.3 (cf. JRC/CONCAWE/EUCAR (2005, 2003 and online: http://ies.jrc.ec.europa.eu/wtw.html 2006)).

\subsection{CFC and HFC emissions}

Emissions from transport include emissions from mobile air conditioners (MAC) in passenger vehicles or cooling/freezing systems of goods transport. We do not discuss emissions from the latter in this report. Air conditioning in cars became common in the United States since 1960. However, mass production in Europe and in the developing countries started later, in about 1995. In 2000 half of the worldwide automotive fleet of 720 million vehicles was equipped with air conditioners (SROC, 2006). This number is increasing. Previously CFC-12 $\left(\mathrm{CCl}_{2} \mathrm{~F}_{2}\right)$ was used as chemical in MAC, but in 2003 HFC-134a $\left(\mathrm{CH}_{2} \mathrm{FCF}_{3}\right)$ was already used in 338 million road vehicles. In the near future they are envisioned to be replaced by $\mathrm{CO}_{2}$ or HFC-152a (difluoroethan, $\mathrm{CHF}_{2} \mathrm{CH}_{3}$ ). The emissions of HFC-134a take place during accidents, through leakage and servicing and at disposal. The recovery rates are low. A US model study estimates the loss by leakage and service to be $10.9 \%$ and the loss during disposal to be $42.5 \%$ of the total MAC charge in developed countries and 69\% in developing countries (DeAngelo et al., 2006).

Indirect emissions arise from additional fuel use of the vehicle in which the MAC is installed. This can amount to $2.5-7.5 \%$ of the total fuel consumption, depending on the operation time. These emissions depend strongly on the local climate and can only be roughly estimated. Systematic inventories for additional fuel consumption are not yet established. But the resulting $\mathrm{CO}_{2}$ emissions are included in the emission figures in Sections 2.1-2.3.

In 2002 about $110-130$ ktonnes of CFC-12 were emitted. This is slightly more than a quarter of the 1990 emissions (400-430 ktonnes). Half of the 2002 CFC-12 emissions were emitted from MAC. 63 ktonnes are estimated for 2003 (SROC, 2006). 


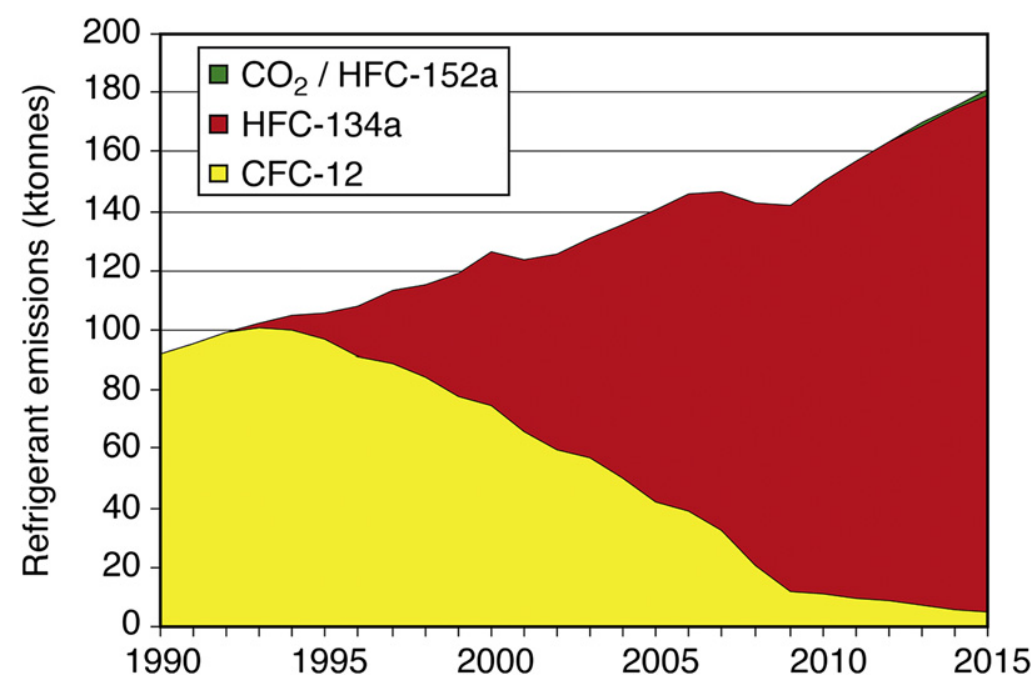

Fig. 5. SROC (2006), Fig. 6a. MAC refrigerant emissions from 1990 to 2015 (Clodic and Palandre, 2004).

A typical air conditioner in a car contains $1 \mathrm{~kg}$ of CFC-12 or $0.8 \mathrm{~kg}$ of HFC-134a (Atkinson, 2000). Fig. 5 shows that the total amount of refrigerants emitted is constantly rising, but now mainly consisting of HFC-134a. In 2002, about two thirds of the 97 ktonnes emitted came from MAC. As can be seen from estimations that were made in 1999 (Fig. 6), much faster progress in the market integration of $\mathrm{CO}_{2}$ or HFC-152a based systems was assumed before. But alternatives to HFC-134a needed longer development and test phases (SAE, 2003). Furthermore, the strong increase in the market share of cars equipped with air conditions of up to more than half of the fleet at present was not expected. Consequently, recent estimates for MAC refrigerant emissions in 2005, suggesting 140 ktonnes, are more than twice as high as projected in 1999 . We can see that as one example how difficult it is to project future developments if the introduction of new technologies is planned.

The introduction of HFC-134a led to a sudden and strong increase of this compound in the atmosphere, reaching mixing ratios of 25.5-30.6 ppt within the ten years after 1995. However, the atmospheric relevance of HFCs is clearly different from CFCs and will be discussed in Section 4.2.

\section{Impacts on air composition}

\subsection{Basics of atmospheric chemistry}

For atmospheric chemistry, the main concern related to land transport derives from emissions of nitrogen oxides (mainly

Refrigerant emissions from the fleet of air conditioned cars in $\mathrm{kt} / \mathrm{a}$

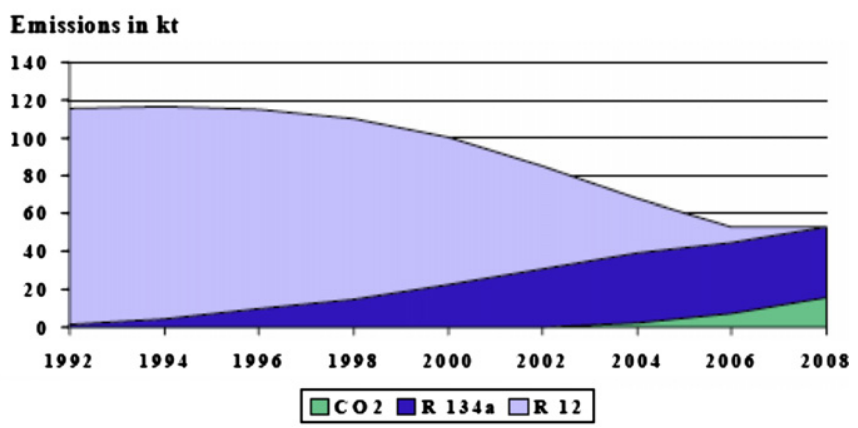

Fig. 6. Refrigerant emissions from the fleet of air conditioned car in kt/yr as estimated in 1999. Source: Preisegger E., Solvay Fluor und Derivate GmbH.
$\mathrm{NO}_{\mathrm{x}}=\mathrm{NO}+\mathrm{NO}_{2}$ ), non-methane hydrocarbons (NMVOC) and carbon monoxide (CO), which are precursors of ozone and thus affect the oxidizing capacity of the atmosphere. Through their impact on $\mathrm{OH}$ they also affect methane, constituting a secondary, longer-lived effect on climate. In contrast to the impact from shipping and aviation, there have been only few publications focusing on global chemical and climate effects of road emissions (e.g. Granier and Brasseur, 2003; Grewe, 2004; Niemeier et al., 2006; Matthes et al., 2007). The main chemical mechanisms of relevance to road emission assessments are summarised in the following paragraphs.

Ozone production in the troposphere proceeds in the presence of $\mathrm{NO}_{\mathrm{x}}$ and sunlight via

$$
\begin{aligned}
& \mathrm{NO}_{2}+\mathrm{h} v \rightarrow \mathrm{NO}+\mathrm{O} \\
& \mathrm{O}+\mathrm{O}_{2}+\mathrm{M} \rightarrow \mathrm{O}_{3}+\mathrm{M} \\
& \mathrm{NO}+\mathrm{HO}_{2} \rightarrow \mathrm{NO}_{2}+\mathrm{OH}
\end{aligned}
$$

The $\mathrm{HO}_{2}$ radical that reconverts $\mathrm{NO}$ into $\mathrm{NO}_{2}$ (reaction (R3)), can be produced from the oxidation of carbon monoxide or hydrocarbons, e.g.

$\mathrm{CO}+\mathrm{OH} \rightarrow \mathrm{CO}_{2}+\mathrm{H}$

$\mathrm{H}+\mathrm{O}_{2}+\mathrm{M} \rightarrow \mathrm{HO}_{2}+\mathrm{M}$

with similar reactions involving methane and other hydrocarbons. $\mathrm{NO}_{\mathrm{x}}$ has a rather short chemical lifetime and its largest effects on ozone are confined to the vicinity of the emission sources. From ozone, the $\mathrm{OH}$ radical is formed in the presence of water vapour and sunlight (Fig. 7):

$$
\begin{aligned}
& \mathrm{O}_{3}+\mathrm{h} v \rightarrow \mathrm{O}^{*}+\mathrm{O}_{2} \\
& \mathrm{O}^{*}+\mathrm{H}_{2} \mathrm{O} \rightarrow \mathrm{OH}+\mathrm{OH}
\end{aligned}
$$

$\mathrm{OH}$ is the main oxidizing agent in the atmosphere, reducing the concentration of $\mathrm{CO}$ and $\mathrm{CH}_{4}$ but also of most other gaseous pollutants. $\mathrm{OH}$ can be enhanced by road transport not only due to the ozone enhancement but also directly due to $\mathrm{NO}_{\mathrm{x}}$ emissions that move the $\mathrm{HO}_{2} / \mathrm{OH}$ balance towards $\mathrm{OH}$. Since $\mathrm{CO}$ and $\mathrm{CH}_{4}$ 


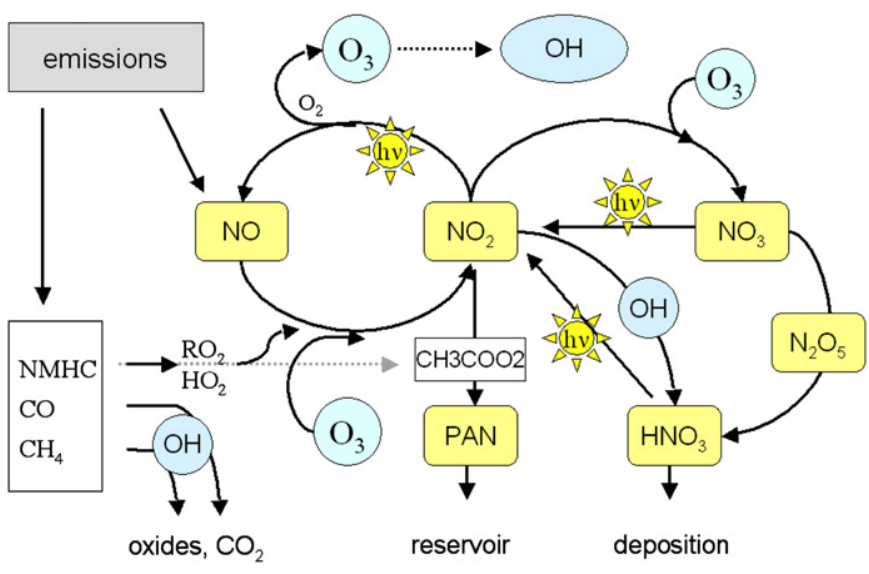

Fig. 7. Basic processes in tropospheric chemistry.

have lifetimes of about 2 months and 8 years, respectively, they constitute a longer-lived effect of road-traffic emissions and can transport the signal over large distances. Enhanced $\mathrm{CO}$ and $\mathrm{CH}_{4}$ levels in turn can reduce $\mathrm{OH}$ in remote unpolluted areas. As stated in Niemeier et al. (2006) the sign in the $\mathrm{OH}$ perturbation by road traffic is determined by the ratio between the intensities of $\mathrm{NO}_{\mathrm{x}}$ and $\mathrm{CO}$ perturbations. $\mathrm{NO}_{\mathrm{x}}$ perturbations enhance $\mathrm{OH}$, while $\mathrm{CO}$ emissions reduce it. The absolute changes in the zonally averaged $\mathrm{OH}$ concentration resulting from the extensive use of automobiles are thus relatively limited (Granier and Brasseur, 2003).

$\mathrm{NO}_{\mathrm{x}}$ as such cannot be transported over large distances due to its short lifetime. However, Matthes et al. (2007) found that the formation of relatively long-lived PAN species (peroxyacetyl nitrates) from NMVOC and $\mathrm{NO}_{\mathrm{x}}$ has the potential to transport the signal of road traffic to remote areas such as the Arctic. PAN is decomposed in areas of subsidence, releasing $\mathrm{NO}_{\mathrm{x}}$ and thus effectively enhancing ozone in remote unpolluted areas. This makes emissions of NMVOC from road traffic important even for remote regions. The ozone production efficiency per emitted $\mathrm{NO}_{\mathrm{x}}$ molecule decreases at higher $\mathrm{NO}_{\mathrm{x}}$ levels. At very high $\mathrm{NO}_{\mathrm{x}}$ concentrations ozone titration becomes important:

$\mathrm{NO}+\mathrm{O}_{3} \rightarrow \mathrm{NO}_{2}+\mathrm{O}_{2}$

which can lead to a local reduction of ozone in high NO emission areas. However, further downwind from road traffic or in case of direct $\mathrm{NO}_{2}$ emission from vehicles with particle filters ozone is increased. Due to the dependence of reaction (R1) on sunlight the ozone production from road traffic is much larger during summer, while in winter ozone net reductions can occur through ozone titration by the emitted NO.

Nitrogen deposition and acid rain are enhanced through roadtraffic emissions of $\mathrm{NO}_{\mathrm{x}}, \mathrm{CO}$ and sulphur components. E.g. $\mathrm{NO}_{\mathrm{x}}$ from road traffic is converted into nitric acid, which is highly water soluble and washed out, leading to nitrogen deposition.

$\mathrm{NO}_{2}+\mathrm{OH} \rightarrow \mathrm{HNO}_{3}$

This reaction can counteract the $\mathrm{OH}$ enhancement due to $\mathrm{NO}_{\mathrm{x}}$ emissions from road traffic, especially under low-sunlight conditions. According to Granier and Brasseur (2003) surface $\mathrm{OH}$ decreases substantially in January in response to automobiles and trucks emissions in the highly polluted regions of Europe and North America where the background nitrogen oxide level is so high that additional $\mathrm{NO}_{\mathrm{x}}$ tends to convert substantial quantities of $\mathrm{HO}_{\mathrm{x}}$ into nitric acid.
Other minor effects of road-traffic emissions exist with respect to heterogeneous chemistry through emissions of particles and to stratospheric ozone depletion through the slowly expiring emission of CFCs from MAC in vehicles. Long-lived CFCs are transported into the stratosphere where they are decomposed by sunlight into inorganic chlorine, in part present as $\mathrm{Cl}$ and $\mathrm{ClO}$ radicals that cause catalytic ozone depletion through

$\mathrm{Cl}+\mathrm{O}_{3} \rightarrow \mathrm{ClO}+\mathrm{O}_{2}$

$\mathrm{ClO}+\mathrm{O} \rightarrow \mathrm{Cl}+\mathrm{O}_{2}$

Most of the stratospheric inorganic chlorine is present as socalled reservoir species, $\mathrm{HCl}$ (hydrochloric acid) and $\mathrm{ClONO}_{2}$ (chlorine nitrate), which themselves do not destroy ozone. However, heterogeneous processes, e.g. on Polar Stratospheric Clouds, which are present under very cold conditions in the Arctic and Antarctic stratospheres, convert the reservoir species back into less stable components that during spring are readily decomposed into $\mathrm{Cl}$ and $\mathrm{ClO}$ by sunlight, leading to severe ozone depletion. Current research in regard to chlorine chemistry has concentrated on the role of the $\mathrm{ClO}$ dimer $(\mathrm{ClOOCl})$ which, according to a recent publication of Pope et al. (2007), appears to be more stable than previously suggested, thus implying a smaller role of chlorine for stratospheric ozone depletion as less $\mathrm{ClO}$ radicals are released.

HFC-134a, which has replaced CFC-12 in new MAC, has a much shorter lifetime ( $\sim 14$ years) because it reacts with $\mathrm{OH}$ in the troposphere. Its effects in the stratosphere are thus much less pronounced.

\subsection{Impacts on global atmospheric composition and chemistry}

\subsubsection{Key species and model approach}

Emissions of long-lived species like $\mathrm{CO}_{2}$, methane and halocarbons as well as short- lived compounds like carbon monoxide, nitrogen oxides and non-methane volatile organic compounds (NMVOC) both can lead to changes in the global atmospheric composition. Here, we focus on chemical impacts of short or medium lived gases. As we saw, their emission influences the formation of secondary pollutants and oxidants like ozone, the hydroxyl radical $(\mathrm{OH})$, the $\mathrm{NO}_{\mathrm{x}}$ reservoir species PAN and methane. Radiative forcing impacts are discussed in Section 4

Carbon monoxide and methane are both removed from the atmosphere by $\mathrm{OH}$ and have a relatively long tropospheric lifetime of a few weeks up to two months and about 8 years, respectively. The background of the $\mathrm{OH}$ depleting carbon monoxide is enhanced by many fossil fuel related and biomass burning sources. Therefore, $\mathrm{CO}$ emissions from land transport are less significant, on a global scale although not negligible and clearly higher than for other transport sectors. Transport emissions of $\mathrm{NO}_{\mathrm{x}}$ and NMVOC have a substantial influence on $\mathrm{O}_{3}$ and $\mathrm{OH}$, and also on methane lifetime through the reactions described in 3.1.

Table 9

Global transport and non-transport emissions in the year 2000 as used in Hoor et al. (2009).

\begin{tabular}{lccccc}
\hline & $\mathrm{NO}_{\mathrm{x}}$ & & \multicolumn{2}{c}{$\mathrm{CO}$} \\
\cline { 2 - 3 } \cline { 6 - 6 } & $\mathrm{TgN} \mathrm{yr}^{-1}$ & $\%$ & & $\mathrm{Tg} \mathrm{yr}^{-1}$ & $\%$ \\
\hline Road (preliminary) & 6.85 & 14.7 & & 73 & 7.4 \\
Ship & 4.39 & 9.4 & & 1.4 & 0.1 \\
Air & 0.67 & 1.4 & & 0 & 0 \\
Non-traffic & 27.8 & 59.7 & & 796 & 81 \\
Biogenic & 6.89 & 14.8 & & 113 & 11.4 \\
Total & 46.6 & 100 & & 983 & 100 \\
\hline
\end{tabular}



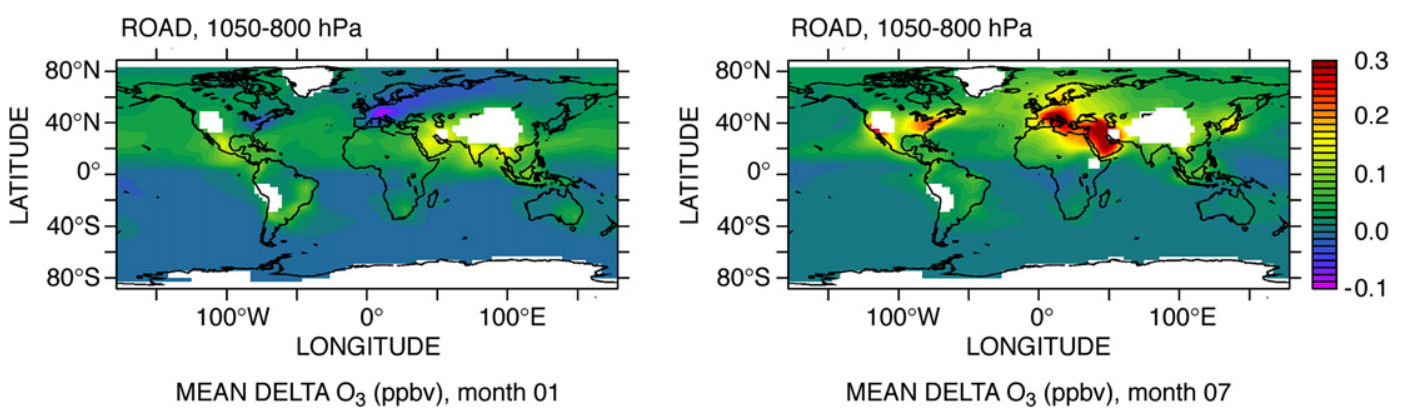

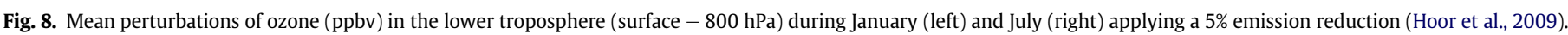

Since impacts of land transport add to or interact with impacts from other sources, they cannot be directly measured in the real world but have to be estimated from models. Only few calculations have been carried out so far (Niemeier et al., 2006; Matthes et al., 2007), the most recent in the EC-Quantify project (Hoor et al., 2009). We discuss Quantify results being aware that they are not based on the most recent emission datasets presented in Section 2, but on an older dataset shown in Table 9.

Calculations using more recent emission data are not available and a linear extrapolation might cause misleading results because of interdependencies described in Hoor et al. (2009). However, in general the impacts described below will be stronger for the emissions presented in Section 2 of this article.

In order to estimate the impacts of transport emissions against the background of all natural and anthropogenic emissions, "base case" model runs have been carried out including all emissions. The base case is compared with a "perturbed case" model run in which the transport emissions are reduced by $5 \%$ (Hoor et al., 2009). This approach was chosen and preferred to a direct $100 \%$ reduction of the transport emissions to allow to add up the effects of each transportation mode and to avoid non-linear responses of the chemical system due to interactions with different chemical background conditions at different locations. Such interactions are switched off in a 100\% reduction approach as applied in an earlier study (Matthes, 2003). In the Quantify calculations shown here all transport sectors were included. The used draft emission inventory of Borken-Kleefeld is described in detail in Hoor et al. (2009). Uncertainty ranges as discussed in Section 2.1 of this report are on average about $30-40 \%$ for $\mathrm{NO}_{\mathrm{x}}$ emissions and 30-60\% for carbon monoxide (this publication, Table 5; Matthes, 2003).

\subsubsection{Impacts on ozone}

The impact of transport emissions on global ozone is presented in Fig. 8 measured as the difference in the concentrations between the base case and the perturbed case.

Based on the $5 \%$ perturbation of road-traffic emissions highest sensitivities in the northern hemisphere can be up to $0.18 \mathrm{DU}$ in summer and $0.07 \mathrm{DU}$ in winter. If a linear scaling of this modelling results to $100 \%$ would be applicable (this is questionable because of the non-linearity of the chemistry) this would mean for the total road traffic contribution up to 3.5 Dobson Units (DU) in summer and up to $1.4 \mathrm{DU}$ in winter. The results are of a similar magnitude compared to respective values of $5.2 \mathrm{DU}$ and $2.1 \mathrm{DU}$ found by Matthes (2003) based on emission data from 1990 with higher $\mathrm{NO}_{\mathrm{x}}$. Changes in the Southern Hemisphere are weak and, probably due to interhemispheric transport, in phase with the Northern Hemisphere. On a global average land transport contributes relatively strongest to the total ozone column in the $\mathrm{NH}$ summer in industrialised regions with dense transport (Eastern US, Europe, Near East, Japan). The strongest impact is seen in regions where at least two relevant factors come together: a large car fleet, limited control of air pollution, dry and sunny weather conditions. Such regions are Italy, Eastern Europe and the Near East. This is because ozone formation depends on photolysis and the $\mathrm{OH}$ concentration. Both are higher in the $\mathrm{NH}$ summer. The chemistry of hydrocarbons has in many cases an additive influence (Matthes, 2003). In the dark winter months, however, the contribution of land transport to ozone formation is minor or can even be slightly negative on a regional scale, for example over Europe. The deviation between different models is in the range of $15-30 \%$ for the most affected regions.
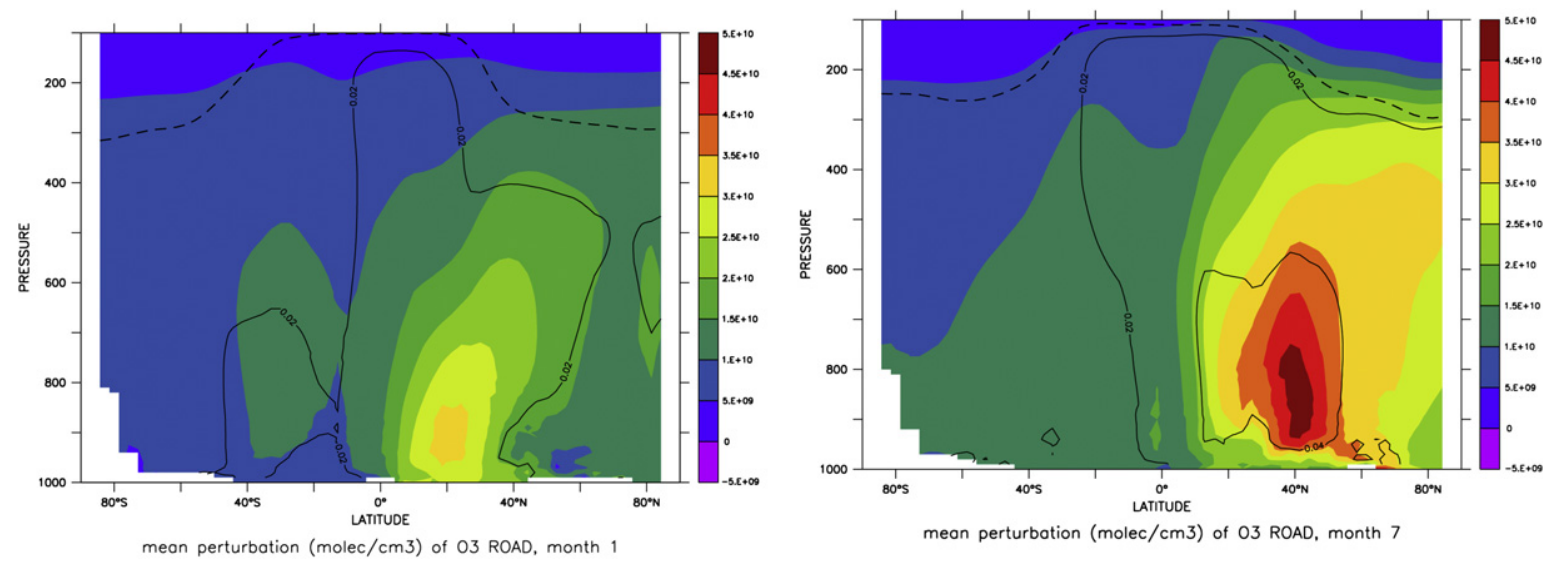

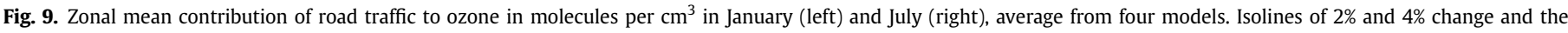
tropopause (dashed line) are shown in the graphs. Source: Hoor et al. Quantify. 
A remarkable result of the models shown in Fig. 9 is that the impacts of road traffic extend from the boundary layer to the free troposphere and even to the Upper Troposphere-Lower Stratosphere (UTLS) region. Although in the UTLS region (250 hPa layer, $11 \mathrm{~km}$ altitude) aircraft emissions dominate the traffic impact, road emissions can reach a similar magnitude in summer. Ship emission impacts, in contrast, are more strongly confined to the planetary boundary layer $(\mathrm{PBL})$ because of less vigorous convection, which is much stronger over land, especially during summer. Ozone is transported from the source regions to the free troposphere and UTLS region where its contribution to climate change is strongest. Therefore, it is more meaningful for the illustration of the climate effect to show the total tropospheric ozone column rather than ozone changes in the PBL.

The relative contribution of road-traffic emissions to atmospheric ozone, again if linearly scaled from a $5 \%$ perturbation, reaches about $2-6 \%$ zonally averaged in the Northern Hemisphere troposphere in July. Maxima are in the lower troposphere midlatitudes. Matthes et al. (2007) found values twice as high (4-12\%), but again based on emission data of the year 1990. They also mention that calculated $\mathrm{NO}_{\mathrm{x}}$ tends to be overestimated in their model compared to the observed values in high $\mathrm{NO}_{\mathrm{x}}$ regions. Differences between the model and observed values of the $\mathrm{NO}_{2}$ columns are $15-30 \%$. Furthermore, we need to consider that during the period from 1990 to 2000 many relevant emissions $\left(\mathrm{NO}_{\mathrm{x}}, \mathrm{CO}\right.$ and NMVOC) have been reduced in large parts of the industrialised world due to the widespread use of catalytic converters.

In the Quantify results the globally averaged impact of road traffic on ozone in the PBL is only moderate with differences in the perturbed case of 1-2 ppb. In the mid-latitudes it is most pronounced and shows a clear seasonality. The regional impact can be stronger and reaches for example $3 \mathrm{ppb}$ in summer in the Eastern US and central Europe whereas Matthes et al. (2007) found even changes up to $5 \mathrm{ppb}$. It seems that in some cases the pollutants are transported downwind from the original region exhibiting a similar effect of ozone production in the downwind regions.

\subsubsection{Impacts on $\mathrm{OH}$}

As for $\mathrm{OH}$ concentration, moderate changes in the monthly average are modelled for a perturbed system. While ozone is in many regions increased by transport even in winter $\mathrm{OH}$ varies more significantly in sign. In the $\mathrm{NH}$ winter road-traffic emissions slightly decrease the $\mathrm{OH}$ concentration due to emissions of $\mathrm{CO}$ and NMVOC. Both are direct sinks for $\mathrm{OH}$. However, the difference between the perturbed case and the base case is less than $1 \%$.

In $\mathrm{NH}$ summer the $\mathrm{OH}$ concentration is clearly increased, in particular over high traffic regions. This increase is $2-4 \%$ in the mid troposphere and close to the boundary layer between $20^{\circ}$ and $60^{\circ}$ North if scaled to $100 \%$ (reaching about $0.18 \%$ or $5 \cdot 10^{3}$ molecules $\mathrm{cm}^{-3}$ for a $5 \%$ perturbation). The reason is that $\mathrm{OH}$ is more effectively recycled by $\mathrm{NO}_{\mathrm{x}}$ due to the photolysis of $\mathrm{NO}_{2}$ and additional $\mathrm{OH}$ is formed from photochemically produced ozone, in particular in summer. On the other hand, the $\mathrm{OH}$ production is less sensitive to perturbations at the high $\mathrm{NO}_{\mathrm{x}}$ levels in polluted regions, since the reaction of $\mathrm{OH}$ with $\mathrm{NO}_{2}$ is also a sink for $\mathrm{OH}$ (Lelieveld et al., 2002). Therefore, in the clean marine boundary layer emission from ship transport lead to higher $\mathrm{OH}$ formation per molecule $\mathrm{NO}_{\mathrm{x}}$ than road transport does. In summer, the reducing effect of $\mathrm{CO}$ is relatively weak and minor compared to that of $\mathrm{NO}_{\mathrm{x}}$. Varying $\mathrm{OH}$ concentrations lead also to changes in the methane lifetime as discussed in Section 4.1.

Globally averaged methane-lifetime reduction due to roadtraffic emissions are estimated to be on the order of $1.6 \%$, not including feedback factors to account for the long-term steady state (Fuglestvedt et al., 1999; Hoor et al., 2009).

\subsection{Impacts on air quality and health}

Air quality in most European cities does not always meet the limit values set by European regulation, and still has major negative impacts on human health and welfare. Land transport and in particular road transport has a considerable negative influence on air quality. Evidence on health impacts of air pollution has been gathered through numerous studies conducted by scientists of various disciplines and published since the late 1980s (Pope, 1989, 2000; Pope et al., 1995, 2002; Brunekreef et al., 1995; Brunekreef and Holgate, 2002; Brunekreef and Forsberg, 2005; Zmirou et al., 1998; Jędrychowski, 2000; Nyberg et al., 2000; Schwartz, 2000; Peters et al., 2000, 2001; Katsouyanni et al., 2001; Hoek et al., 2002; Leikauf, 2002; Brook et al., 2004; Boldo et al., 2006; Naess et al., 2007). The results of such studies have been condensed and comprehensively evaluated in several WHO publications (WHO, $2000,2002,2005 a, b)$ and in relation to land transport impacts in WHO (2003); Krzyzanowski et al. (2005) and WHO (2006). According to WHO estimates more than 2 million premature deaths each year are attributed to urban outdoor air pollution and indoor air pollution from the burning of solid fuels. More than half of them are occurring in developing countries (WHO, 2005b). A comparison with other leading risk factors is given in Fig. 10 .

Most of the air pollutants are related to respiratory and cardiovascular diseases. Some of them are also carcinogenic. Their detailed impacts, partially discussed in the above literature, are subject of comprehensive medical research and cannot be assessed in this report.

The effects of transport-related pollution can be categorized by scale in local and regional: "local" concerning urban air quality and health impacts due to particles, their toxic components and toxic short-lived gases, and "regional" pertaining to the welfare losses from acid deposition, tropospheric ozone (Faiz, 1993) and indirectly climate change.

\subsubsection{Urban scale}

Many regions in the world undergo increasing urbanisation and motorisation and more than half of the world's population is estimated to live in urban areas. Approximately $9 \%$ of the EU-25 population live closer than $200 \mathrm{~m}$ from a road with more than 3 million vehicles per year, and as many as $25 \%$ live within 500 m (EEA, 2007). The land transport directly emits primary air pollutants and precursors of secondary air pollutants. Harmful primary pollutants are particulate matter (PM), carbon monoxide (although only in high concentrations), nitrogen oxides, ammonia and nonmethane volatile organic compounds (NMVOCs), such as benzene, and most polycyclic aromatic hydrocarbons (PAHs). Sulphur dioxide emissions from land transport have been strongly reduced and are now less relevant. Secondary traffic-related pollutants which often can extend from the local to the regional scale include gases such as ozone, peroxyacetyl nitrate (PAN), formaldehyde (HCHO) and secondary particles. The secondary organic aerosol (SOA) generally belongs to the fine PM mode $\left(\mathrm{PM}_{2.5}\right)$ and consists for example of sulphate aerosol or particulate nitrate organic compounds of low volatility.

3.3.1.1. Particles. In urban conditions, the particle size distributions vary rapidly in shape and magnitude following the instantaneous traffic variation and local meteorology.

The number size distribution is influenced by nucleation, coagulation, condensational growth, plume dilution, and vertical mixing during transport from the street to the urban background (Turco and Yu, 1999). The total particle number measured in urban areas often correlates well with $\mathrm{NO}_{\mathrm{x}}$ and shows a distinct diurnal variation, indicating a common traffic source (Ketzel et al., 2004; 


\section{World}

\section{Deaths in 2000 attributable to selected leading risk factors}

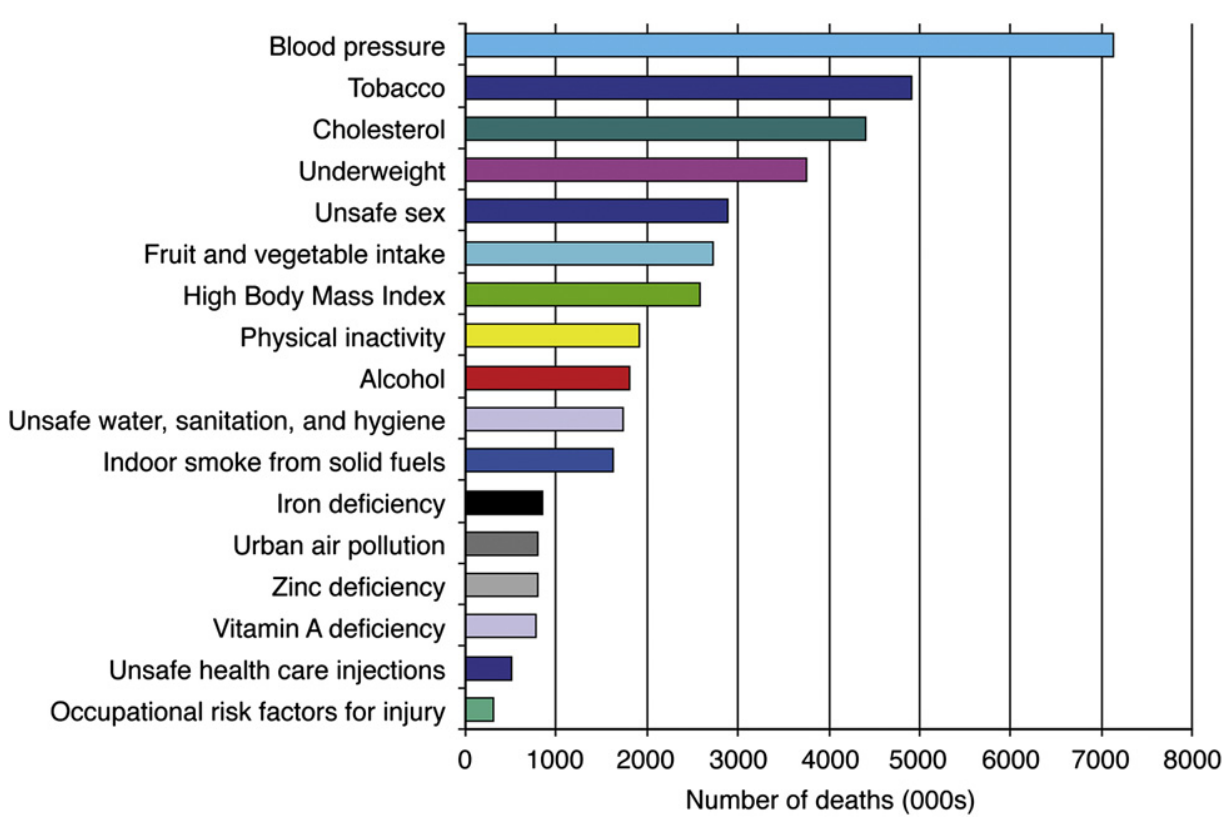

Fig. 10. Deaths in 2000 attributable to selected leading risk factors (WHO, 2002).

Hussein et al., 2004). Traffic emissions are able to affect submicron particle number concentrations around major roads and may be a dominant source of ultrafine particles $\left(\mathrm{PM}_{0.1}\right)$ in the urban atmosphere (Despiau and Croci, 2007; Rodriguez et al., 2007). For example, $1 \mathrm{~h}$ after a traffic peak at street level significant increases (bursts) in concentrations of particles around $30 \mathrm{~nm}$ have been reported. Exhaust emissions formed in the combustion processes affect mostly the particulate matter load in the fine mode. Some combustion products form also secondary particles belonging to the fine and ultrafine modes. Brake wear and wear of the road surface is an important factor for the highest concentrations in the coarse mode (Manoli et al., 2002). The contribution to particulate mass ranges from place to place from a few percent up to $80 \%$ (Almeida et al., 2005; Johansson et al., 2007). It was also found that the traffic contribution in the coarse size fraction $(1.9-72 \mu \mathrm{m})$ was approximately $80 \%$ up to $150 \mathrm{~m}$ from the road, it dropped abruptly by a factor of 2 over a distance of 150-200 $\mathrm{m}$ and declined further to $20 \%$ at $1500 \mathrm{~m}$ from the road (Wrobel et al., 2000).

Out of all known air pollutants excluding dioxins, the strongest health effects are currently assigned to PM (e.g. Ibald-Mulli et al., 2002; Pope et al., 2002; Kappos et al., 2004; Dominici et al., 2006). PM is generally monitored as $\mathrm{PM}_{10}$. However the levels of the finer fraction $\mathrm{PM}_{2.5}$, if measured, give a better indication of the PM health effects. Particles physical and chemical properties as well as substances that adhere to their surfaces (as e.g. PAHs) influence their harmfulness. PM lifetime in the atmosphere differs significantly with their size. The lifetime of $\mathrm{PM}_{0.1-2.5}$ is in the order of weeks to months - which allows them to travel over continents. In consequence, $\mathrm{PM}_{2.5}$ can affect people living far from their emission source, but still have due to higher concentration the strongest impacts on a local scale. The coarse PM $\left(\mathrm{PM}_{2.5-10}\right)$ are more easily deposited by sedimentation and thus have rather local impacts. Particulates from traffic may contain diverse elements, as $\mathrm{Mg}, \mathrm{Al}, \mathrm{Si}$, $\mathrm{P}, \mathrm{S}, \mathrm{K}, \mathrm{Ca}, \mathrm{Ti}, \mathrm{Mn}, \mathrm{Fe}, \mathrm{Cu}, \mathrm{Zn}$ and also $\mathrm{Pb}$ and other heavy metals (Wrobel et al., 2000).
Primary $\mathrm{PM}_{2.5}$, which have been found to have considerable inflammatory potency, usually contain crustal material, fugitive suspended dust, organic and elemental carbon (soot), inorganic ions and heavy metals. Secondary $\mathrm{PM}_{2.5}$ consist mainly of SOA, which can also origin from traffic (Brook et al., 2007; Rappenglück et al., 2005). Other components like sulphate and nitrate salts show lower toxic potency. PM containing $\mathrm{As}, \mathrm{Cr}, \mathrm{Ni}, \mathrm{Pb}$ or those which bound specific PAHs (e.g. benzo-( $\alpha$ )-pyrene), are carcinogenic. Nitrated polyaromatic hydrocarbons (nitro-PAHs) include the most carcinogenic substances known to man and can be found in diesel exhaust fumes.

$\mathrm{PM}_{2.5}$ are believed to be the most harmful, because when inhaled they can penetrate deep into the lungs. In particular, the effects of long-term PM exposure on mortality (life expectancy) seem to be attributable to $\mathrm{PM}_{2.5}$ rather than to coarser particles (Brunekreef and Forsberg, 2005; WHO, 2006). Relative risks (RR) for selected pollutants estimated in meta-analysis studies prepared by WHO (Anderson et al., 2004) are presented in Fig. 11.

The average loss of life expectancy due to $\mathrm{PM}_{2.5}$ in 2000 was estimated at 8.6 months in Europe, varying from around 3 months in Finland to 12-36 months in Benelux, Silesia and the Po Valley (Amann et al., 2004; WHO, 2006). The total number of premature deaths was estimated to be 348,000 in the 25 EU countries.

3.3.1.2. Gaseous species. Gaseous species are often monitored in air quality networks and also investigated in many single studies. Jimenez et al. (2003) demonstrated that the spatial and temporal distribution of $\mathrm{CO}$ and $\mathrm{NO}_{\mathrm{x}}$ follows that of the traffic, while Pfeffer (1994) and Perrino et al. (2002) showed that the mean concentrations of gaseous pollutants at very busy junctions are considerably higher than those of areas that are not directly affected by road traffic. Ambient NMVOC levels are mainly affected by motor vehicle emissions where high levels of aromatic hydrocarbons (toluene, benzene and xylenes) have been detected and associated with diverse public transport systems (Velasco et al., 2007; 


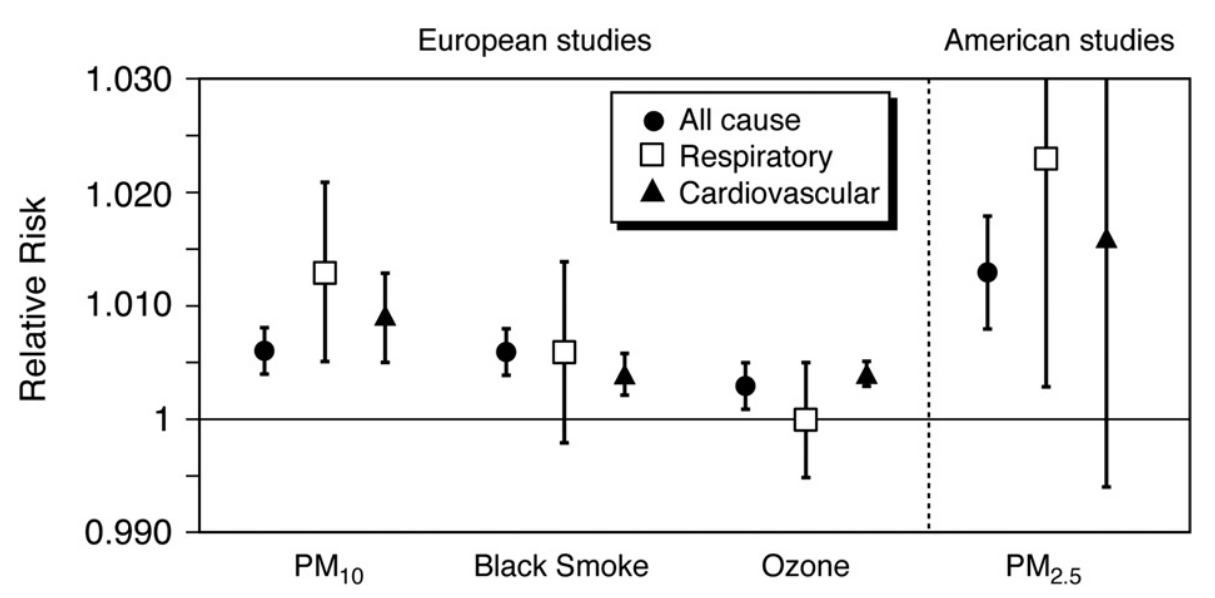

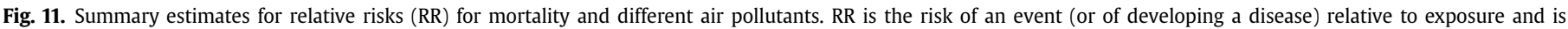

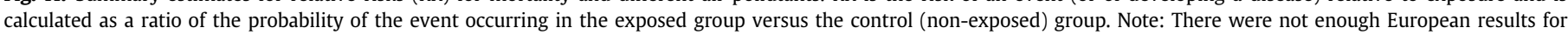
a meta-analysis of effects of $\mathrm{PM}_{2.5}$. The relative risk for this pollutant is from North American studies (WHO, 2006 after Anderson et al., 2004).

Muezzinoglu et al., 2001). Traffic-related hydrocarbons (m, p, o-xylenes, toluene, ethene, propene) were found to be responsible for the generation of ozone impacts above $50 \mathrm{ppbv}$ (Rappenglück et al., 2005).

PAHs observed concentrations were found to be associated predominantly with emissions from road traffic although other sources such as fuel oil, coal combustion, and incineration contribute as well (Marr et al., 2006; Harrison et al., 1996). The traffic contribution of PAHs to busy street air was estimated to be up to $90 \%$ on working days and $60 \%$ during weekends and its contribution to the city background air was estimated to be $40 \%$ (Nielsen, 1996). In the same study, the PAHs contribution from diesel vehicles was about $67 \%$ of the total PAHs traffic contribution.

Ammonia emissions from traffic have their origin usually in gasoline-powered motor vehicles equipped with three-ways catalytic converters (Fraser and Cass, 1998; Moeckli et al., 1996).

Photochemical models are applied based on emission inventories in order to assess theoretically the impact of traffic emissions on air quality. Comparisons to simulations without traffic emissions show that for example ozone peak values can double due to the traffic influence (Fig. 12, Borrego et al., 2000).

3.3.1.3. Ozone. Night and early morning depletion of ozone are explained by the increase of NO traffic emissions. Hourly modelling using a simple constrained chemical model showed that the
$\mathrm{NO}_{2} / \mathrm{NO}_{\mathrm{x}}$ emissions ratio from road traffic has increased markedly from a mean of about 5-6 vol\% in 1997 to about 17 vol\% in 2003 (Carslaw, 2005). It was shown that besides from high background ozone the increased use of continuous regeneration diesel particle filters (CRT) contribute to the increasing trends in the $\mathrm{NO}_{2} / \mathrm{NO}_{\mathrm{x}}$ emissions ratio. Such filters require excess $\mathrm{NO}_{2}$ for regeneration and prevent at the moment that the $\mathrm{NO}_{\mathrm{x}}$ problem and the particle problem can be tackled in parallel.

Consequences of elevated ozone levels for health are respiratory diseases. At concentrations exceeding $240 \mu \mathrm{g} \mathrm{m} \mathrm{m}^{-3}$ (EU alert threshold for $\mathrm{O}_{3}$ ) both healthy adults and asthmatics would experience significant reductions in lung function as well as airway inflammation. At lower concentrations elderly people and those with respiratory diseases are most affected. Due to its low solubility in water ozone can penetrate deep into the lungs. Tropospheric $\mathrm{O}_{3}$ causes eye irritations and can be linked with allergy development as well as with aggravation of allergic reaction (Krzyzanowski et al., 2005). As the amount of $\mathrm{O}_{3}$ an individual is exposed to depends on the time spent outdoors, children and people working outside are most at risk. Although health impacts of ozone have been less investigated than of PM, existing studies in Europe and beyond (e.g. Mudway and Kelly, 2000; Gryparis et al., 2004; Bell et al., 2005, 2006; Ito et al., 2005; Levy et al., 2005) show convincing, though small, positive associations between daily mortality and ozone levels, independent of the effects of PM (see Fig. 11).
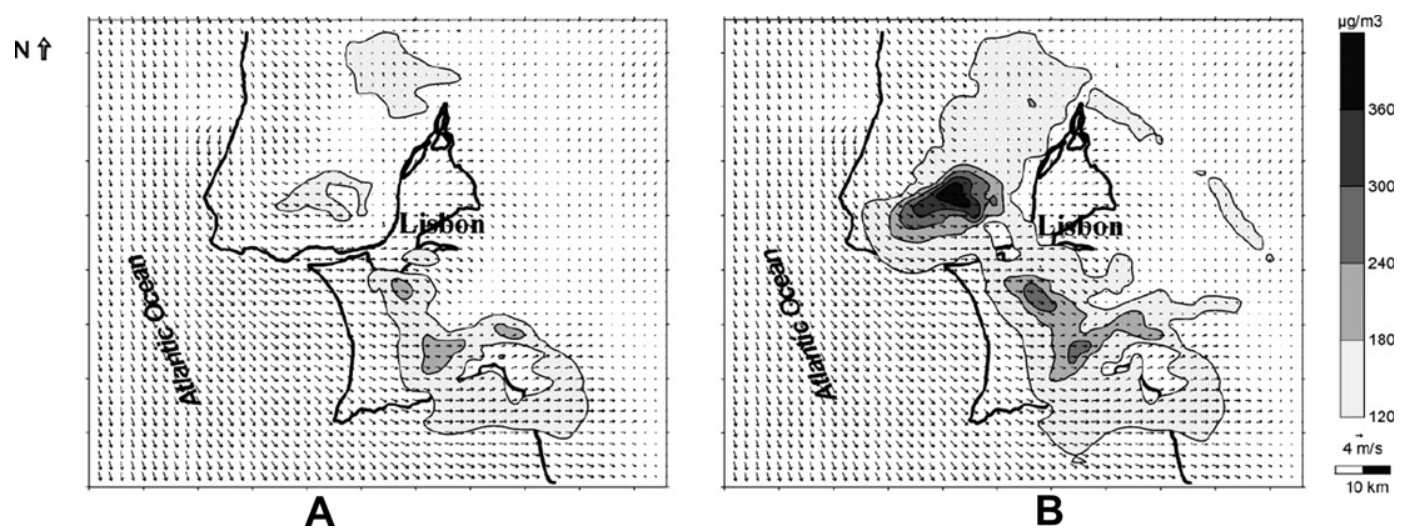

Fig. 12. Simulation results of ozone peak values in July for two emissions scenarios at Lisboa: (A) without traffic emissions; (B) with traffic emissions (Borrego et al., 2000). 


\subsubsection{Regional scale}

While ozone peak values affect mainly the local population living in cities or the periphery, transport's contribution to the global elevation of background ozone has regional impacts.

They are primarily assessed with the help of models as described in part 3.2 of this publication. According to the EMEP 3D Eulerian oxidant model exceedances of the accumulated exposure thresholds (AOT) of 40 and $60 \mathrm{ppb}$ are substantially reduced from 1990 to 2010, assuming feasible emission reductions. But significant exceedances remain, especially in southern Europe. Reductions in road-traffic emissions beyond those included in the Trend scenario could still make an appreciable contribution to reducing ozone levels towards guideline values. Heavy-duty vehicles and evaporative emissions are predicted to make the largest contributions, followed by passenger car exhaust (Reis et al., 2000).

Besides from immediate health effects of air pollution, humans are also indirectly affected by damages to soils, ecosystems, vegetation, crops and water sources. Such can be a result of regionally increased ozone, which is e.g. negatively influencing crop growth. They can also result from deposition of acidifying or eutrophying nitrogen species, as well as heavy metals incorporated into PM. Finally, by its capacity to induce climate change, traffic-related $\mathrm{CO}_{2}$, $\mathrm{O}_{3}$ and halocarbons are likely to affect human health by climate change-related exposures. Such may be increases in heat waves, floods, storms, fires and droughts, with the consequences of malnutrition as well as the migration of some infectious diseases (IPCC Climate Change, 2007a,b,c). Due to increasing knowledge about health effects of air pollution, these effects are a bigger global issue today than they were in 20th century (Juda-Rezler, 2006).

\section{Impacts on radiative forcing and climate}

\subsection{Impacts of greenhouse gases}

The different changes in greenhouse gases that are due to land transport are briefly reviewed in this section and supplemented with results from recent literature and the Quantify project. Quantify estimates are based on 5 different models. For each of them land transport emissions haven been decreased by $5 \%$ and results are obtained by an extrapolation to $100 \%$ (see also Section 3.2 of this report).

\subsubsection{Carbon dioxide}

The main impact of land transport on climate comes from carbon dioxide $\left(\mathrm{CO}_{2}\right)$. Due to its long atmospheric residence time $\mathrm{CO}_{2}$ is well-mixed throughout the troposphere and the stratosphere. As the current emissions from land transport are almost three times as large as the emissions from the aviation and shipping sectors combined (Eyring et al., 2005), its relative contribution to radiative forcing is significant. The long residence time of $\mathrm{CO}_{2}$ also requires that the historical development of emissions are taken into account when calculating the contribution to $\mathrm{CO}_{2}$ enhancement and thus the radiative forcing at a given point in time. The current radiative forcing by $\mathrm{CO}_{2}$ is estimated by IPCC (2007a,b,c) to be $1.66 \mathrm{~W} \mathrm{~m}^{-2}$, based on a total increase of nearly 100 ppmv since pre-industrial times. Schultz et al. (2004) estimate that surface transport (including maritime shipping) by the year 2000 had contributed $17.4 \mathrm{ppmv}$ to the $\mathrm{CO}_{2}$ increase, which would translate into a radiative forcing of nearly $290 \mathrm{~mW} \mathrm{~m}^{-2}$. In a recent study Fuglestvedt et al. (2008) calculated a value of 150 $( \pm 17) \mathrm{mW} \mathrm{m}^{-2}$ from road transport and $21( \pm 3) \mathrm{mW} \mathrm{m}^{-2}$ from rail traffic. Indirect emissions related to rail traffic (production of electric power) add another $3.8( \pm 1) \mathrm{mW} \mathrm{m}^{-2}$. In comparison, they obtain best estimates of $35 \mathrm{~mW} \mathrm{~m}^{-2}$ and $21 \mathrm{~mW} \mathrm{~m}^{-2}$ for the shipping and aviation sectors, respectively.

Future radiative forcing for a given point in time will depend on the time evolution of emissions, which in turn will reflect future policies, technologies, and economic growth. More accurate statements can be made for the future impact of current emissions on a given time horizon. Integration of the radiative forcing over a future time horizon for a one-year pulse of current global emissions can be used to compare the impact of different climate gases in units of $\left(\mathrm{W} \mathrm{m}^{-2}\right) \cdot \mathrm{yr}$ (see IPCC, 2007a,b,c; their Fig. 2.22). The contribution of each climate gas depends on the chosen time horizon and becomes relatively more important on longer time horizons in the case of a long-lived gas such as $\mathrm{CO}_{2}$. For a detailed discussion compare also Fuglestvedt et al. (2010). Fuglestvedt et al. (2008) use emissions from the EDGAR database for 2000 and calculate that, on a 100-year time horizon, the contribution from $\mathrm{CO}_{2}$ is nearly $400 \mathrm{~mW} \mathrm{~m}^{-2} \mathrm{yr}$ for road transport, compared to about $100 \mathrm{~mW} \mathrm{~m}^{-2} \mathrm{yr}$ for shipping and aviation combined. Their shipping emissions are based on own calculations consistent with Endresen et al. (2007) and their aviation emissions from Eyers et al. (2004).

\subsubsection{Ozone}

Ozone has a relatively short lifetime of only a few weeks in the lower troposphere and is thus non-homogeneously distributed, so that models are commonly used to calculate its global mean radiative forcing. Increases near the surface are known to have a smaller impact on radiative forcing than increases in the upper troposphere (Lacis et al., 1990; Hansen et al., 1997). Therefore, the contribution of land transport to ozone radiative forcing per $\mathrm{kg}$ of fuel burnt is assumed to be smaller than for aviation, although in particular in summer its impact extends to the upper troposphere.

Niemeier et al. (2006) applied a chemical transport model and emissions from the POET (Olivier et al., 2003) and EDGAR-3 (Olivier et al., 2001) databases to calculate an ozone-related radiative forcing of $50 \mathrm{~mW} \mathrm{~m}$. Fuglestvedt et al. (2008) obtain 54 $( \pm 11) \mathrm{mW} \mathrm{m}^{-2}$, compared to a best estimate of $22 \mathrm{~mW} \mathrm{~m}^{-2}$ from aviation and $32 \mathrm{~mW} \mathrm{~m}^{-2}$ from shipping. The rail sector contributes another $2 \mathrm{~mW} \mathrm{~m}^{-2}$ according to their study. They also note that the radiative forcing per ozone burden change is larger for land transport than for shipping, probably because of more efficient vertical mixing occurring over land areas that extends the ozone increase towards higher altitudes (see 3.2 cross section Fig. 9).

In Quantify, the perturbed ozone fields were provided for detailed radiative forcing calculations (Myhre et al., in preparation). Table 10 shows results for the different models translated into the effect of total road emissions, subdivided into long-wave, shortwave and net components. Four models perturbed road emissions by a small amount to assure linearity and scaled the modelled changes in ozone to a $100 \%$ change in road emissions. The E39C model (G. Myhre, pers. Comm.) used an alternative method as described in Grewe (2007). The range of results must be seen as a measure of uncertainty in current model studies of this kind.

For future radiative forcing from ozone change, Fuglestvedt et al. (2008) obtain about $50 \mathrm{~mW} \mathrm{~m}^{-2}$ yr for road emissions on a 100 -

\section{Table 10}

Annual-mean long-wave, short-wave, and net radiative forcings due to road emissions for the five models that participated in the first Quantify ozone impact calculation. Unit: $\mathrm{mW} \mathrm{m}^{-2}$

\begin{tabular}{llrllll}
\hline Model & RF & TM4 & OsloCTM2 & p-TOMCAT & LMDZINCA & E39C \\
\hline Spectrum & LW & 19.6 & 25.5 & 15.6 & 25.5 & 70.4 \\
& SW & 6.7 & 7.2 & 3.6 & 7.4 & 20.9 \\
& Net & 26.3 & 32.7 & 19.2 & 32.8 & 91.3 \\
\hline
\end{tabular}


year horizon, about as large a value as for aviation and shipping combined. Given the relatively short lifetime and inhomogeneous distribution of ozone, future changes in spatial emission distributions will alter the radiative forcing per ozone burden change, as ozone production efficiency, ozone lifetime, and its radiative forcing efficiency vary in space.

\subsubsection{Methane}

Methane is not emitted from road transport in significant amounts, but is changed through the emission of ozone precursors. Depending on the $\mathrm{NO}_{\mathrm{x}} / \mathrm{VOC}$ and $\mathrm{NO}_{\mathrm{x}} / \mathrm{CO}$ ratios in the exhaust gases, $\mathrm{NO}_{\mathrm{x}}$ emissions tend to increase $\mathrm{OH}$ as described in Section 3.2. $\mathrm{OH}$ stands for the main loss of methane in the atmosphere. Also ozone produced from emissions of $\mathrm{NO}_{\mathrm{x}}$ and other ozone precursors increases $\mathrm{OH}$ levels. Resulting reductions in the lifetime of methane in part offset the positive radiative forcing of ozone. The changes in methane lifetime, translated into the impact of total emissions from each transport sector, are shown in Table 11 for the road sector and all transport sectors combined as calculated in Quantify.

The models predict reductions in methane lifetime between one and two percent. This impact compared to the total impact from transport is not as large as the fraction of road emissions within the transport emissions. In particular, for road emissions the models calculate a much smaller impact on methane lifetimes than for a corresponding reduction in ship emissions. This is mainly due the high $\mathrm{NO}_{\mathrm{x}} / \mathrm{CO}$ and $\mathrm{NO}_{\mathrm{x}} / \mathrm{NMVOC}$ ratios in shipping emissions, and the generally low $\mathrm{NO}_{\mathrm{x}}$ levels in marine areas.

Fuglestvedt et al. (2008) calculated the radiative impact of methane change due to each transport sector and obtained negative radiative forcings of $-12 \mathrm{~mW} \mathrm{~m}^{-2}$ for road transport, $-43 \mathrm{~mW} \mathrm{~m}^{-2}$ from shipping and $-10 \mathrm{~mW} \mathrm{~m}^{-2}$ from aviation. Although uncertainties exist in terms of the exact magnitude of the impact all models agree on the partial offset of the positive ozone radiative forcing by the reduction in methane lifetime. This offset appears to be smaller in relative terms for the road sector than for the shipping and aviation sectors.

\subsubsection{Nitrous oxide}

The global warming potential of $\mathrm{N}_{2} \mathrm{O}$ is larger than that of $\mathrm{CO}_{2}$ and indirect emissions from biofuel production may increase in the future. Nevertheless, its impact on climate is estimated to remain small. According to Fuglestvedt et al. (2008) even on a 100-year time horizon the radiative forcing from current $\mathrm{N}_{2} \mathrm{O}$ emissions from road transport will be less than $1 \mathrm{~mW} \mathrm{~m}^{-2}$ and thus negligible compared to the other forcing agents (Fuglestvedt, pers. comm.).

\subsection{Impacts of halogenated compounds}

Halogenated hydrocarbons (or "halocarbons") are efficient greenhouse gases. However, their impact on the climate system and radiative forcing is not only due to their global warming potential but also indirectly due to their ozone depletion potential.

Table 11

Methane lifetime in the base case (years), and reductions in methane lifetime in percent due to road emissions (second row) or due to road, aviation, and shipping emissions combined (third row), calculated by the Quantify models.

\begin{tabular}{lllll}
\hline Case & TM4 & Oslo CTM2 & p-TOMCAT & LMDz-INCA \\
\hline Base & 9.0924 & 7.5838 & 11.562 & 9.129 \\
Road & -1.9 & -1.4 & -1.6 & -1.1 \\
Road + Air + Ship & -7.2 & -5.8 & -9.5 & -4.6 \\
\hline
\end{tabular}

\subsubsection{Contribution of mobile air conditioners (MAC)}

to global warming

The global warming contribution from mobile air conditioners has two origins. The carbon dioxide emission due to the increase in fuel consumption is already included in the total carbon dioxide emission estimate for vehicles. However, direct emissions from the release of the refrigerants in MAC, dominate. Their contribution to the forcing depends on their global warming potentials (GWP).

On a 100-year time horizon, the GWP of CFC-12 is 10,900, while that of the replacing HFC-134a is 1430 (IPCC Climate Change, 2007a,b,c, WG I, Table TS.2), as the lifetime of HFC-134a amounts to only 14 years (WMO, 2002, Tables $1-6)$. This implies a reduction of the climate impact per tonne of chemical used, and the burden for the atmosphere measured in $\mathrm{CO}_{2}$ equivalents is decreasing (Fig. 13), although the total amount of refrigerants produced is continuously increasing (see Section 2.5, Fig. 5 and inset in Fig. 13).

Annual emissions from $\mathrm{MAC}$ in $\mathrm{CO}_{2}$ equivalents $\left(\mathrm{CO}_{2}\right.$-eq) are estimated to stablise at about $280 \mathrm{Tg} \mathrm{CO}_{2}$-eq per year in 2010. For 2003, $612 \mathrm{Tg} \mathrm{CO}_{2}$-eq are estimated of which $514 \mathrm{Tg}$ came still from CFC-12. Such amounts are clearly relevant for global warming. The $700 \mathrm{Tg} \mathrm{CO}_{2}$-eq from mobile air conditioning in 2002 correspond to $17 \%$ of the estimated $4300 \mathrm{Tg} \mathrm{CO}_{2}$ emitted by road transport in 2000 (see Section 2.2), or $2.7 \%$ of the $26.3 \mathrm{Pg} \mathrm{CO}_{2}$ from anthropogenic fossil fuel use and cement manufacture in 2002 (CDIAC website, Marland et al., 2007). CFC-12 and HFC-134a, used in mobile air conditioners, lead to radiative forcings of $170 \mathrm{~mW} \mathrm{~m}^{-2}$ and $5.5 \mathrm{~mW} \mathrm{~m}^{-2}$ in 2005, respectively (IPCC, 2007a,b,c).

For the future a larger share of HFC-152a (difluoroethan, $\mathrm{CHF}_{2} \mathrm{CH}_{3}$ ) is planned. This is a halogenated compound with a global warming potential of 140 , which is nearly 10 times lower than that of HFC-134a. Moreover, modern air condition systems are in general better sealed than the older ones, implying less need for refilling during the lifetime of the vehicle. The replacement of HFCs with $\mathrm{CO}_{2}$ in the next generation of cars implies reduced emissions in terms of $\mathrm{CO}_{2}$ equivalents due to the relatively lower GWP value of $\mathrm{CO}_{2}$ compared to CFCs and HFCs. But at present and in the near future MAC have a significant market share in the use of halocarbons. Even when taking into account the expected decrease in emissions, MAC would still contribute about $10 \%$ of the $\mathrm{CO}_{2}$ equivalents that are due to global transport between 2010 and 2015 (Fig. 14).

It is not sure how MAC are going to develop if there are strong changes in the powertrain technology they are connected with and if Diesel and Otto engines are going to be completely replaced. For the near future a US EPA model study estimates that the global HFC

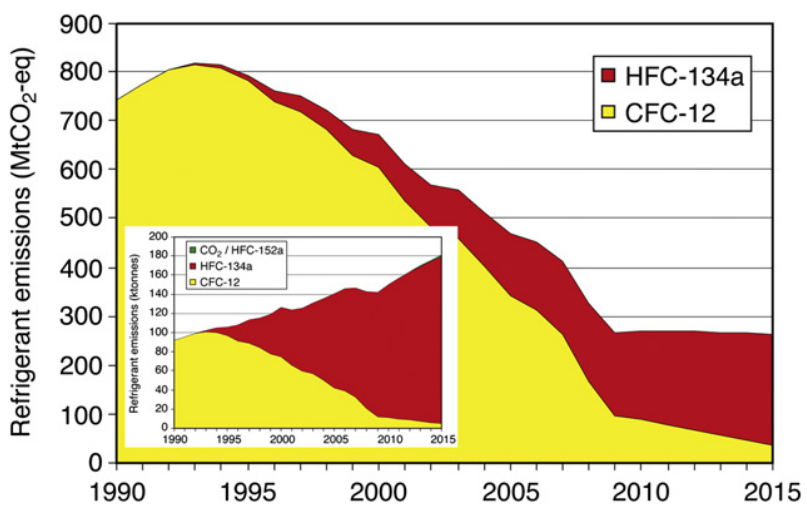

Fig. 13. SROC (2006), Fig. 6b. MAC refrigerant emissions in $\mathrm{CO}_{2}$-eq from 1990 to 2015 . CFC-12 and HFC-134a emissions are transformed into $\mathrm{CO}_{2}$-eq based on their GWP, as given in the IPCC Second Assessment Report (IPCC, 1996; Clodic and Palandre, 2004). 


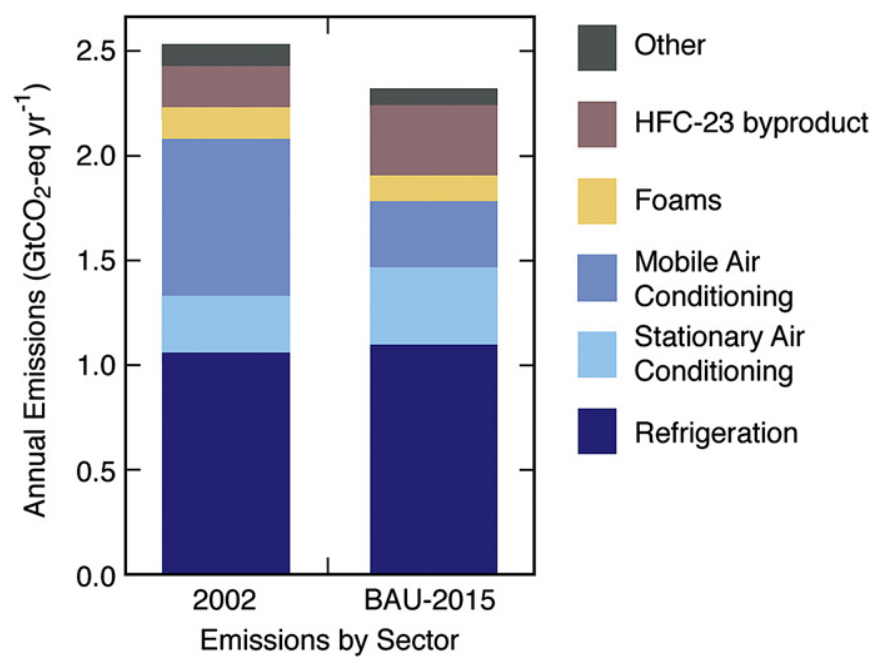

Fig. 14. Historical data for 2002 and Business-As-Usual (BAU) projections for 2015 of greenhouse gas $\mathrm{CO}_{2}$-equivalent direct annual emissions, related to the use of CFCs, HCFCs and HFCs. SROC (2006) fig. SPM-4.

emissions, which replace CFC and HCFC emissions, will rise strongly from $117 \mathrm{Tg} \mathrm{CO}_{2}$-eq in 2000 to $627 \mathrm{Tg} \mathrm{CO}_{2}$-eq in 2020, of which still more than two thirds are emitted in OECD countries. The MAC shares of emissions in the US (and other Annex I countries) are going to decrease from 36\% (47\%) in 2005 to 20\% (37\%) in 2020, but in China and India they are expected to increase from $41 \%$ to $66 \%$ (DeAngelo et al., 2006, Section IV.2).

\subsubsection{Impacts on ozone depletion}

Regarding the protection of the stratospheric ozone layer, the transition from CFCs-12 to HFC-134a in the early 1990s, which is now completed also in developing countries, is a clear progress. HFC-134a is estimated not to have an ozone depleting potential.

This means that the threat for the ozone layer derives primarily from banks of CFC-12. Banks are the total amount of substances contained in existing equipment, chemical stockpiles, foams and other products not yet released into the atmosphere. Because of the long atmospheric lifetime (100 years) and high ozone depletion potential (0.82) of CFC-12 these banks and present emissions will continue to contribute to ozone depletion in the coming decades. CFC-12 makes the largest contribution to stratospheric chlorine levels, about 28\% estimated for 1998 (WMO, 1998) and is just about to peak in the atmosphere.

The stratospheric ozone depletion (about 3\% since 1980) has led to a stratospheric cooling of about $0.6 \mathrm{~K}$ per decade and a negative radiative forcing of about $-150 \mathrm{~W} \mathrm{~m}^{-2}$.

The total CFC-12 indirect forcing from all sources contributes $-34 \mathrm{~mW} \mathrm{~m}^{-2}$ to this value for the time 1980-2000 (SROC, 2006 Chapter 1). This compensates only for $25 \%$ of the $140 \mathrm{~mW} \mathrm{~m}^{-2}$ due to the CFC-12 positive RF for the time 1970-2000. Therefore, the negative RF contribution from MAC through ozone depletion is of less relevance than the direct positive contribution to global warming discussed above. From 1990 to 2000 MAC contributed about one third to the total CFC-12 emissions, but in the decades before clearly less than one quarter. Therefore the negative radiative forcing from MAC can be estimated to be smaller than $-10 \mathrm{~mW} \mathrm{~m}^{-2}$ for the time 1980-2000.

Although there are high uncertainties in such estimations and also in projections for the global warming contribution it seems clear that the impacts from mobile air conditioners remain to be relevant in the future, primarily for climate change and to a much lesser extent for ozone depletion.

\subsection{Impacts of aerosol on radiative forcing}

Aerosols from land transport interact with the radiation passing the atmosphere trough reflexion, scattering or absorption and therefore have an impact on the radiative forcing. Balkanski et al. (2010) compared the results of three models with different radiative and aerosol codes to estimate the contribution to the radiative forcing of the aerosol produced through road activities. All three models show maxima for the total sum of the black carbon (BC), organic carbon $(O C)$ and sulphate direct aerosol effect at Northern mid-latitudes and also over North Africa and the Arabian Peninsula, regions with relatively low cloud cover. Other regions where maxima occur as a consequence of activities from road transport are: Western and Central Europe, Eastern US, South Asia and Eastern China. Not surprisingly, these regions are also where the highest emissions take place (Fig. 15). The aerosol radiative forcing from road transportation is dominated by black carbon. Fig. 15

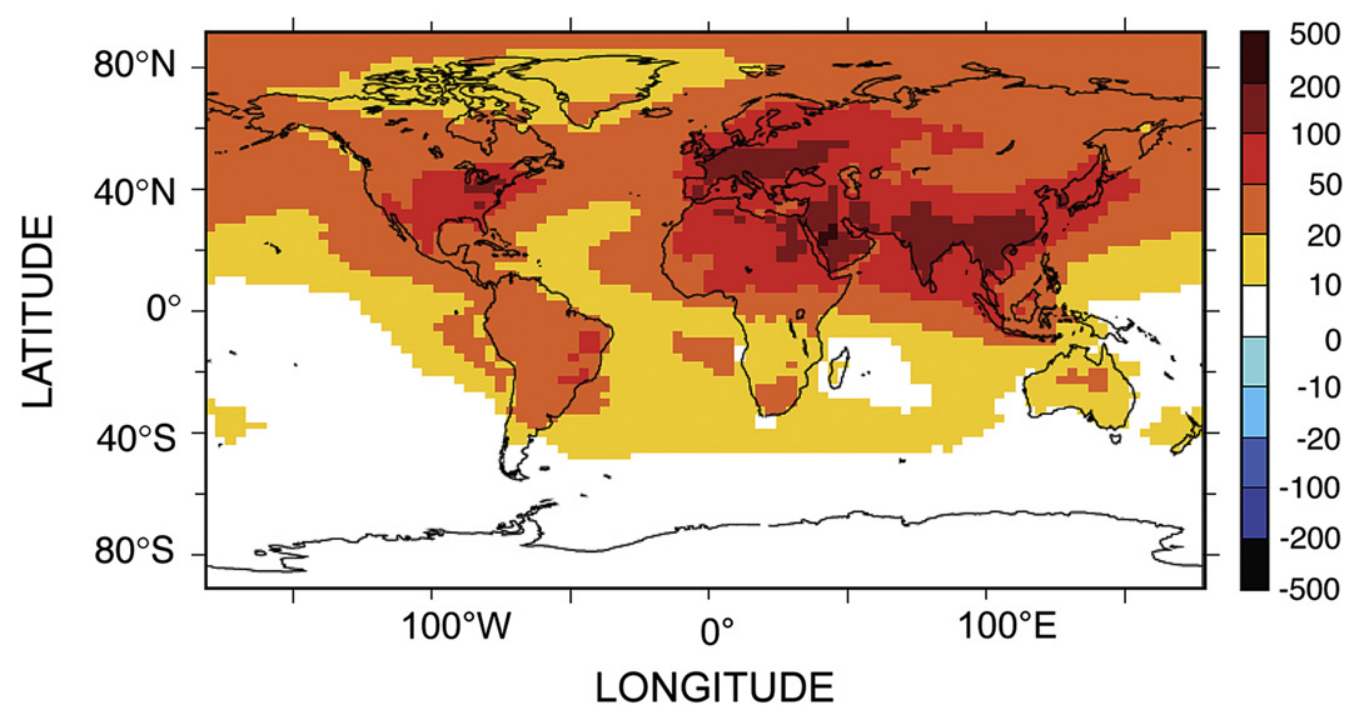

Fig. 15. January top of the atmosphere radiative forcing $\left(\mathrm{mW} \mathrm{m}^{-2}\right)$ due to black carbon emitted from road transportation. 
Table 12

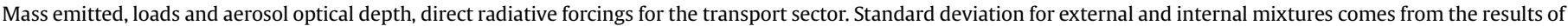
two difference models described in Balkanski et al. (2010).

\begin{tabular}{|c|c|c|c|c|c|c|}
\hline & 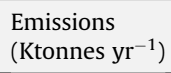 & $\begin{array}{l}\text { Column Burden } \\
\left(\mu \mathrm{g} \mathrm{m}^{-2}\right)\end{array}$ & $\begin{array}{l}\text { Optical depth } \\
(\times 1000)\end{array}$ & $\begin{array}{l}\text { External mixture } \\
\left(\mathrm{mW} \mathrm{m}^{-2}\right)\end{array}$ & $\begin{array}{l}\text { Internal mixture } \\
\left(\mathrm{mW} \mathrm{m}^{-2}\right)\end{array}$ & $\begin{array}{l}\text { Range }^{\mathrm{b}} \text { published by } \\
\text { Fuglestvedt et al. (2008) }\end{array}$ \\
\hline Internal BC & 721.6 & 36.0 & 0.184 & $+31.7 \pm 10.7$ & $+43.5 \pm 12.3$ & $+23 \pm 9$ \\
\hline OC & 326.7 & 6.88 & 0.077 & $-2.4 \pm 1.4$ & $-2.4 \pm 1.4$ & $-8 \pm 4$ \\
\hline $\mathrm{SO}_{4}$ & $1894.6^{a}$ & 9.8 & 0.530 & $-9.4 \pm 2.5$ & $-9.4 \pm 2.5$ & $-12 \pm 5$ \\
\hline Total & & & & $+19.9 \pm 11.1$ & $+31.7 \pm 12.6$ & $+3 \pm 11$ \\
\hline
\end{tabular}

a Emissions are calculated for $\mathrm{SO}_{2}$; load, optical depth and radiative forcing are calculated for sulphate.

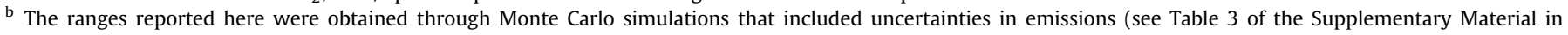
Fuglestvedt et al., 2008).

shows its geographical distribution for January. Black carbon's top of the atmosphere yearly averaged forcing is $+31.7 \mathrm{~mW} \mathrm{~m}^{-2}$ when aerosols are assumed to be externally mixed and $+43.5 \mathrm{~mW} \mathrm{~m}^{-2}$ when they are considered internally mixed. The column burden of organic carbon produced from road traffic is about 6 times less than of black carbon (Table 12). The radiative forcing of organic carbon from road traffic is small $\left(-2.4 \mathrm{~mW} \mathrm{~m}^{-2}\right)$ in comparison to $\mathrm{BC}$ or sulphate. The radiative forcing calculated for sulphate aerosol amounts to $-9.4 \mathrm{~mW} \mathrm{~m}^{-2}$ when averaged globally.

\subsubsection{Comparison with previously published results}

Köhler et al. (2001) did a rough calculation based upon a simplified description of the $\mathrm{BC}$ cycle and assumed emissions of $\mathrm{BC}$ from roads that are 3 times the inventory from Borken et al. (2007). They estimated a direct radiative forcing (DRF) for BC of $80 \mathrm{~mW} \mathrm{~m}^{-2}$. If we scale the amount of black carbon that is used by these authors to that used in the present study, the DRF obtained is $27 \mathrm{~mW} \mathrm{~m}^{-2}$ in good agreement with the results presented here for the external mixture. Fuglestvedt et al. (2008) computed the radiative forcing for both well-mixed greenhouse gases and aerosols emitted from the transport sector. Aerosol radiative forcings were estimated based upon a global 3D simulation from the Oslo-TM2 chemical transport model. The model was run for 18 months, the first 6 months were used to initialise the aerosols fields and the last 12 months used to estimate this forcing. In addition an uncertainty range representing one standard deviation was estimated for these distributions. This uncertainty estimate takes into account uncertainties in fuel consumption, emission factors, atmospheric transport and removal as well as radiative forcing. The radiative forcing for $\mathrm{OC}$ in this study is substantially weaker than in Fuglestvedt et al. (2008). The mean estimate for BC (external mixture) in this study is stronger than in Fuglestvedt et al. (2008). Fuglestvedt et al. (2008) compared UiO model to previous results from the literature and estimated a range of the radiative forcing of $\mathrm{BC}$ from road activities. This range estimated is from 14 to $32 \mathrm{~mW} \mathrm{~m}^{-2}$. The results reported here indicate higher values from 24.4 to $57.6 \mathrm{~mW} \mathrm{~m}^{-2}$ when both externally and internally mixed $\mathrm{BC}$ is considered.

Ammonia from traffic is produced mainly by cars equipped with catalytic converters. Concentrations of ammonia are 5-10 times higher at sites influenced by traffic than at rural sites (Perrino et al., 2003). Locally the presence of high ammonia concentrations could contribute by complexation with salt to nitrate formation. To our knowledge the importance on the global scale of the land traffic has not been estimated.

These results can be put in perspective by comparison with the radiative forcing of total fossil fuel emissions. For black carbon, Forster et al. (2007) report in chapter 2 of the IPCC (2007a,b,c) report a direct black carbon radiative forcing estimate from fossil fuel of $200( \pm 100) \mathrm{mW} \mathrm{m}^{-2}$. We infer from the numbers reported here that road traffic represents $7-16 \%$ of the total fossil fuel radiative forcing.

\subsection{Effects on visibility, clouds and cloudiness}

Besides from the direct effect, aerosol can influence radiative forcing indirectly via its influence on transparency of the atmosphere and changes in cloud cover and cloud properties. However, there is no evidence that land transportation has a similar effect on cloudiness as observed on low stratus clouds for ship transportation (Eyring et al., 2010), or high level cirrus clouds for aviation (Lee et al., 2010). For sure, land transport has besides from pollution and health impacts also an influence on visibility at surface level which are mixed with impacts of other sources of pollutants.

For example, in connection to the dramatic increase of vehicles in Chinese cities in the 1990s the deterioration of visibility is analysed by Song et al. (2003a). High concentration of $\mathrm{PM}_{2.5}$ is measured both in the summer and winter (a daily average of $60-80 \mu \mathrm{g} \mathrm{m}^{-3}$ ) and direct inverse correlation between visibility and concentrations of $\mathrm{PM}_{2.5}$ during the period 1999-2000 for every season is shown in Song et al. (2003b) as well as on an hourly basis for selected episodes by Bergin et al. (2001). Source apportionment of fine-particle pollution based on a measurement campaign and a modelling study for selected sites in Beijing (Zhang et al., 2004) provides evidence of road transport impacts: about $15 \%$ of $\mathrm{PM}_{2.5}$ stem from mobile sources accompanied by about $21 \%$ of secondary road dust. NPRI (2006) is addressing the issue of road dust impact to the environment, with respect to the visibility problem emphasising the role of $\mathrm{PM}_{2.5}$, which is close to the wavelength of the visible spectrum and thus affecting not only the visibility range, but the colour, clarity and contrast of scenes (Malm et al., 2000a,b). Projects like MILAGRO have been studying extensively the environmental impact of a megacity urban environment at regional scale. Detailed measurement of the aerosol composition with its $\mathrm{PM}_{2.5}$ fraction is described by Moffet et al. (2008). Stone et al. (2008) provide source apportionment analysis and conclude that during MILAGRO in the Mexico City area motor vehicles account for about $47 \%$ of the ambient organic carbon at the urban site and $31 \%$ at the peripheral site.

It must be assumed that such road transport-related aerosol burdens have indirect effects on cloud development and radiative forcing. Compared to shipping and aviation, their role might be less relevant in relation to greenhouse gases, since over land the conditions for condensation processes are not comparable to those in ship tracks or contrails. On the local scale, for example Schwarz et al. (2007) found in the Houston area of 4 million inhabitants that the black carbon heating effect due to an about $25 \%$ enhancement of $\mathrm{BC}$ absorption is not large enough to impact the tropospheric stability significantly. It might play some role in bigger megacities like Mexico City or New York area. The real impact of aerosols included in a computation by Jiang and Feingold (2006) for warm convective clouds is shown to be different for the case of direct effects included or not. There is negligible effect on cloud fraction and cloud depth when only indirect effects are taken into account, 
but the optical depth of clouds is increasing with higher droplet concentration. When direct effects and the dynamical coupling are included, the blocking of solar radiation, the further cooling of the surface and heating of aerosols contribute to the stabilisation of the atmosphere. This results in a decrease of the cloud fraction and cloud depth. These effects play a much more significant role than aerosol-cloud processes themselves. However, permanent changes in the aerosol composition and mixing from different sources in the continental boundary layer will make it difficult to attribute a radiative forcing value to the land transport sector for such indirect effects. Respective global estimations are not yet available.

\subsection{Climate change and future impacts}

In 2004, road transport made up for $4.7 \mathrm{Pg} \mathrm{CO}_{2}$, which is $17 \%$ of the global energy-related $\mathrm{CO}_{2}$ emissions and about three quarters of the total transport emissions of $6.2 \mathrm{Pg} \mathrm{CO}_{2}$ (IPCC Climate Change, 2007a,b,c, WG III, Chap.5). Current emissions from transport are responsible for $17 \%$ of the integrated net forcing over 100 years from all current man-made emissions. Land transport gives a $\mathrm{CO}_{2}$ forcing of $150( \pm 17) \mathrm{mW} \mathrm{m}^{-2}$ from road vehicles and $25( \pm 7) \mathrm{mW} \mathrm{m}^{-2}$ from rail (direct + indirect), which is together $12 \%$ of the total man-made $\mathrm{CO}_{2}$ forcing since pre-industrial times. Furthermore, road transport is responsible for $15 \%$ of the total man-made ozone forcing, about $54( \pm 11) \mathrm{mW} \mathrm{m}^{-2}$ (Fuglestvedt et al., 2008).

The dominating amount from road transport accumulated during a relatively short high emission history of not much more than 50 years. Transport has at the moment the highest growth rate among all end-user sectors. Therefore, the relevance for climate change will increase, in particular in developing countries.

The share in $\mathrm{CO}_{2}$ emissions of non-OECD countries is $36 \%$ now and is expected to increase rapidly to $46 \%$ by 2030 (IPCC Climate Change, 2007a,b,c, WG III, Chap.5). In Eastern Asia the $\mathrm{NO}_{\mathrm{x}}$ and $\mathrm{CO}_{2}$ emissions from road transport doubled from 1990 to 2000.

Due to the enormous dynamic in growth just in the recent years and diverse alternative technologies discussed present projections do not dare to give an outlook beyond 2050. But, unless there is a major shift away from current patterns of energy use, total transport energy use and carbon emissions is projected to be about $80 \%$ higher by 2030 compared to 2004 values (IPCC Climate Change, 2007a,b,c, WG III, Chap.5), most coming from land transport. In 2050 , as much as $30-50 \%$ of the total $\mathrm{CO}_{2}$ emissions are projected to come from the transport sector (JRC/CONCAWE/EUCAR, 2006). Details about the present scenarios are described in Sections 5.5 and 5.6.

From this it is clear that the climate impact of transport will be primarily based on long-lived greenhouse gases, in particular carbon dioxide. Since mitigation is easier to realise for stationary energy consumers, the relative share of the road transport contribution to global warming is going to grow. Therefore, general climate impacts as described in the recent IPCC Climate Change (2007a,b,c) report's scientific basis will be soon attributable with a more than $20 \%$ fraction to road transport.

Expected impacts according to IPCC Climate Change (2007a,b,c) summary for policymakers are for example a temperature increase of about $0.2^{\circ} \mathrm{C}$ per decade in the global average. Land surface will warm stronger. The Arctic regions are most affected, changing in turn the conditions for land transport. Winter road conditions in higher latitudes could improve, with consequences in commercial activities (see ACIA, 2004, www.acia.uaf.edu). Opposite, in permafrost zones negative effects might appear with higher temperatures shortening the winter-road season (Instanes et al., 2005). A sea level rise between 18 and $59 \mathrm{~cm}$ until the end of the century is expected and an additional sea level rise due to rapid melting of glaciers in particular in the Arctic is possible, affecting coastal settlements and transport infrastructure. Sea ice is going to shrink and snow cover is projected to contract. This leads to reductions of the Earth albedo. The warming of the oceans favours stronger tropical cyclones leading to higher damage in coastal regions. Since warmer air holds more water the water cycle is going to intensify, leading to stronger rain events and higher evaporation. Since increases in rainfall will be unevenly distributed, some regions are going to experience more severe droughts. Extreme precipitation and storms could e.g. imply in traffic limitations, road and railroad closures, train delays and cancellation (O'Brien et al., 2004).

It is hardly predictable, to what extent aerosol emissions from road transport will contribute to the global energy balance as part of the direct or indirect aerosol effect. Since the major forcing comes at the moment from black carbon, the present effect is positive. However, particle emissions are highly undesirable due to their negative health impacts. They have already been significantly reduced and will be more reduced according to more strict emission regulations in the near future. The lifetime of particles is short. Therefore, particle impacts are not going to make a large contribution to the long-term positive radiative forcing effects as shown in Fig. 17.

Radiative forcing values as shown in Fig. 16 are useful to evaluate the impact of historical emissions on climate until present. However, they are not necessarily useful to evaluate impacts of present and future emissions on the future climate. Decision making for the future requires other metrics as discussed in Fuglestvedt et al. (2008). Their applicability depends on the purpose. UNFCCC decided to use the Global Warming Potential with a 100-year time horizon $\left(\mathrm{GWP}_{100}\right)$ in the Kyoto Protocol. Shine et al. $(2005,2007)$ have proposed the Global Temperature Potential (GTP) as an

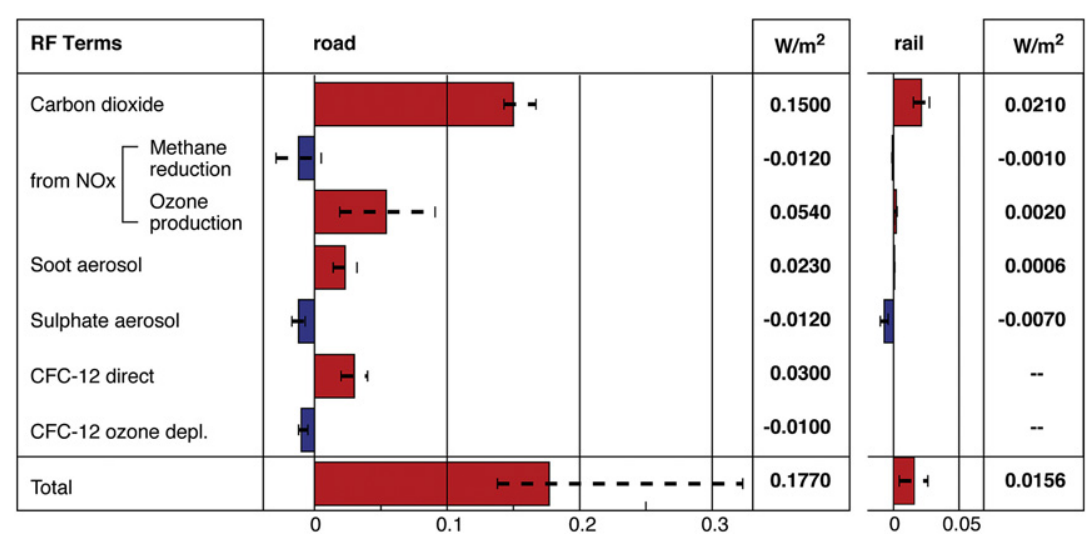

Fig. 16. Radiative forcing for road and rail transport in 2000. 
Table 13

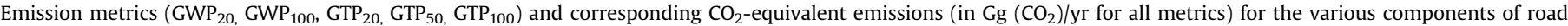

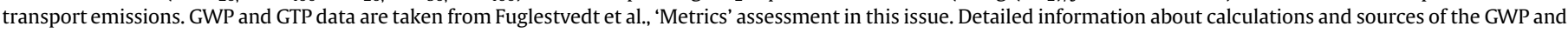
GTP values are given there.

\begin{tabular}{|c|c|c|c|c|c|c|c|c|c|c|}
\hline & $\mathbf{G W P}_{20}$ & GWP $_{100}$ & $\mathbf{G T P}_{20}$ & $\mathbf{G T P}_{50}$ & $\mathbf{G T P}_{100}$ & $\begin{array}{l}\mathrm{CO}_{2} \text {-eq emissions } \\
\text { (GWP } \\
\text { (Go-based) }\end{array}$ & $\begin{array}{l}\mathrm{CO}_{\mathbf{2}} \text {-eq emissions } \\
\text { (GWP100-based) }\end{array}$ & $\begin{array}{l}\mathrm{CO}_{2} \text {-eq emissions } \\
\text { (GTP } \\
\text { GTo-based })\end{array}$ & $\begin{array}{l}\mathrm{CO}_{2} \text {-eq emissions } \\
\text { (GTP } \\
\text { (G0-based) }\end{array}$ & $\begin{array}{l}\mathrm{CO}_{2} \text {-eq emissions } \\
\text { (GTP100-based) }\end{array}$ \\
\hline $\mathrm{CO}_{2}$ & 1 & 1 & 1 & 1 & 1 & 4174 & 4174 & 4174 & 4174 & 4174 \\
\hline NOx & 19 & -11 & -87 & -29 & -2.9 & 169 & -98 & -772 & -257 & -26 \\
\hline CO & 6.0 & 2.0 & 3.7 & 0.77 & 0.29 & 655 & 218 & 404 & 84 & 32 \\
\hline NMVOC & 14 & 4.5 & 7.5 & 1.5 & 0.66 & 191 & 61 & 102 & 20 & 9 \\
\hline Soot BC & 1600 & 460 & 470 & 77 & 64 & 1107 & 318 & 325 & 53 & 44 \\
\hline Soot OC & -240 & -69 & -71 & -12 & -10 & -73 & -21 & -21 & -4 & -3 \\
\hline SOx dir. & -140 & -40 & -41 & -6.9 & -5.7 & -262 & -75 & -77 & -13 & -11 \\
\hline CFC-12 & 11000 & 10900 & 11500 & 11800 & 9200 & 658 & 652 & 688 & 706 & 550 \\
\hline HFC-134a & 3830 & 1430 & 3140 & 795 & 225 & 253 & 94 & 207 & 52 & 15 \\
\hline
\end{tabular}

emission metric going one step further in the chain from emission values to concrete consequences of climate change. It is consistent with the policy target of constraining the global mean surface temperature increase below a threshold (e.g. the EU's target of keeping it below $2{ }^{\circ} \mathrm{C}$ above pre-industrial levels). Tables 12 and 13 and Fig. 17a,b show the $\mathrm{GWP}_{20}, \mathrm{GWP}_{100}, \mathrm{GTP}_{20}, \mathrm{GTP}_{50}, \mathrm{GTP}_{100}$ and $\mathrm{CO}_{2}$-equivalent emissions for these metrics for the various components of the land transport emissions. Details on input data and how the metrics are calculated are given in Fuglestvedt et al. (2008).

Fig. 17 demonstrates a clear difference between short term and long-term impacts. In the short term, two factors play a major role additionally to the $\mathrm{CO}_{2}$ effect: 1 ) Methane is increased by $\mathrm{CO}$ emissions and decreased by $\mathrm{NO}_{\mathrm{x}}$ emissions via $\mathrm{OH}$ reduction or formation, resulting in warming or cooling impacts. 2) Aerosols can either cause a warming, if they consist of black carbon (BC), which is an important short term factor, or cause a cooling if they consist of sulphate, which is a less important opponent in land transport. Both effects become significantly weaker in their GWP if a 100-year time scale is considered and are nearly negligible if the global temperature potential is estimated. For the long term only very long-lived GHG play a role: $\mathrm{CO}_{2}$ and to some extent $\mathrm{CFC}-12$ from air conditioners.

\section{Future developments}

\subsection{Present standards and regulations}

The European Union regulates land transport-related air emissions by automobile emissions standards (Euro) and by automotive fuel quality standards. Emissions from road vehicles are regulated individually for light-duty vehicles (LDV = cars and light vans) and for heavy-duty vehicles (HDV), i.e. road vehicles heavier than 3.5 tonnes (trucks and buses). A whole series of amendments have been issued to stepwise tighten the limit values. Also non-road vehicles and machinery, as well as two- and three-wheeled vehicles have been included. The first set of modern European emission standards, Euro 1, entered into force in 1993. Euro standards regulate the emissions of nitrogen oxides $\left(\mathrm{NO}_{\mathrm{x}}\right)$, hydrocarbons (HC), carbon monoxide (CO) and particulate matter (PM) over a standardised drive cycle and are expressed in mg of pollutant per $\mathrm{km}$ (LDV) or per kWh (HDV). All vehicle types must be tested in order to obtain a type approval. On April 2009 a new Regulation (EC) No 443/2009 limiting $\mathrm{CO}_{2}$ emissions from new passenger cars was adopted at EU as one of six legislations that make up the EU energy and climate package. Average $\mathrm{CO}_{2}$ emissions from all new cars sold in the EU should come down to $130 \mathrm{~g} \mathrm{~km}^{-1}$ by 2015 . There is also a non-binding long-term objective of $95 \mathrm{~g} \mathrm{~km}^{-1}$, to be attained by 2020 .

For LDV, the emission standard so far in force was Euro 4 (since 2005) defined by Directive 98/69/EC. Diesel vehicles were allowed to emit around three times more $\mathrm{NO}_{\mathrm{x}}$ than gasoline. Emissions of PM from gasoline vehicles are not regulated since they are very low. Since September 2009 Regulation (EC) No 715/2007 defining the Euro 5 and Euro 6 standards is applied. Euro 5 will define standards for $\mathrm{PM}, \mathrm{HC}$ and $\mathrm{NO}_{\mathrm{x}}$ from 2009 for new models with the main goal of a large reduction of PM emission from diesel cars. Euro 6 is scheduled to enter into force in September 2014 and shall further reduce the emissions of $\mathrm{NO}_{\mathrm{x}}$ from diesel vehicles (Table 15). However, recent studies have shown that it might be difficult to comply with the air quality limit for $\mathrm{NO}_{2}$ which shall be reduced in parallel from $180 \mathrm{mg} \mathrm{km}^{-1}$ to $80 \mathrm{mg} \mathrm{km}^{-1}$. A higher share of socalled "direct $\mathrm{NO}_{2}$ emissions" have been observed for modern diesel passenger cars and heavy-duty vehicles using standard particle filter systems (Palmgren et al., 2007). For comparison, the US state of California along with ten other US states, has currently a much tougher $\mathrm{NO}_{\mathrm{x}}$ standard of approximately $40 \mathrm{mg} \mathrm{km}^{-1}$.

Concerning regulations for HDV, Euro IV was in force since October 2005 and Euro V - since October 2008. In December 2007 the EU Commission presented a proposal for the Euro VI standard and put forward four different suggestions, considering different fuel types, for stakeholder consultation (Elvingson, 2007). The proposed diesel engine standards (EU A-EU D) are compared to the

Table 14

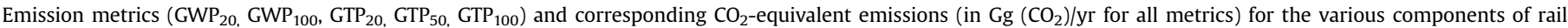

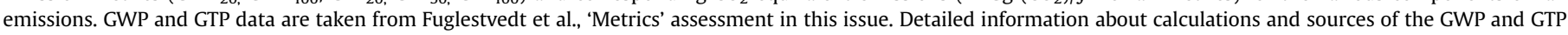
values are given there.

\begin{tabular}{|c|c|c|c|c|c|c|c|c|c|c|}
\hline & $\mathbf{G W P}_{20}$ & GWP100 & $\mathbf{G T P}_{20}$ & $\mathbf{G T P}_{50}$ & $\mathbf{G T P}_{100}$ & $\begin{array}{l}\mathrm{CO}_{2} \text {-eq emissions } \\
\text { (GWP } \\
\left.\mathbf{G O}_{2} \text {-based }\right)\end{array}$ & $\begin{array}{l}\mathrm{CO}_{2} \text {-eq emissions } \\
\text { (GWP } \mathbf{1 0 0} \text {-based) }\end{array}$ & $\begin{array}{l}\mathrm{CO}_{2} \text {-eq emissions } \\
\text { (GTP } \\
\left.\mathrm{GT}_{20} \text {-based }\right)\end{array}$ & $\begin{array}{l}\mathrm{CO}_{2} \text {-eq emissions } \\
\left(\mathrm{GTP}_{50} \text {-based }\right)\end{array}$ & $\begin{array}{l}\mathrm{CO}_{\mathbf{2}} \text {-eq emissions } \\
\text { (GTP }{ }_{100} \text {-based) }\end{array}$ \\
\hline $\mathrm{CO}_{2}$ & 1 & 1 & 1 & 1 & 1 & 119.7 & 119.7 & 119.7 & 119.7 & 119.7 \\
\hline NOx & 19 & -11 & -87 & -29 & -2.9 & 7.49 & -4.33 & -34.28 & -11.43 & -1.14 \\
\hline Soot BC & 1600 & 460 & 470 & 77 & 64 & 175.28 & 50.39 & 51.49 & 8.44 & 7.01 \\
\hline Soot OC & -240 & -69 & -71 & -12 & -10 & -11.49 & -3.3 & -3.4 & -0.57 & -0.48 \\
\hline SOx dir. & -140 & -40 & -41 & -6.9 & -5.7 & -84 & -24.0 & -24.6 & -4.14 & -3.42 \\
\hline
\end{tabular}




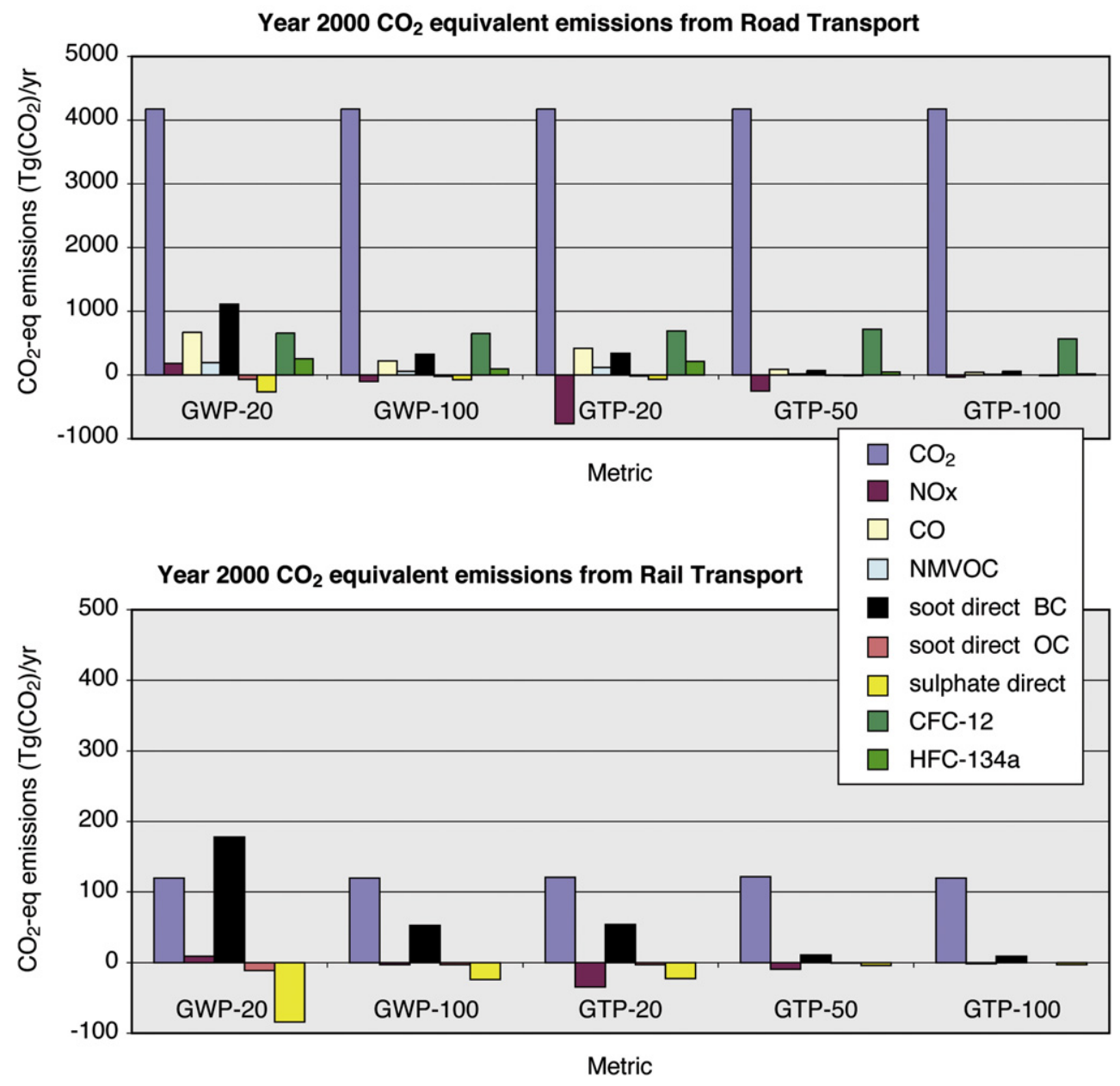

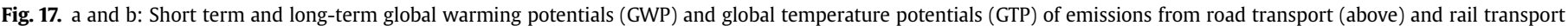
(below) given in Tables 13 and 14. Please note the one order of magnitude difference in the y-axis..

Japanese and US requirements for HDV in Fig. 18. In June 2009, scenario EU A which represents the close global harmonisation with forthcoming US and Japanese standards, was adopted for Euro $\mathrm{VI}$ in EC Regulation 595/2009. It sets $\mathrm{NO}_{\mathrm{x}}$ emission limit at $0.4 \mathrm{~g} \mathrm{kWh}^{-1}$ and PM mass limit for $10 \mathrm{mg} \mathrm{kWh}^{-1}$. This would require a higher rate of cooled exhaust gas recirculation (EGR) in addition to the use of a more efficient selective catalytic reduction (SCR) system.

As for fuel quality, common EU specifications for gasoline, diesel and gasoil used in road vehicles, inland waterway barges and nonroad mobile machinery have been set by the Fuel Quality Directive 98/70/EC amended by 2003/17/EC Directive. They focus mainly on sulphur and for gasoline on lead and aromatics. Since 1 January 2002 all gasoline sold in the EU is unleaded, while the limit on the

Table 15

The new Euro standards $\left[\mathrm{mg} \mathrm{km}^{-1}\right.$ ] for $\mathrm{NO}_{\mathrm{x}}$ and $\mathrm{PM}$ from passenger cars (Acid News, 2007).

\begin{tabular}{lcccl}
\hline & Euro 3 & Euro 4 & Euro 5 & Euro 6 \\
\hline Obligatory for new cars & 2000 & 2005 & Sept 2009 & Sept 2014 \\
$\mathrm{NO}_{\mathrm{x}}$ - diesel cars & 500 & 250 & 180 & 80 \\
$\mathrm{NO}_{\mathrm{x}}$ - petrol cars & 150 & 80 & 60 & 60 \\
$\mathrm{PM}$ - all cars & 50 & $25^{\mathrm{a}}$ & 5 & 5 \\
\hline
\end{tabular}

a Diesel cars only. sulphur content of gasoline and diesel is 50 ppm since 1 January 2005. 1 January 2009 maximum sulphur content for diesel and petrol is lowered to $10 \mathrm{ppm}$. Also the maximum permitted content of polyaromatic hydrocarbons (PAHs) in diesel is reduced by one third, i.e. to $8 \%$ by mass.

\subsection{Vehicle technologies}

Today, almost all road vehicles worldwide and to some extent trains as well are propelled by internal combustion engines which convert the chemical energy of the fuel into mechanical energy at the wheel. Greenhouse gas emissions result mainly from the combustion of carbon containing fuels. Reduction of GHG emissions is possible by (a) lowering energy consumption by improving the drivetrain efficiency, (b) by reducing vehicle energy demand and (c) using alternative drivetrains.

\subsubsection{Improving drivetrain efficiency}

Gasoline engines today are dominated by the homogenous charge stoichiometric combustion process. They work well with a three-way catalyst to reduce air pollutant emissions (Eichlseder and Blassnegger, 2006). Measures to reduce fuel consumption near to mid-term aim to (1) improve part load efficiency (e.g. downsizing with turbocharging, cylinder deactivation), (2) tackle throttle losses by direct injection of fuel and variable valve control, (3) improving high pressure efficiency and (4) address power losses 


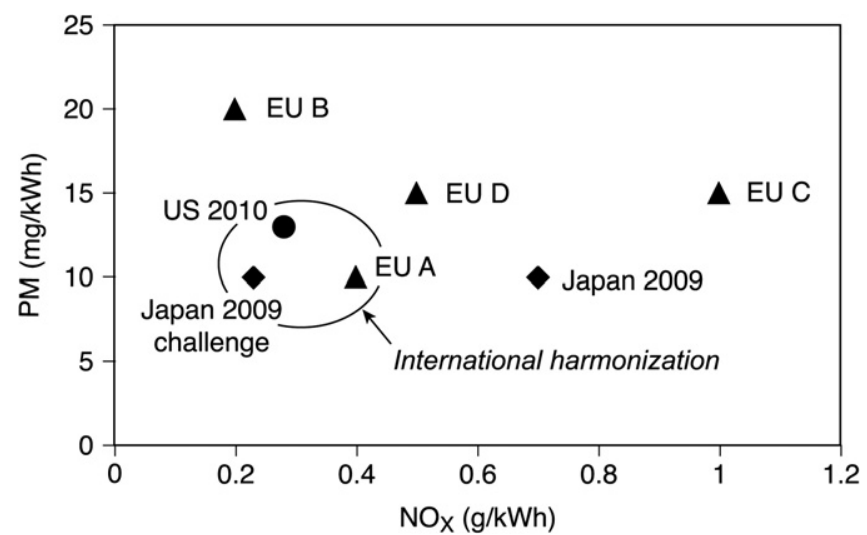

Fig. 18. Current standards and proposed scenarios for HDV standards (Elvingson, 2007).

through e.g. friction or auxiliary units. Several studies examined $\mathrm{CO}_{2}$ reduction of individual measures (e.g. Atkinson et al., 1999; NRC, 2002; Smokers et al., 2006). Fuel consumption improvements, related to the New European Drive Cycle (NEDC), of up to $25 \%$ at the same driving performance for European middle class vehicles have been demonstrated (Fraidl et al., 2007). Fuel economy of diesel engines in real world driving however cannot be reached due to thermodynamic reasons. Diesel engines have already been improved in the past, e.g. by direct injection, and therefore offer a lower potential for improvements. Still, downsizing with turbocharging and reduction of friction losses may lower fuel consumption also in Diesel engines.

Transmissions are inevitable for internal combustion engines (ICE). They operate at speeds higher and torques lower than those requested at the vehicles wheels (Kasseris, 2006). Optimised gearboxes and dual clutches can improve fuel economy by $1-5 \%$ (Smokers et al., 2006).

Hybrid drivetrains consist of at least two different energy converters and two energy storage components. There are several different hybrid architectures in combination with ICE and levels of hybridisation. The latter is distinguished by the power of the electric motor. Hybrid drivetrains make use of engine displacement downsizing and automated gearswitch. Advantages are recuperation of brake energy, enhanced driving performance and improvements in engine efficiency due to downsizing. Disadvantages are higher costs, added system complexity and increase of vehicle weight.

Hybrid vehicles are available since the 1990ies. In 2006 approximately 400,000 hybrid cars were sold which is less than $1 \%$ of the world car production. For the future, an increasing number of hybrid models are announced. The energy savings potential is reported for low hybridisation (start-stop) and driving within cities between 3\% and $12 \%$ (Japan) and for full hybrid vehicles 19\% in US Highway cycle and $44 \%$ in the US City and NEDC cycle (Schmidt, 2006).

Different hybrid architectures, omitting direct mechanical link of ICE and wheels by a pure electric drive are also proposed (series hybrid). This includes so-called range-extender or plug-in hybrids where the ICE/generator on board is used to recharge the battery at high efficiency while the battery can also be charged from the power grid.

Alternative concepts are combustion engines like free piston engines with linear alternators, which directly produce electricity without driving a conventional generator (Achten et al., 2000; Max, 2005; Pohl and Gräf, 2005).

Recovery of waste energy is a way less well explored to improve engine efficiency. Only $25-35 \%$ of the chemical energy in the fuel is converted into mechanical energy by the engine. The rest is lost as heat in the engine cooling system and the exhaust. 1-2\% can be recovered today e.g. through thermal electric generators (Thacher et al., 2007), fuel economy improvements of up to $5 \%$ are projected (Friedrich et al., 2007).

Reductions of the vehicle energy demand are possible by influencing three factors: inertia weight, aerodynamic drag and rolling resistance.

Lightweight construction to lessen vehicle mass is a prominent example, tackling power needs to accelerate and to climb. $100 \mathrm{~kg}$ less weight leads to reductions of between 4 and $17 \mathrm{~g} \mathrm{CO}_{2} \mathrm{~km}^{-1}$ (Espig et al., 2006). Higher strength steels as well as lightweight materials as Aluminium, Magnesium, glass fibre and carbon fibre reinforced plastics are already used to some extent in vehicle structures today. Further potential to reduce $60-120 \mathrm{~kg}$ for a midsize car has been shown with additional costs of $100 €$ to approx. $800 €$ (SLC, 2007).

Rolling resistance depends on the material of the tire, the construction of the tire and the radius, tire pressure and driving speed. Studies indicate that tire pressure should be increased by 0.02-0.04 MPa which would lower fuel consumption by $1-2.5 \%$. Tire industry has proposed new concepts for wheels which are intended to lower rolling resistance until 2030 by $50 \%$.

Aerodynamic resistance results from the product of aerodynamic drag $\left(c_{w}\right)$ and frontal area $(A)$. While there is a continuous decrease in $c_{W}$, A shows an increase. Regarding average European middle class vehicles, $c_{w}$ has decreased from 0.35 in 1995 to 0.3 in 2006. Further potential is given by optimising car underside and engine air flow. $A c_{w}$ of 0.2 seems in reach in the mid term (Schedel, 2007). Lowering of aerodynamic resistance by $10 \%$ is feasible at relative low cost. At constant driving at $120 \mathrm{~km} \mathrm{~h}^{-1}$, this would lower fuel consumption by $20 \%$.

\subsubsection{Alternative drivetrains}

Alternative drivetrains have in theory a higher potential to reduce GHG emissions than the options discussed above. Electric vehicles offer true zero carbon and air pollution emissions on the road. Battery- and fuel-cell electric vehicles are the most prominent alternatives to the internal combustion engine.

Battery-electric vehicles carry their energy along on-board in chemical form. However, the present nickel metal hydride (NiMH) batteries have the disadvantage of low energy density and high additional weight, clearly reducing the driving range. A NiMH battery allowing $100 \mathrm{~km}$ non-stop travel would weigh $340 \mathrm{~kg}$ (Van Mierlo et al., 2006) at high costs. More recent high-energy lithiumIon batteries, which are still subject to safety concerns, reduce the weight to $180 \mathrm{~kg}$ (Van Mierlo et al., 2006) at even higher costs today.

Fuel-cell vehicles produce the electricity for propulsion by electrochemical reactions of hydrogen with oxygen. They have their energy stored on board in form of hydrogen or materials to produce hydrogen from. FCVs provide high efficiency for the production of electricity and locally zero emission driving. But they shift emissions to the hydrogen production, depending on the energy source (see also Section 5.3). Polymer electrolyte membrane fuel cells (PEMFC) are preferred for vehicle applications due to their high power density, which offers low weight, cost and volume (Neburchilov et al., 2007; Zhang et al., 2006). Average drive cycle efficiencies have reached 36\% equivalent to 4.31 Diesel $/ 100 \mathrm{~km}$ (EDC) (von Helmolt and Eberle, 2007). Major problems to be addressed are durability with cycling of the fuel cell stack (status: 2000 h, target: $5000 \mathrm{~h}$ ) (Budd, 2006), operating temperature range (status: $-20{ }^{\circ} \mathrm{C}$, target: $-40{ }^{\circ} \mathrm{C}$ ) and cost reductions (status: $120 \$ \mathrm{kWe}^{-1}$, target: $\left.25-35 \$ \mathrm{kWe}^{-1}\right)$ (DoE, 2007). Hydrogen onboard storage is a further critical issue to provide sufficient driving range. A target of hydrogen storage of $6 \mathrm{wt} \%$ on a system basis is generally considered hard to reach (Ross, 2006). Status 
today is 3-4 wt\% (Chalk and Miller, 2006). Fuel cells can also be used for trains and ships.

\subsubsection{High-speed rail}

High-Speed Rail (HSR) is an opportunity to make land transport more competitive to air transport. It consists of rail technologies capable of speeds above $250 \mathrm{~km} \mathrm{~h}^{-1}$ and up to $400 \mathrm{~km} \mathrm{~h}^{-1}$, travelling on new dedicated tracks. HSR offers time savings, additional capacity, reduced externalities and higher average load factors compared to conventional trains (De Rus and Nash, 2007). HSR can provide journey times competitive with air transport distances up to $650 \mathrm{~km}$. Compared to passenger aircrafts, HSR's energy consumption is approximately 2-3 times more efficient. Differences in $\mathrm{CO}_{2}$-emissions are even higher (factor 6-25) depending on the electricity mix used by HSR (Janic, 2003). However, HSR consumes more energy than lower speed trains and cars on motorways. Nevertheless, it is generally acknowledged that HSR emits less pollutants than airplanes and private cars (Campos and de Rus, 2009). The major disadvantage of HSR manifests in very high capital costs due to huge initial investments (De Rus and Nash, 2007).

\subsection{Alternative fuels and lifecycle analysis}

Alternative fuels constitute an option to lower GHG emissions apart from other motivations like lowering crude oil dependency, support of agriculture and local air pollution abatement. A considerable number of fuel options are suggested, characterised by varying carbon and hydrogen content and ranging up to zero carbon emissions at the time of energy conversion in the vehicle.

\subsubsection{Natural gas (CNG, GTL)}

Natural gas has about $20 \%$ lower $\mathrm{CO}_{2}$-emissions per $\mathrm{MJ}$ fuel compared to gasoline due to its higher content of hydrogen. While until recently average NG fleet vehicles in Europe could save only up to $6 \%$ due to less well adopted engine technology (Umierski et al., 2004) more recent vehicles can save up to $19 \%$ despite of approx. $200 \mathrm{~kg}$ more weight.

Conversion of natural gas to synthetic fuels like synthetic Diesel, Methanol, Dimethyl ether or gasoline is another way to use it as an energy source for transport. This leads to very clean fuels, generally lowering air pollutant emissions, but does not contribute to a $\mathrm{CO}_{2}$ reduction compared to the direct use of natural gas, as there is generally energy lost in the conversion step.

\subsubsection{Renewable fuels from biomass and waste}

Biofuels offer the benefit of a more or less balanced carbon cycle in contrast to fossil fuels. The $\mathrm{CO}_{2}$ of biofuels emitted as they are burned, was absorbed from the atmosphere by the plants in a relative short period. However the production process lowers the net benefit, depending on feedstock, production means (e.g. fertilizers etc.) and conversion technologies used.

Today, bioethanol from sugar cane (Brazil) and corn (US) and biodiesel from rape seed and palm oil used in Europe are the dominant biofuels used in transport. Bioethanol is currently blended with gasoline, and biodiesel is blended with fossil diesel both options are used in conventional ICE vehicles.

Bioethanol is produced from biomass which contains sugars or substances that can be converted into sugars such as starch or cellulose. GHG emissions are reduced today only moderately by about 13\% (Farrell et al., 2006; US-context).

Biodiesel from oil seeds represents almost $80 \%$ of the liquid biofuel produced in Europe in 2006 (EurObserv'ER, 2007). Rape seed, and to a lower extent sunflower, palm oil and animal fat is used as feedstock. Since pure biodiesel use is not in agreement with emission regulations the trend is towards blending with conventional diesel up to $5 \%$ by volume (EN 590). Best estimate for net reduction in GHG emissions is $37 \%$ within a range of $10-66 \%$ (Edwards et al., 2007). The technology for more advanced, 2nd generation biodiesel with lower emissions is in the demonstration stage (WSDA, 2007).

Biomethane (Biogas) can be produced from a variety of biomass e.g. maize, cereals, sunflower, grass and waste by anaerobic digestion. Optimised methane yield from versatile crop rotations that integrate production of food, feed and energy, are possible (Amon et al., 2007). Biogas also makes decentralised production possible, which is energy efficient due to saved transports.

Major barriers for biofuels are higher costs, compatibility with conventional fuels and availability of technology for more advanced biofuels. Moreover, the combination of food, feed and fuel in one crop raises concern on influences of food production and prices, which could be observed already in the case of maize production in Mexico. Although land is available to some extent due to overproduction in some areas, the economic influence is still given. Therefore energy plants, which do not contribute to food production, seem to be better suited for fuel production. Second, in order to improve crop yield, genetic engineering is and will be applied. This however has met scepticism and regulatory hurdles in many countries (Torney et al., 2007). The use of biomass for heat and power generation leads generally to higher GHG reductions than the conversion to transport fuels. However, it has to be recognised that less options exist for liquid alternative fuels for the transport sector

Although biofuels tend to show a positive effect on GHG emissions, several authors warn of hidden costs and adverse impacts on environment and society due to large scale production of biofuels (e.g. Palmer et al., 2007). Many important environmental effects of biofuels seem not well understood or taken into account, e.g. the influence of $\mathrm{N}_{2} \mathrm{O}$ emissions (Crutzen et al., 2008). For state-of-the-art lifecycle analysis see e.g. Delucchi (2006) or Zah et al. (2007). An overview of net $\mathrm{CO}_{2}$-eq emissions of alternative fuels is given in Fig. 19.

\subsubsection{Hydrogen and electricity}

Hydrogen $\left(\mathrm{H}_{2}\right)$ as an alternative energy carrier has the advantage that it can be produced from a wide variety of primary energy sources, fossil as well as renewable, e.g. wind, solar-thermal, photovoltaic, tidal/wave energy, geothermal, and biomass and waste. Today, most of the world's hydrogen is produced from natural gas. Hydrogen offers true zero emission at the tailpipe, if combined with fuel cells. If burned in internal combustion engines, only $\mathrm{NO}_{\mathrm{x}}$ remains as significant air pollutant emission. Difficulties arise from the storage of hydrogen: energy density of gaseous hydrogen is low by volume, and in liquid form, very low temperatures are needed, which results in a lower overall efficiency and higher costs (Aceves et al., 2006). One of the main obstacles for the broad use of $\mathrm{H}_{2}$ for transport is the lack of an adequate infrastructure for its distribution and the high costs for implementing it

Electricity in battery-electric vehicles is recently discussed as a true alternative to hydrogen. This avoids the energy transformation cascade associate with the use of $\mathrm{H}_{2}$. Advanced concepts of storing fluctuating renewable electricity in batteries of vehicles connected to the grid are under discussion, but the opportunities are not well assessed at the moment.

\subsubsection{Life-cycle perspective}

For the evaluation of the numerous technological options to mitigate greenhouse gas emissions of surface transport, the very complex, site dependent interrelations in ecology and economy have to be taken into account.

Life-cycle analysis (LCA), outlined in ISO 14040 et seq (2006), offers a methodology to address the potential environmental 


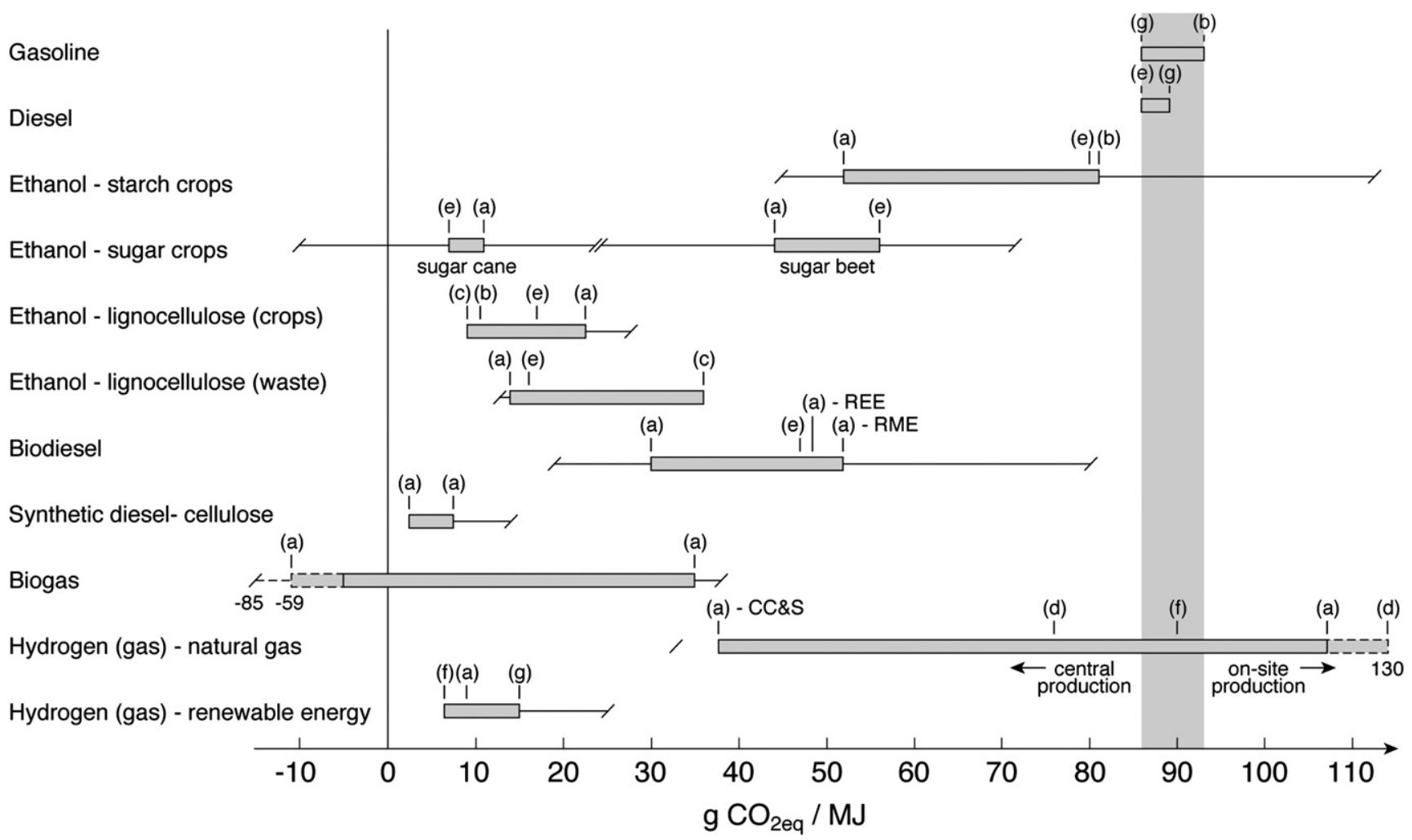

Fig. 19. Summary on net $\mathrm{CO}_{2}$-eq emissions for some alternative fuels. Sources: (a) Edwards et al. (2007); (b) Farrell et al. (2006); (c) Kemppainen and Shonnard (2005); (d) MacLean and Lave (2003); (e) Ryan et al. (2006); (f) Wietschel et al. (2006); (g) Own calculations.

impacts throughout a product's life cycle in a consistent way. For transport, three life-cycle stages of the vehicle, 'upstream' (materials processing, parts assembly and distribution), 'on-the-road' operation, and 'downstream' (scrapping and disposal/recycling) plus the fuel cycle stages (extraction, processing and transport) have to be considered.
'Well-to-wheel' analysis describes an important part of a complete LCA, focusing only on propulsion system and fuel pathways. Several studies have been conducted for different geographic regions and time horizons e.g. by Edwards et al. (2007), Choudhury et al. (2002), Mizuho (2004), Schäfer et al. (2006) and Baba and Ishitani (2003). Exemplary results are presented in Fig. 20

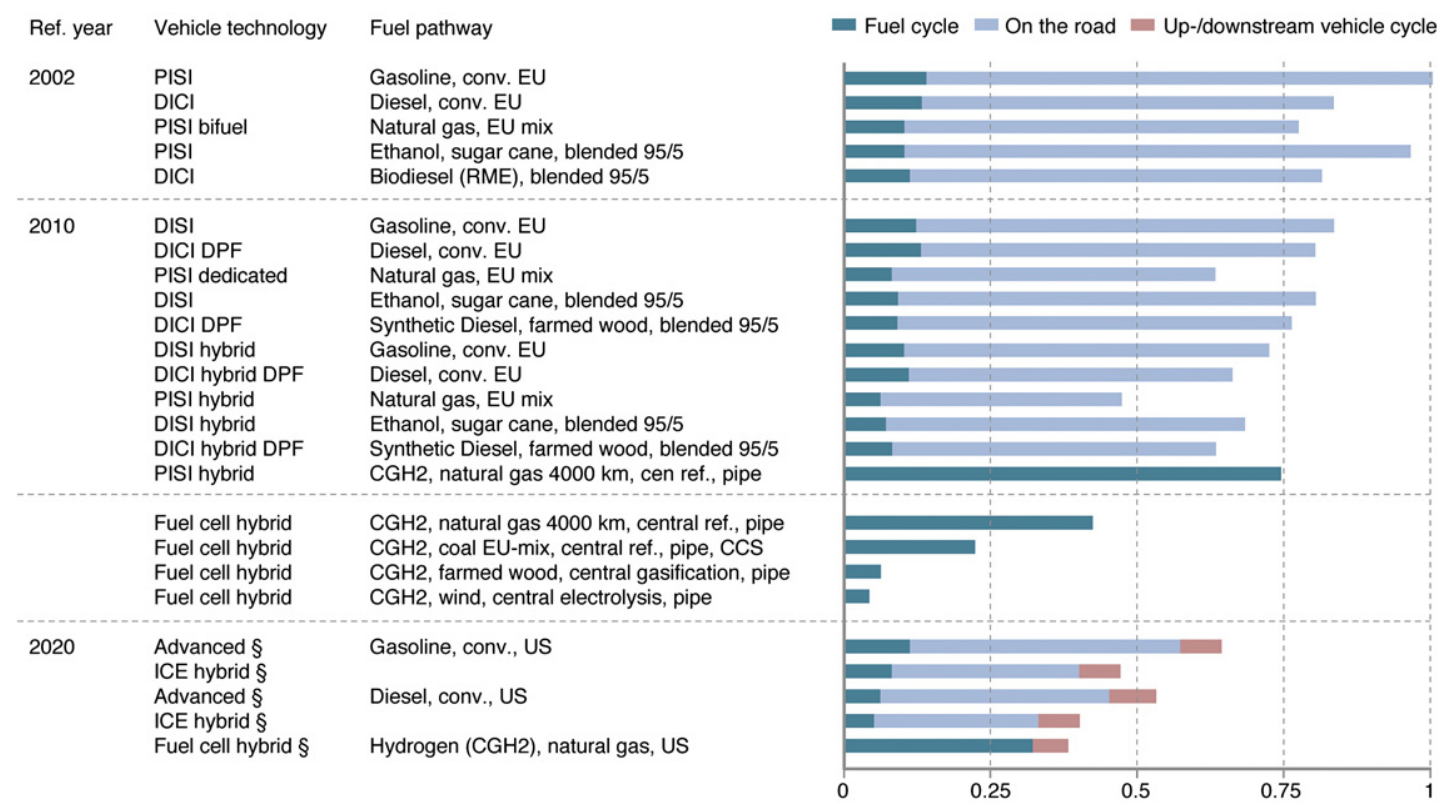

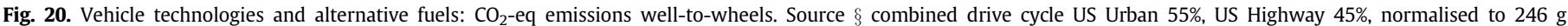

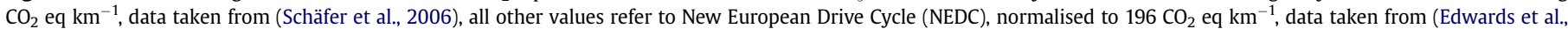
2007). Figure composed by Stephan Schmid. 
showing that potentially car technologies are conceivable which reduce $\mathrm{CO}_{2}$-eq emissions by about $50 \%$, on the long run even more. However for most technologies their economic viability on a large scale must still be proven.

Heavy goods road transport is less intensively assessed.

Problems of well-to-wheel studies limiting the validity and comparability of studies are uncertainty of data, differences in system boundaries and major differences in giving credits to by-products (Delucchi, 2006; Farrell et al., 2006). Up- and downstream processes for building and disposal of the vehicle are rarely taken into account. They become however more important with increase of lightweight design, the use of alternative powertrains and low-carbon fuels (Schäfer et al., 2006).

Despite given uncertainties we can conclude that generally more different fuels and more vehicle technologies are seen in the future concurrently.

\subsection{Mobility management and policy option}

\subsubsection{Transport policy and environmental assessment}

Transport regulation strategies in Europe, as expressed in the White Paper for European Transport policy (2001) aim at bringing about substantial improvements in the quality, sustainability and efficiency of transport. They also propose measures designed to gradually achieve a decoupling of constant transport increase and economic growth, in order to reduce the pressure on the environment. Major recommendations focussed on balancing modes of transport, eliminating bottlenecks, placing users at the heart of transport policy and on managing the globalisation of transport.

The strong growth of road transport compared to other land transport modes disables a correct exploitation of rail and shipping systems and, also, leads to the infrastructure saturation generating traffic congestion and pollution. To solve these problems the White Paper's action plan suggests measures aiming for the improvement
Table 16

External and infrastructure costs of heavy goods vehicle travelling $100 \mathrm{~km}$ on a motorway with little traffic in Euro.

\begin{tabular}{lc}
\hline External and infrastructure costs & Average range [EUR] \\
\hline Air pollution & $2.3-15$ \\
Climate change & $0.2-1.54$ \\
Infrastructure & $2.1-3.3$ \\
Noise & $0.7-4$ \\
Accidents & $0.2-2.6$ \\
Congestion & $2.7-9.3$ \\
Total & $8-36$ \\
\hline
\end{tabular}

of quality in the road sector, a revitalisation of the railways, a controlled growth in air transport, an adaption of the maritime and inland waterway transport system and a link between modes of transport. Placed into action, these measures have the potential to reduce significantly the number of road based transportation as demonstrated in Fig. 21.

To achieve a cohesive territory and a proper sustainable development, an interconnected European transport system, based on multi-modal corridors, high-speed passenger networks and improved traffic conditions, is needed. At the same time, roads must be safer, the transport costs should be transparent, intermodal transport systems must be implemented, the rights and obligation of users should be clearly defined and urban transports should be used in a rational way. As an example, infrastructures should be taxed considering its real direct and indirect costs, including externalities, i.e. indirect consequences for third parties, often for public goods. One of the goals is usually to reduce road transport with its larger harmful externalities especially in the freight sector. Table 16 shows the cost levels generated by a heavy goods vehicle covering $100 \mathrm{~km}$ on a motorway in open country at off-peak times. Estimates are made for the costs of air pollution (cost to health and damaged crops), climate change (floods and

CARGO CAPACITY COMPARISON

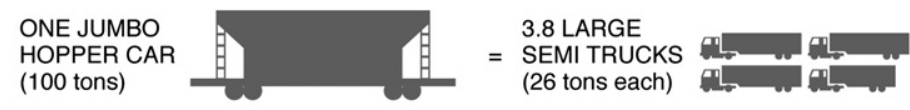

ONE BARGE $(1500$ tons $)=15$ JUMBO HOPPER CARS

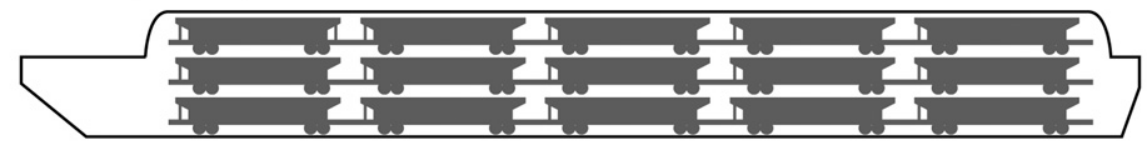

ONE BARGE $(1500$ tons $)=58$ LARGE SEMI TRUCKS

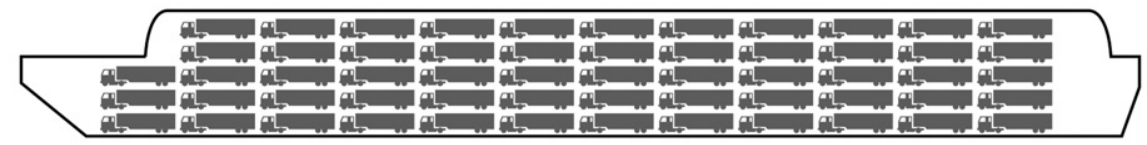

15 BARGE TOW $=2$ 1/4 ONE-HUNDRED CAR UNIT TRAINS OR 870 TRUCKS

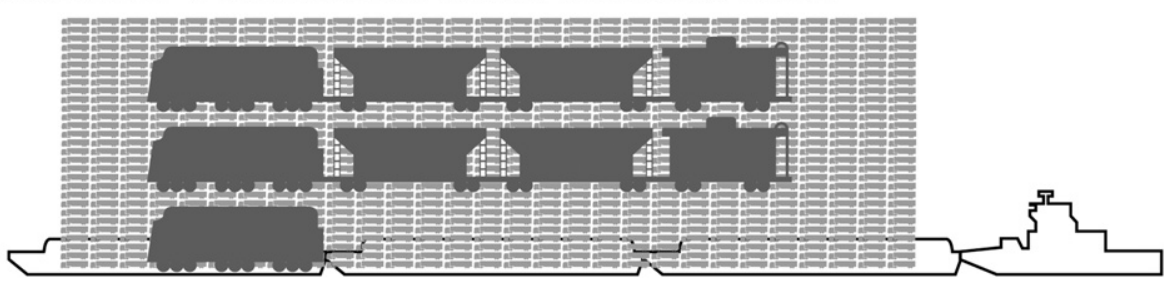

Fig. 21. Cargo capacity comparison. Figure by G. Feyerherd based on www.ccpa-ohioriver.com. 
damaged crops), infrastructure, noise (cost to health), accidents (medical costs) and congestion (loss of time).

The management of transport globalisation faces a challenge since a large part of transport systems are regulated at international levels. These regulations are implemented to ensure easy trades and commerce overlooking, in many cases, issues related to the environment. To invert this tendency, measures promoting proper funding for well planned infrastructures, efficient alternative transport systems (railway and shipping) and the usage of new technologies not only in vehicles, but also in infrastructures and infrastructure planning, are needed.

The contribution of the Strategic Environmental Assessment (SEA), stated by Directive 2001/42/EC, should also be considered due to its potential to reduce transport emissions and their impact on air quality and climate change. In transport, SEA is particularly useful in assisting decisions on a multi-modal approach, comparing alternative planning and management options in an integrated way and providing decision-makers with the relevant information to enable them to take the most sustainable decision (European Commission, 1999). The most updated guidance document specific for the transport sector (European Commission, 2005a) is based on the results of the BEACON project (Beacon, final report 2005). The integration of SEA in transport planning was also a major issue of COST 350 (2006). An example of SEA applied to Portuguese High-Speed Rail Network demonstrate that, despite its higher investment when comparing with the traditional railway, it has positive effects such as the decrease of externalities related to accidents, climate change and air quality.

\subsubsection{Land use and transport planning}

Two important elements required for the reduction of transport emission have been discussed in Sections 5.2 and 5.3: vehicle technology and fuel properties. Land use planning, related to the numbers of kilometres travelled, is another essential tool due to its impact on transport demand, particularly for road traffic.

An integration of land use and transport planning is a key issue to reduce negative environmental impacts from transportation. For example, sprawling of urban areas creates an inefficient land use pattern, generates traffic and often disables public transport systems. Better community planning and more compact development help people live within walking or bicycling distance of some of the destinations they need to get to everyday such as work,

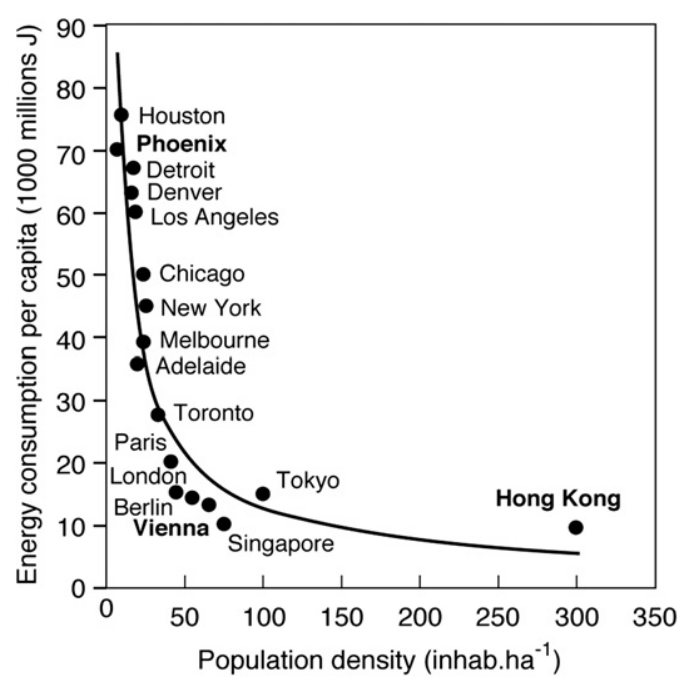

Fig. 22. Energy consumption per capita and population density for several world cities (adapted from Newman and Kenworthy, 1999). shops, schools. If they choose to use a car, trips are short. One of the consequences of urban sprawl, intimately related with atmospheric emissions and air quality, is the growing consumption of energy. Fig. 22 presents data from a number of world cities, revealing that there is a consistent link between population density and energy consumption: high-energy consumption rates are associated with lower population densities, characteristic of sprawling urban environments. Increased energy consumption is in turn leading to the increase of $\mathrm{CO}_{2}$ emissions to the atmosphere.

Fig. 23 presents the relationship between $\mathrm{CO}_{2}$ emissions and population density for several European cities. It seems that emissions decrease progressively with the increase of urban densities, although not as evidently as in the case of energy consumption, revealing that other factors such as climate, fuel mix and industry activity are probably more important. A study (Borrego et al., 2006) investigated the effects of different city structures in air quality through the application of dispersion and photochemical models. In this study, in order to nullify the effects from local meteorology and other uncontrolled variables, three cities with distinct urban structures - dispersed, corridor and compact - were idealised. Result shows that the disperse city has the lowest emissions per area and the compact city has the lowest absolute emissions.

Research conducted by the UK government has suggested that spatial planning policies could reduce projected transport emissions by $16 \%$ over a 20 -year period (European Sustainable Cities, 1996). Recent research published by the US Urban Land Institute (Ewing et al., 2007) identify compact city development with mixed uses (housing, commercial and industrial developments) as the best way in land pattern changes to reduce vehicle greenhouse gas emissions. It is reported that compact development may reduce the need to drive between $20 \%$ and $40 \%$ and reduce total transportation-related $\mathrm{CO}_{2}$ emissions from current trends by $7-10 \%$ as of 2050

The complexity of the interaction between transport and landuse makes it difficult to find how the system affects human behaviour. The TRANSLAND study has concluded that land-use and transport policies are only successful with respect to reduction of travel distances and travel time and reduction of share of car travel if they make car travel less attractive, i.e. more expensive or slower. On the other hand, transport policies to improve the attractiveness of public transport have in general not led to a major reduction of car travel (TRANSLAND, 2000).

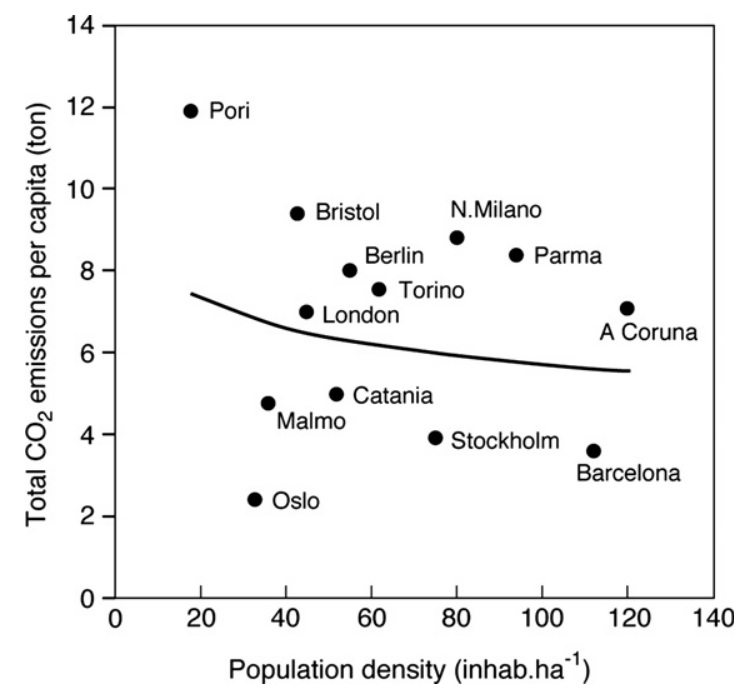

Fig. 23. $\mathrm{CO}_{2}$ emissions per capita and population density for several world cities (adapted from Tarzia, 2003). 


\subsubsection{Mobility management}

Mobility management aiming to influence travel choice by encouraging changes in behaviour on the part of organisations and individual travellers is one of the strategies to reduce the amount of road traffic. The desired behavioural changes include more efficient use of vehicles, for example through higher vehicle occupancies or less empty running, a switch to more sustainable transport modes and even increasing teleworking to reduce daily travels where appropriate. Mobility management is so far mainly being applied in a local and regional context focusing on the everyday mobility, especially commuting to work or to school (European Commission, 2004). The benefits of promotion range about a 10-20\% decrease in car travel (MOST project, 2003).

The "Sustainable urban Transportation" project (SUTRA, 2003) developed a consistent and comprehensive approach and planning methodology for the analysis of urban transportation problems that helps to design strategies for sustainable cities. Combining an indicator based approach with simulation models and scenario analysis, socio-economic and environmental impact assessment, and a public information component, SUTRA includes awareness building and educational aspects for citizens and stake-holders participating in urban decision making processes. The effects of the measures included in the scenario definitions demonstrate that no single measure can have a dramatic effects by itself. Only the combination of mobility management and transport planning measures can lead to significant effects.

Although transport problems are well identified and their solutions are also known and accepted, there is a lack of action on implementation. Most action plans are still at the pilot stage and are locally applied. Although a precautionary approach is needed in order to avoid negative side effects, e.g. due to increased exposure to air pollution in compact cities, the full implementation of stated policies and measures at regional, supranational and even international scale is expected to have a strong impact on emission reduction and will contribute to the mitigation of transport impacts on climate and ozone.

The Section 5.4 was written in close cooperation by Prof. Carlos Borrego, Prof. Myriam Lopes and Dr. Oxana Tchepel at University of Aveiro, Portugal. The lead authors would like to express their thanks for this contribution to the Land Transport Assessment.

\subsection{Scenarios of future road transport exhaust emissions}

Scenarios for road transport on the global or supranational level have mostly focussed on fuel demand and related $\mathrm{CO}_{2}$ emissions. Very few scenarios incorporate exhaust emissions as well. Of course, they differ in their assumptions, the degree of detail, the input data and their treatment, etc. according to the purpose they have been designed for. The purpose of relevant road transport emission scenarios can be classified as follows:

a) Scenarios that investigate the impact of policies implemented up to a certain point in time, sometimes called frozen policy, current legislation or do-nothing scenarios. They may serve to illustrate the outcome of autonomous developments without any further (external) action, measure or policy. Often they are used as the backdrop when illustrating the impact of measures that have been, will be or could have been taken. The "International Energy Outlook" is an example for such a scenario type (US-DoE, 2006).

b) Some scenarios assume the continuation of certain trends observed in the past, in addition to very likely policies or measures to be implemented in the foreseeable future above and on top of all policies or measures that have already been implemented. Scenarios of this kind are often called trend, forecast or business-as-usual scenarios. Examples reviewed here include the 'Reference' or 'Baseline' scenarios of Fulton and Eads (2004), IEA (2006), Turton (2006), European Commission (2004), and a road scenario of the IPCC SRES B2type presented here for the first time (Borken-Kleefeld et al., in preparation).

c) Some scenarios intend to analyse the consequences of dedicated policies that have not necessarily yet been scheduled for implementation, of technologies still under development or of other changes yet to be seen. This kind may be termed policy scenarios as they usually require an active change from past practise. Examples reviewed here include the ACT and TechPlus scenarios of IEA (2006), and the road scenarios of the IPCC SRES A1B-, A2- and B2-types presented here for the first time (Borken-Kleefeld et al., in preparation).

All these three scenarios are forecasting scenarios: The analysis starts from a given (historic) year and produces - in our case likely, possible or feasible future fuel consumption and emission estimates as a function of the driving forces modelled. Thus the future results are open and not prescribed per se.

d) Backcasting scenarios take a different approach: The future state is prescribed e.g. in terms of energy consumption or emissions; the necessary developments are then determined inversely. Such scenarios are used to analyse possible pathways and required changes in structures, behaviour and technologies that typically go far beyond business-as-usual assumptions in order to arrive at a desired target state. The example reviewed here is the "Energy Revolution" scenario (Greenpeace/EREC, 2008; Krewitt et al., 2009).

It is important to keep in mind that scenarios are not predictions of the future (compare Grunwald, 2002). Scenarios rather summarize the current knowledge and expectations about possible future developments. Therefore, scenarios may differ in the analysis what interaction are important and in the assumed future development of the main driving forces. Different scenarios from one of the four classes listed above can inform about different knowledge, interpretation or indeed uncertainty in input data, future assumptions, concepts and relationships, etc. which all claim to apply to the same subject. Scenarios of different classes represent more variability and their modelled differences are at least partly due to a different approach and input data. Nonetheless, in the best cases they serve to analyse the consequences of certain policies or measures, in particular relative to the incremental difference in assumptions. Table 17 summarises important characteristics of scenarios on road transport's long-term fuel consumption (and sometimes exhaust emissions) to be considered in the following.

\subsubsection{Global $\mathrm{CO}_{2}$ emission scenarios for road transportation}

5.5.1.1. Forecasting scenarios. There are only few global scenarios for road transportation and most focus on the fuel demand. We review global exhaust emissions first and then analyse regional differences (Fig. 24).

The US Energy Information Administration has published its International Energy Outlook annually. The future global fuel supply and demand is projected under "frozen policy" assumption. For the version 2006 refereed here (US-DoE, 2006) policies that have not been enacted by 2006 are not considered. No autonomous trends are assumed; new technologies are only taken into account if they are either legislated or cost-effective from a private consumer perspective, i.e. paying back an extra investment within up to 3 years (John Maples, US-EIA, pers. comm. 6 May 2009). Under these 
Table 17

Summary of scenario characteristics relevant for road transport's long-term fuel consumption and/or exhaust emissions.

\begin{tabular}{|c|c|}
\hline Type & ‘Original name’ and scenario characteristics \\
\hline \multicolumn{2}{|c|}{ International Energy Outlook 2006 (US-DoE, 2006) } \\
\hline Frozen GDP sensitivity & $\begin{array}{l}\text { 'Reference': Policies enacted by Jan. 2006; ‘High/Low economy': Variation of Reference scenario with } \\
\text { higher/lower growth rates of GDP }\end{array}$ \\
\hline \multicolumn{2}{|c|}{ Sustainable Mobility 2030 Project (Fulton and Eads, 2004) } \\
\hline Frozen & $\begin{array}{l}\text { 'Reference': Policies enacted by } 2003+\text { policy trajectories: Same energy intensity developments as IEA's } \\
\text { WEO } 2002 \text { 'Reference Case', but about } 10 \% \text { higher transport activity, for both passenger and freight transport. } \\
\text { (Further tightening of veh. exhaust em. standards in developing countries; no further reduction in LDV fuel economy. } \\
\text { Otherwise historic trends and extrapolation from } 2030 \text { to } 2050 \text {.) }\end{array}$ \\
\hline \multicolumn{2}{|c|}{ Energy Technology Perspectives 2050 (IEA, 2006) } \\
\hline Trend & $\begin{array}{l}\text { 'Baseline': Equal to 'reference scenario' of the World Energy Outlook 2005, but extended from } 2030 \text { to 2050. Calculates } \\
\text { effects of technology developments of policies already enacted }\end{array}$ \\
\hline Policy & $\begin{array}{l}\text { 'Accelerated Policy Scenario ACT Map'; Analysis the impact of technologies and best practices aimed "at reducing } \\
\text { energy demand and emissions, and diversifying energy sources. The focus is on technologies which exist today or are } \\
\text { likely to become commercially available in the next two decades" }\end{array}$ \\
\hline Policy & 'TECH Plus'; As above, but “more optimistic assumptions” about the rate of technological improvements \\
\hline \multicolumn{2}{|c|}{ Quantify Road scenarios (Borken-Kleefeld et al., 2008) } \\
\hline Policy & $\begin{array}{l}\text { A1B: Interpretation of the IPCC SRES } 2000 \text { storyline A1B. GDP and population projections taken from marker scenario. } \\
\text { Own assumptions/derivation of passenger and freight transport volume, vehicle efficiency improvements, exhaust } \\
\text { emission control, fuel shares. Transport volumes and road transport's energy consumption calibrated to y2000 levels }\end{array}$ \\
\hline Policy & A2: Interpretation of the IPCC SRES 2000 storyline A2. Approach as above \\
\hline Policy & B1: Interpretation of the IPCC SRES 2000 storyline B1. Approach as above \\
\hline Policy & B2: Interpretation of the IPCC SRES 2000 storyline B2. Approach as above \\
\hline \multicolumn{2}{|l|}{ (Turton, 2006) } \\
\hline Policy & $\begin{array}{l}\text { B2 transportation scenario: Own interpretation of SRES } 2000 \text { B2 marker scenario (Riahi and Roehrl, 2000); GDP and } \\
\text { energy consumption calibrated to y2000 values, updated population projections. Car travel demand modelled from } \\
\text { time-money budgets based on Schafer ( } 2000 \text { ); autonomous efficiency improvements for car of } 2 \% \text { per decade. Road } \\
\text { freight transport energy demand scaled from } 2000 \text { levels with general transport energy development of original } \\
\text { B2 scenario (Riahi and Roehrl, 2000) }\end{array}$ \\
\hline \multicolumn{2}{|c|}{ European Energy and Transport Scenarios (European Commission, 2004) } \\
\hline Frozen & $\begin{array}{l}\text { 'Baseline': Policies enacted or in implementation by end 2001. Including effects from the VA with ACEA/JAMA/KAMA } \\
\text { on reduction of passenger car fuel consumption. Excluding policy forced implementation of Biofuels Directive }\end{array}$ \\
\hline Policy & $\begin{array}{l}\text { 'High-efficiency and renewables’ } \Leftrightarrow \text { 'Energy policy’: Active policies to promote higher vehicle fuel efficiency and full } \\
\text { compliance with Biofuels Directive }\end{array}$ \\
\hline Policy & $\begin{array}{l}\text { 'Promoting rail and higher load factors': Active policy to increase modal share of rail and public road transport and } \\
\text { higher capacity utilisation - corresponding to an implementation of the Transport White Paper Scenario C by } 2010\end{array}$ \\
\hline Policy & $\begin{array}{l}\text { 'Extended policy options' } \Leftrightarrow \text { 'Full policy options': Active policy combining the above scenarios 'High-efficiency and } \\
\text { renewables' and 'Promoting rail and higher load factors', in other words: A full implementation of the Biofuels Directive } \\
\text { and of the Transport White Paper Scenario C by } 2010\end{array}$ \\
\hline
\end{tabular}

assumptions the global fuel demand of the transport sector is expected to increase by about $50 \%$ over the period $2000-2030$. This forecast has hardly changed for the most recent 2009 version (USDoE, 2009). Average growth rates in non-OECD countries are projected at about 2.3\% per year, almost a factor 3 higher than in OECD countries $(0.8 \%$ p.a. $)$; given the differing absolute consumption level, non-OECD countries account for about two thirds of total demand increase, accounting in 2030 for more than $40 \%$ of total global fuel demand in the transport sector. The EIA does not assume an increase in biofuels in the transport sector. Therefore global $\mathrm{CO}_{2}$ emissions from transportation are expected to grow at the same rate as fuel demand in the period.

Fulton and Eads (2004) projected fuel consumption and exhaust emissions from transportation globally in work for a group of automobile manufacturers, suppliers and oil companies. The future developments of vehicle mileage, fuel efficiency and exhaust emission control are modelled from past trends. Developing countries are assumed to gradually adopt as stringent exhaust emission standards as industrialised countries. Data quality is considered good for OECD countries, but mostly poor for developing countries. In fact, in the so-called 'Reference Case' the same assumptions are made e.g. for vehicle mileage, emission factors, fuel and vehicle shares, change rates etc. for all developing regions together without differentiation. The 'Reference Scenario' can be classified as a business-as-usual scenario. Under these assumptions, global road passenger travel is calculated to increase by $40 \%$ and $90 \%$ in 2030 and 2050 respectively, while road freight transport increases by $125 \%$ and $240 \%$ in the same period. Transport volumes grow and remain high in OECD regions, but highest growth rates are assumed for developing countries. With assumed autonomous vehicle efficiency improvements fuel consumption and $\mathrm{CO}_{2}$ emissions from road transportation are calculated to increase from the year 2000 level by $64 \%$ and $118 \%$ until 2030 and 2050 respectively. In the same period the assumed further tightening of vehicle exhaust emission standards throughout all world regions results in a continuous decline of exhaust emission of $\mathrm{NO}_{\mathrm{x}}, \mathrm{VOC}, \mathrm{CO}$ and $\mathrm{PM}$ down by $-70 \%$ in 2030 and $-90 \%$ in 2050 , relative to the year 2000 level each. Non-fossil fuels are assumed to account for less than $2 \%$ of global road transport fuel consumption. Central for the results are assumed improvements in efficiency and exhaust emission controls.

The International Energy Agency has published Energy Technology Perspectives 2050 (ETP) (IEA, 2006, 2008b). A business-asusual scenario, based on the Agency's World Energy Outlook (IEA, 2008a) is developed for 2050. This 'Reference Scenario' serves as background to two active policy scenarios. These are designed to analyse how much fuel consumption and $\mathrm{CO}_{2}$ emissions could be reduced under optimistic assumptions about technological progress and about dedicated policies. Data are only given for the total transport sector; road transport accounted for about $80 \%$ of total demand. The 2008 version of Energy Technology Perspectives 2050 (IEA, 2008b) reflects increased policy attention to fuel savings and 
a

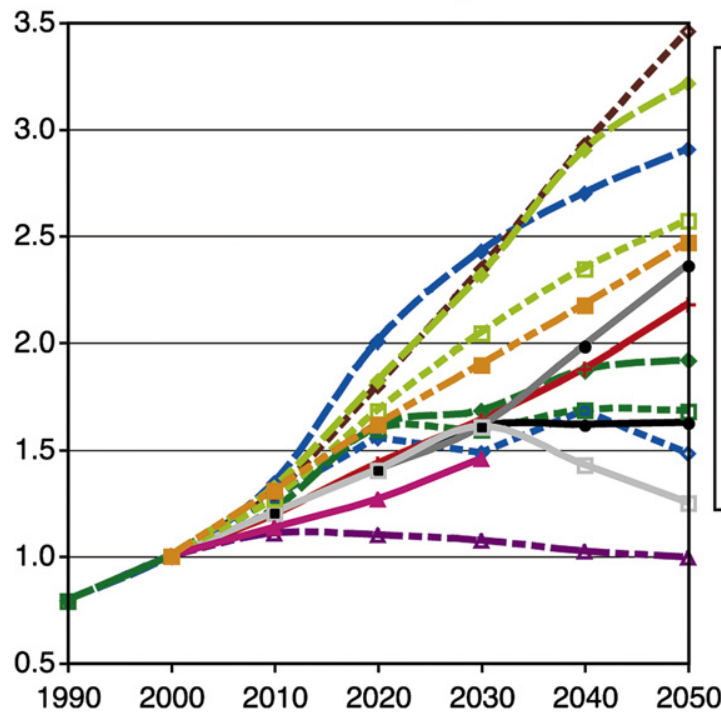

b 3.5
$\mathrm{CO}_{2}$ emission development

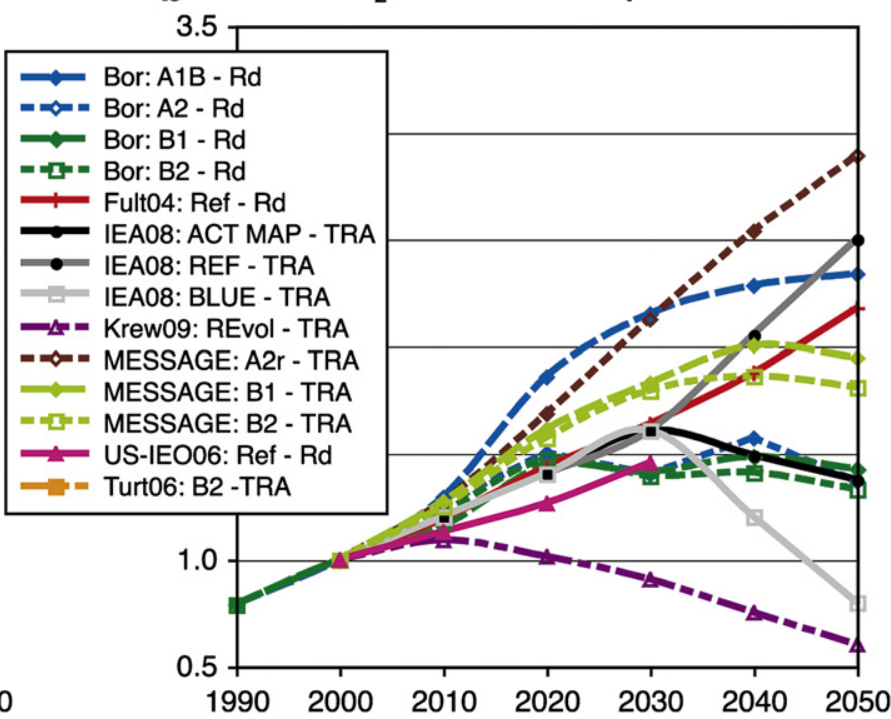

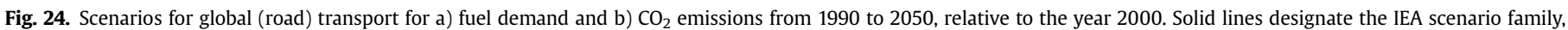

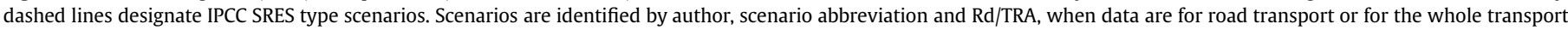

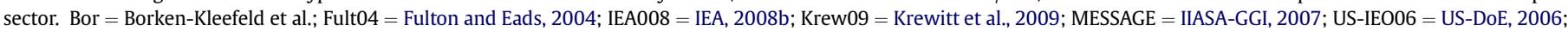
Turt06 = Turton, 2006 .

carbon emissions, progress on conventional vehicles' fuel efficiency and the potential electrification of the road transport. Global transport fuel demand is projected to increase by more than $60 \%$ and about $140 \%$ until 2030 and 2050 respectively from the level in the year 2000. The projected increase in the business-as-usual case is about $5 \%$ up from the previous estimate (IEA, 2006) and somewhat higher than estimated by Fulton and Eads (2004).

Most would be supplied from oil, with liquified coal or gas providing $22 \%$ and biofuels only $3 \%$ in 2050 . 2nd generation biofuels would not have become commercially viable. The resulting $\mathrm{CO}_{2}$ emissions, including upstream emission for the provision of the different fuels, are projected at $18 \mathrm{Gt}$, about $150 \%$ above the emissions in the year 2000. This increase could be reduced if technologies and policies are actively pursued to reduced and diversify energy demand, according to IEA (2008b): Two policy scenarios analysed the impact of much higher improvements of the vehicles fuel efficiencies and of a strong decrease of prices for biofuels and renewable hydrogen in the transport sector in the period 2030-2050. Transport demand remained as in the 'Reference Scenario'.

The 2008 version of the Accelerated Technology Scenario (ACT Map) calculates the impact if technologies were applied that are economical at a carbon charge of up to US\$50 per tonne $\mathrm{CO}_{2}$ avoided. This could stimulate development and deployment of a light-duty vehicle fleet that is $50 \%$ more efficient than in 2005 , compared to $20 \%$ efficiency improvement according to the baseline scenario. This would reflect a maximum use of fuel efficient technologies for conventional gasoline and diesel cars, a dieselization of the fleet, a lower growth of light trucks, vans and SUVs, and a dominance of hybrid vehicle concepts by 2050 . About one quarter of the vehicles could be plug-in hybrids running half the time on grid electricity. Truck efficiency improvements could grow in the same period to $35 \%$, compared to $25 \%$ improvement in the baseline. 2nd generation biofuels would increase under these assumptions to a share of $17 \%$, more than a factor 5 increase relative to the baseline projection. Low-GHG electricity could provide about $2 \%$ of the final energy demand. Fossil synfuels would not be used in this scenario. Under these assumptions, total fuel demand could be $30 \%$ lower than in the business-as-usual projection for 2050, but still more than $65 \%$ higher than in 2000. Together with the substitution of synfuels by low-GHG biofuels (and electricity) total $\mathrm{CO}_{2}$ emissions could be $45 \%$ lower than the projected baseline in 2050 .

In the BLUE map scenario more speculative breakthroughs in either fuel cell or battery technology are assumed. Then more hydrogen, plug-in hybrid or battery-electric vehicles could be deployed. These vehicles offer the double advantage of a significantly higher fuel efficiency and low-carbon energy (provided the hydrogen or electricity is produced from low-carbon primary fuels). This might reduce global transport fuel demand by $47 \%$ and reduce the related $\mathrm{CO}_{2}$ emissions by more than $67 \%$, each below the projected 2050 baseline.

5.5.1.2. Policy scenarios. IPCC's Special Report on Emission Scenarios (Nakicenovic et al., 2000) developed a set of global scenarios of GDP and population long-term developments, along with four qualitative storylines about the development of efficiencies and primary energy supply. Key assumptions for the four scenario storylines are summarised in Table 18. Broadly speaking, scenarios A1B and A2 put more emphasis on economic growth, while scenarios B1 and B2 assume a reduction in consumption and a higher environmental awareness. Fuel efficiency improvements are high to very high in scenarios A1B and B1, moderate in scenario B2 and low in scenario A2. The share of low-carbon fuels is assumed high in B1 and B2, medium to high in A1B and low in A2. No dedicated climate mitigation measures are assumed. By many B2 is considered as a business-as-usual scenario, while B1 is considered as an environmentally oriented policy scenario, A2 as a laissez-faire non-globalised market oriented scenario and A1B as a globalised, market oriented high growth scenario. Note, that Nakicenovic et al. (2000) assume a significantly higher growth in GDP than the more recent IEA outlooks. Thus, transport and fuel demand are already above the IEA projections. 
Table 18

Key assumptions for the different IPCC emission scenario families (Nakicenovic et al., 2000).

\begin{tabular}{|c|c|c|c|c|}
\hline Scenario family & A1B - 'Global economy’ & A2 - 'Fragmented economy' & B1 - 'Global ecology’ & B2 - 'Fragmented trend' \\
\hline Population growth & Low & Low & Low & Medium \\
\hline GDP growth & Very rapid & Medium & High & Medium \\
\hline Energy use & Very high & High & Low & Medium \\
\hline Oil and gas availability & $\begin{array}{l}\text { Medium (=exploitation of } \\
\text { non-conventional oil) }\end{array}$ & Low & Low (=peak and decline) & Medium \\
\hline $\begin{array}{l}\text { Pace of energy/oil \& gas } \\
\text { exploitation }\end{array}$ & $\begin{array}{l}\text { Rapidly new }+ \text { More efficient } \\
\text { technologies }\end{array}$ & Slow & Rapidly clean + resource effic. & Medium \\
\hline $\begin{array}{l}\text { Oil \& gas exploitation } \\
\text { favouring }\end{array}$ & Balanced with other energy sources & Regional & Efficiency \& dematerialisation & "Dynamics as usual" \\
\hline Philosophy & $\begin{array}{l}\text { Convergence }+ \text { Interactions } \\
\text { between regions. (Global Economy, } \\
\text { high growth \& technology) }\end{array}$ & $\begin{array}{l}\text { Self-reliance, } \\
\text { local/regional identities }\end{array}$ & $\begin{array}{l}\text { Service + Information economy. } \\
\text { Dematerialisation (Global Ecology, } \\
\text { growth, efficiency and biofuels) }\end{array}$ & $\begin{array}{l}\text { Local/regional solutions } \\
\text { on economic, social, } \\
\text { environm. Issues }\end{array}$ \\
\hline
\end{tabular}

Here we discuss the emission projections for the whole transport sector ${ }^{2}$ for IPCC scenario families B1, B2 and A2 $\mathrm{r}^{3}$, as calculated with the MESSAGE model (Riahi et al., 2006; IIASA-GGI, 2007; Riahi, personal communication, 17 Jan 2008). The B2 scenario is interpreted as a business-as-usual scenario. Global fuel demand is assumed to grow by more than 100\% from 2000 until 2030 and by almost $160 \%$ until 2050 respectively. The growth rates calculated by Turton (2006) for this scenario, also using the MESSAGE model, are comparable: $+90 \%$ until 2030 and $+150 \%$ until 2050 for all transportation globally. Both arrive at thus at 15-20\% higher transport fuel demand in 2050 than the Energy Technology Perspectives (IEA, $2008 \mathrm{~b}$ ) reviewed above. Transport's $\mathrm{CO}_{2}$ emissions grow less and even stagnate at $+80 \%$ above the year 2000 level between 2030 and 2050 as biofuels are assumed to be phased in. In 2030 and 2050 their share is $10 \%$ and $23 \%$ respectively. Furthermore, the supply gap resulting from declining oil reserves is covered by synfuels derived from natural gas or coal. Their shares grows continuously to $6 \%$ and $14 \%$ in 2030 and 2050 . However, in stark contrast to the expectations in the Energy Technology Perspectives of IEA (2008b), their production is assumed to be coupled with carbon capture and storage (CCS), so upstream $\mathrm{CO}_{2}$ emissions are limited. Therefore, the emission growth is almost a factor of 2 lower than in IEA (2008b). Hydrogen and electricity are assumed to have less than $5 \%$ share in 2050, in line with the assumptions of the 2006 version of the ETP 2050 (IEA, 2006), but more than in the most recent 'Perspectives' (IEA, 2008b).

The laissez-faire scenario A2r calculated a much higher growth in fuel demand: Relative to 2000 transportation fuel demand grows by $130 \%$ and $250 \%$ until 2030 and 2050 respectively. As much less biofuels or $\mathrm{CCS}$ are used, $\mathrm{CO}_{2}$ emissions grow in the same periods by $110 \%$ and $190 \%$, respectively. Illustrating the effects of policy, the 'global ecology' scenario B1 is assumed to have almost twice as high GDP growth as scenario A2r until 2050 but also assumes dedicated improvements in fuel efficiency and decarbonisation globally. Hence with slightly lower growth rates for the fuel demand than A2r the resulting $\mathrm{CO}_{2}$ emissions grow only by $80 \%$ and $95 \%$ until 2030 and 2050 respectively. A strong decarbonisation of the transport fuel is assumed to set in from 2030 onwards. Though only few details are given the key developments are efficiency improvements and low-carbon fuels, partly the result of an assumed widespread application of carbon capture and storage.

Genuine transport interpretations of these same storylines (Nakicenovic et al., 2000) were developed within the Quantify project; they are presented here for the first time (cf. Borken-

\footnotetext{
${ }^{2}$ Again, we can assume that $80 \%$ of total transport fuel demand is for road transportation in 2000

${ }^{3}$ A2r is a revised version of the original A2 scenario.
}

Kleefeld et al., 2008 for details on the base year 2000; BorkenKleefeld et al., forthcoming). The assumed developments for population and GDP are taken over from the respective marker scenarios, and transport demand is derived for twelve world regions separately. No dedicated climate mitigation measures are assumed. But current policy trends (as off end 2007) are continued into the future, notably as concerns the introduction and further tightening of exhaust emission standards in more and more world regions; this is important for the non- $\mathrm{CO}_{2}$ emissions. According to these scenarios, fuel demand for road transportation is going to increase strongly over the next decades, but always much less than in the respective MESSAGE scenario: In the case of high economic growth (A1B: increase by factor 6.7), fuel demand in 2050 may be $190 \%$ higher than in 2000 , about $50 \%$ higher than projections by the IEA (2006, 2008b). Biofuels as well as gas- and coal-derived synfuels could provide $13 \%$ each in 2050 , totalling more than 500 Mtoe. Low-carbon electricity or hydrogen might achieve $5 \%$ supply share, if this technology was pushed. Consequently $\mathrm{CO}_{2}$ emissions grow in scenario A1B by about 130\% from 2000 to 2050 , significantly less than fuel demand. This growth corresponds to the projections in the ETP reports (IEA, 2006, 2008b). If fuel efficiency policies were more aggressively pursued, as assumed in scenario B1, fuel demand might only grow by $90 \%$ from 2000 to 2050 , with global GDP growing by a factor of 4.8 over the same period. This is about $50 \%$ lower than the trend projections by the IEA (2006, 2008 b). About $20 \%$ of the demand could be covered by - mostly 2nd generation - biofuels, policy support provided. This assumption corresponds to the ACT Map scenario (IEA, 2008b). Low-carbon electricity or hydrogen could reach $4 \%$ supply share in 2050 , mostly assumed in urban light-duty travel. Consequently fossil $\mathrm{CO}_{2}$ emissions could be grow only by $43 \%$ until 2050 . With efficiency policies and restraint in transport demand, the overall fuel demand could grow only by $68 \%$ until 2050, when GDP grows by a factor 4.1 (scenario B2). With the development of 2nd generation biofuels given priority, about $20 \%$ of the fuel demand could be covered in 2050. Then growth in fossil $\mathrm{CO}_{2}$ emissions could be as low as $33 \%$.

Without efficiency polices, as in scenario A2, fuel demand could still grow by $48 \%$ when global GDP is estimated to be a factor 2.7 higher in 2050. Without development of new energy carriers or reduction of carbon emissions petroleum might supply $86 \%$ of the fuel, $8 \%$ by fossil synfuels and $5 \%$ by 1 st generation biofuels. This would be the most $\mathrm{CO}_{2}$-intensive energy supply and $\mathrm{CO}_{2}$ emissions grow roughly in line with fuel demand growth $(+37 \%)$, only slightly reduced by a dieselization of the light-duty fleet.

5.5.1.3. Backcasting scenarios. A different perspective is provided by the Energy [R]evolution scenario developed by Greenpeace and the European Renewable Energy Council (Greenpeace/EREC, 2008; Krewitt et al., 2009). This is a backcasting scenario designed to 
illustrate a possible pathway how to reduce global $\mathrm{CO}_{2}$ emissions by $60 \%$ compared to 2005 , with emissions from the transport sector to be reduced by $40 \%$ over this period. This contrasts strongly with all forecasting results discussed above: All but one, the speculative ETP 2008 BLUE Map scenario (IEA, 2008b), calculate an increase of $\mathrm{CO}_{2}$ emissions of at least $30 \%$ in that period. Hence, a very aggressive efficiency improvements as well as significant trend breaks in behaviour must be assumed in order to achieve the significant cuts in road transport's $\mathrm{CO}_{2}$ emissions (Greenpeace/EREC, 2008):

- Growth in passenger and freight transport demand must be contained in order to achieve the $\mathrm{CO}_{2}$ target. Passenger transport demand per capita is assumed to be even $10 \%$ less in the OECD regions in 2050 compared to the Reference Scenario 4. Through improved logistics, the growth in road freight transport is assumed to be 5\% less than in the Reference Scenario, taken from Fulton and Eads (2004).

- Furthermore, road transport needs to be shifted to a (much improved) rail. It is assumed that about $7.5 \%$ of car travel can be shifted to bus and rail, which in turn are assumed to be $70 \%$ and $80 \%$ respectively more energy efficient. Consequently, total car travel grows only by $120 \%$ from 2005 to 2050, compared to $200 \%$ in the Reference Scenario. For trucking, the authors assume that $5 \%$ and $2.5 \%$ of medium and heavy-duty truck transport can shifted to rail.

- The vehicle fuel efficiency for all, cars, light, medium and heavy trucks, and buses must increase twice as much as under trend assumptions. This is aided by an aggressive hybridisation and electrification of vehicles. The fuel efficiency of light-duty vehicles needs to be increased by a factor 4 from $10 \mathrm{l}_{\text {ge }} / 100 \mathrm{~km}$ in $2005-2.5 \mathrm{l}_{\text {ge }} / 100 \mathrm{~km}$ in 2050 . This is still a factor 2 lower than trend projections in the Reference Scenario for 2050. According to the authors, this might be achieved by a significant downsizing and about 30\% less vehicle weight, $20-25 \%$ improvement of the conventional diesel and gasoline powertrains, about one third of dedicated full hybrid vehicles, more than one third battery-electric and plug-in hybrid vehicles with up to $80 \%$ grid electric drive, an reduction of auxiliary, aerodynamic and friction losses by $50 \%$ as well as a significant shift to smaller vehicles in general (Schmid, 2009).

The fuel efficiency of trucks (measured in MJ per tonne-km) needs to increase by more than a factor of 2 until 2050 relative to 2005 . This is another $45 \%$ below the already improved value in the Reference Scenario for 2050.

If these measures were implemented then transport fuel demand would grow only little and could decline from 2040 onwards to the year 2000 level.

- The remaining $\mathrm{CO}_{2}$ reduction gap is covered by a $36 \%$ share of renewable energy in final energy demand of the transport sector. This is supplied by about 300 Mtoe biofuels and 370 Mtoe renewable electricity; together this is almost a factor 5 more renewable energy supply than the 2050 value in the Reference Scenario, but much less than in the most optimistic ETP 2050 BLUE Map scenario (IEA, 2008b). Renewable hydrogen does not play a major role in 2050 principally due to the high costs for the build-up of the supply infrastructure;

\footnotetext{
${ }^{4}$ IEA's World Energy Outlook 2008 (IEA, 2008a) is used as Reference Scenario, with data for 2050 extrapolated. See the discussion of Energy Technology Perspectives 2050, version 2008 (IEA, 2008b) in the text.
}

furthermore fuel-cell vehicles are assumed to offer only little efficiency advantage over plug-in hybrids.

Only when all these factors together are achieved then a reduction of transport's $\mathrm{CO}_{2}$ emissions by $40 \%$ below the year 2000 level might be achievable. A dedicated, consistent and longterm policy and major investments are needed. Major technological advances must be matched with a trend break in consumer behaviour: Lower passenger and freight transport demand and a decided preference for smaller, possibly less performing but also less consuming conventional, hybrid and electric vehicles. But even in this most ambitious (and speculative) scenario the potential $\mathrm{CO}_{2}$ emission reductions in the transport sector will be below the average (or the required) reductions of other parts of the economy/society. If this is so, then other sectors will have to reduce beyond average to cover up the required emission reduction.

In all scenarios much of the growth results from developing regions, notably in Asia, while emissions form industrialised countries often remain at high levels. This is because in the OECD, the dynamics is lower while developing regions have a broader span of potential pathways. We illustrate these differences by the example of emission scenarios for Europe (Western, Central and Eastern) and developing Asia (i.e. excluding Japan and Korea) in Fig. 25.

Conclusions from the forecasting, the policy and the backcasting scenarios for road transport are:

- Under business-as-usual assumptions fuel demand and $\mathrm{CO}_{2}$ emission from global transportation would more than double from 2000 to 2050 (Fulton and Eads, 2004, IEA, 2008b). Under various policy assumptions the fuel demand could increase by $50-190 \%$, depending on economic development and the fuel efficiency of the vehicles. $\mathrm{CO}_{2}$ emission may consequently increase between $40 \%$ and $130 \%$ compared to 2000 , depending on policies pursued (IIASA-GGI, 2007; Borken-Kleefeld et al., forthcoming).

- The growing fuel demand cannot be supplied from oil alone. Gas- and coal-derived liquid synfuels could fill the gap. However, as they would have about twice as high upstream emissions as petroleum fuels, this would push $\mathrm{CO}_{2}$ emissions (IEA, 2008b). If the production was however coupled with carbon capture and storage (CCS) technologies, synfuels could become climate friendly fuels (IIASA-GGI, 2007).

- Biofuels are the most promising medium term fuel offering much lower carbon emissions, definitely when produced from ligno-cellulose. This could become competitive at about US\$ 50 per tonne $\mathrm{CO}_{2}$ avoided. Electricity receives increasing attention, but major breakthroughs in battery technology are needed. Hydrogen is considered a niche fuel, i.e. barriers for their widespread application appear considerable until 2050 (IEA, 2008b; IIASA-GGI, 2007; Borken-Kleefeld et al., forthcoming).

\subsubsection{Global non- $\mathrm{CO}_{2}$ emission scenarios for road transportation}

Scenarios for non- $\mathrm{CO}_{2}$ emissions of road transportation globally were only developed by Fulton and Eads (2004) and BorkenKleefeld et al. (forthcoming, Data can be accessed at www.ipquantify.eu). Beyond assumptions about the development of fuel consumption and $\mathrm{CO}_{2}$ emissions one needs assumptions about the potential development of the vehicle fleet mix in terms of vehicle categories (e.g. shift between light- and heavy-duty vehicles or between passenger cars and light vans), of vehicle sizes and - most importantly - of the future exhaust emission control technologies and regulations. Both, Fulton and Eads (2004) and Borken-Kleefeld et al. (forthcoming), assume that exhaust emission standards are 

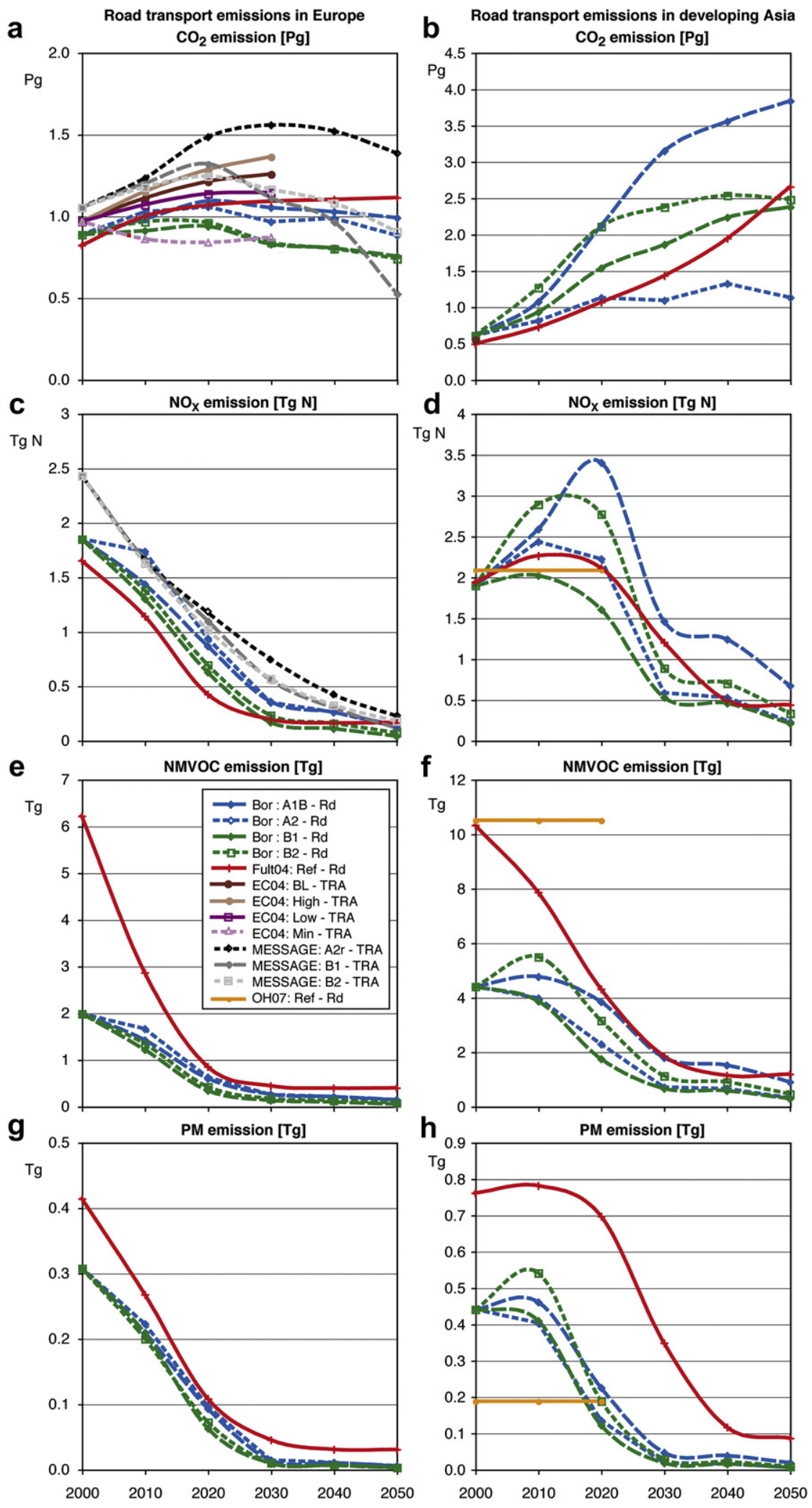

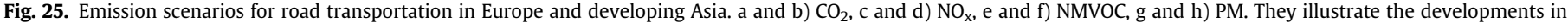
OECD regions and growing developing regions in general. Solid lines designate the IEA scenario family, dashed lines designate IPCC SRES type scenarios. 

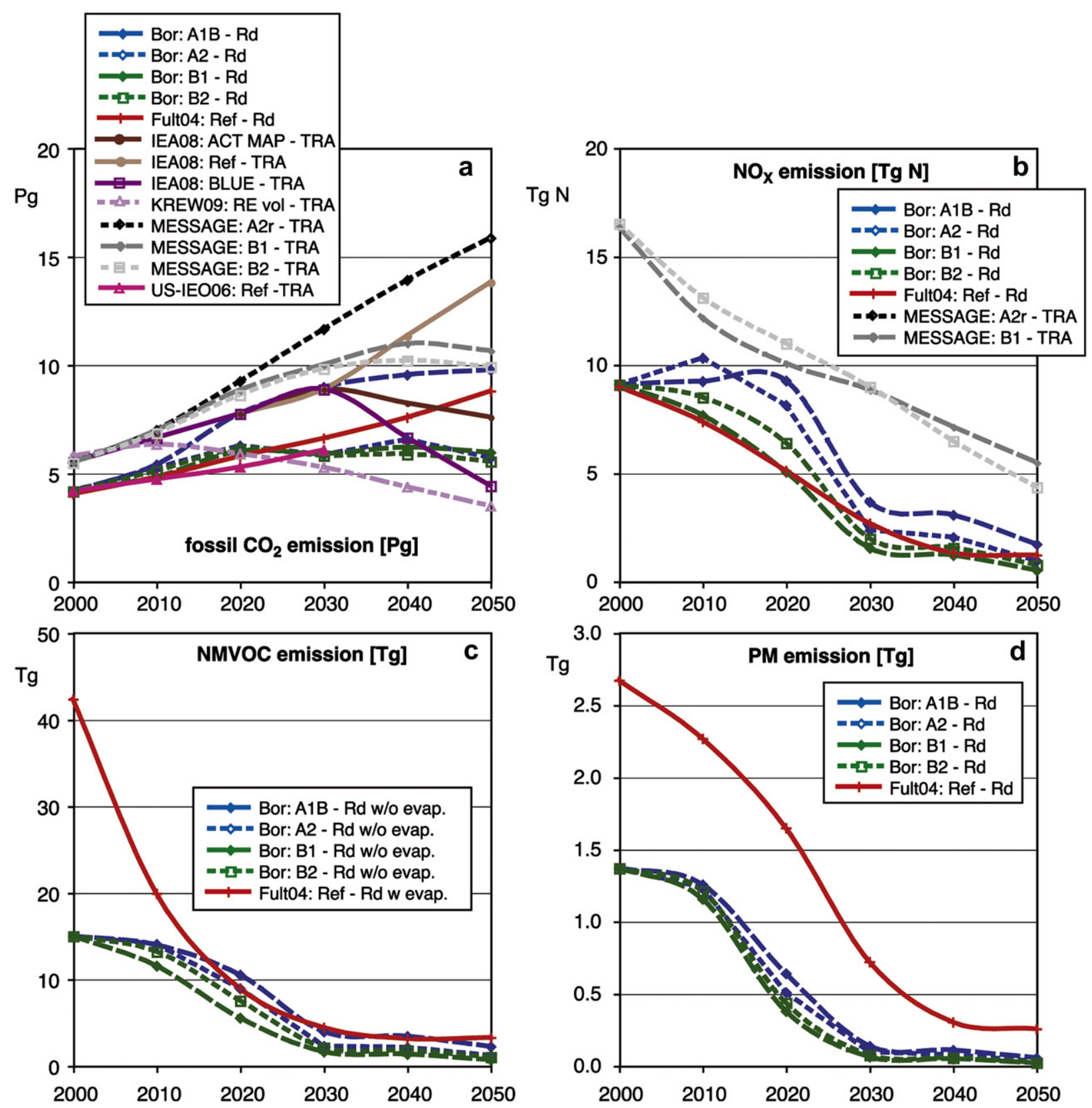

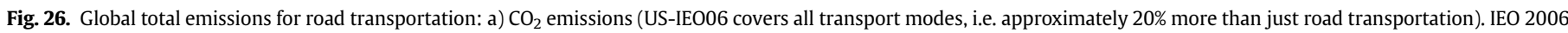

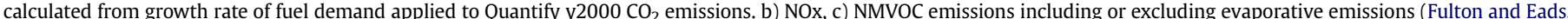

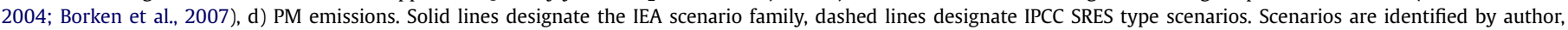

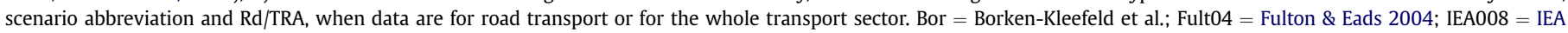
2008b; Krew09 = Krewitt et al. 2009; MESSAGE = IIASA-GGI 2007; US-IEO06 = US-DoE 2006.

further tightened in the OECD regions; it is further assumed that these standards are then adopted in other world regions, notably in Asia where the transport growth is expected particularly strong. The scenarios differ in when exhaust emission controls are assumed to be introduced in the various world regions, how effective they will be in terms of standard level and its enforcement, and what vehicle categories they encompass beyond passenger cars.

According to all scenarios the global emissions of the non- $\mathrm{CO}_{2}$ exhaust compounds $\left(\mathrm{NO}_{\mathrm{x}}, \mathrm{NMVOC}, \mathrm{PM}\right)$ are assumed to be strongly decreased in the year 2050 (Fig. 26). The decrease relative to the year 2000 is between a factor of 5 and 60, depending on the assumed policy and compound. Similar decreases are expected for global emissions of $\mathrm{CO}, \mathrm{SO}_{2}, \mathrm{PM}_{10}, \mathrm{BC}$ and $\mathrm{OC}$. Sooner or later the improvements in vehicle exhaust emission control decouples the total emissions from the transport volume growth. The variation between scenarios is about a factor of 2 in the year 2050, at the significantly lower levels.

In general the change rates agree between Fulton and Eads (2004) and Borken-Kleefeld et al. (2008). However there are different assumptions about the emission developments in the first decades, notably for $\mathrm{NO}_{\mathrm{x}}$ and PM. Fulton and Eads (2004) assume an immediate and continuous decline of all pollutants from the year 2000 onwards. Borken-Kleefeld et al. assume - in their transport interpretation of the SRES scenarios - a varied introduction and uptake of emission controls outside the OECD. For instance, the A1B 
scenario assumes the strongest growth in transport volume together with the introduction of more stringent emission controls worldwide. However for $\mathrm{NO}_{\mathrm{x}}$ emissions this only balances the volume growth up to the year 2030, as the fleet renewal needs some time before it becomes effective. On the other hand, the scenario B1 assumes a tighter and more rapid introduction of emission controls throughout all world regions. This effectively decouples emissions from the transport growth and global emissions for $\mathrm{NO}_{\mathrm{x}}$ could be at only half the level of scenario A1B. The span between the different scenarios, most pronounced for $\mathrm{NO}_{\mathrm{x}}$ emissions, illustrates both the influence of different economic regimes as well as different policies concerning transport emission controls.

In summary, the key measure assumed in all scenarios is the further tightening of vehicle exhaust emission standards. Controling light-duty vehicles, but also mopeds and motorcycles, helps to contain and reduce emissions of $\mathrm{CO}$ and VOC emissions. In order to reduce emissions of $\mathrm{NO}_{\mathrm{x}}, \mathrm{PM}$, and $\mathrm{BC}$ the heavy-duty vehicles need to be included in further emission controls. Technology appears ready for application; no scenario assumes major barriers or cost hurdles. However, a necessary enabling step is the further reduction of the sulphur contents of gasoline and diesel fuels in order for stringent exhaust emission control equipment to work properly. Reducing the sulphur contents to $50 \mathrm{ppm}$ and ultimately below $10 \mathrm{ppm}$ will require major investments in the refinery technology in many countries. Reduction of $\mathrm{PM}, \mathrm{BC}$ and $\mathrm{NO}_{\mathrm{x}}$ becomes effective through exhaust emission control. The control devices remove $90 \%$ and more of pollutants relative to unregulated emissions. However, while $\mathrm{NO}_{\mathrm{x}}$ is indeed reduced, the $\mathrm{NO}_{2}$ share emitted may increase at the expense of NO. Furthermore in the atmosphere reactions with ozone may lead to a stable or even higher $\mathrm{NO}_{2}$ concentration in the atmosphere despite decreasing $\mathrm{NO}_{\mathrm{x}}$ emissions. Therefore, it seems necessary to complement the $\mathrm{NO}_{\mathrm{x}}$ limit value by a specific $\mathrm{NO}_{2}$ emission limit value. Furthermore, effective enforcement appears key to ensure that measures taken are actually working.

\subsubsection{Mitigation costs for road transport}

There are a few estimates about the cost-effectiveness of mitigation options in the road transport sector. McKinsey and Co (2009) provide a global estimate for mitigation options in 2030; they calculate the mitigation potential and extra costs relative to World Energy Outlook 2007, which projected world crude oil prices at US $\$ 200560$ per bbl in 2030 (IEA, 2007). Borken-Kleefeld et al. (2009) have calculated the mitigation options for the industrialised countries (signatories of the UNFCCC KyotoProtocol, Annex I) in 2020. Their baseline is the World Energy Outlook 2008 already discussed above, which projected world crude oil prices at US\$2005 115 per bbl in 2030 (IEA, 2008a). The higher the oil price, the more economical investments in efficiency become. Both studies assume that investment costs for new or additional, more efficient technologies and low-carbon fuels are discounted over the lifetime of the equipment. The mitigation cost curves are presented in Fig. 27.

Both studies concur that many technologies, that would increase fuel efficiency and reduce $\mathrm{CO}_{2}$ emissions pay for themselves by fuel savings over their lifetime. In fact net savings about outweigh net extra spending across the different vehicle categories. Further investments in improving the fuel efficiency of conventional combustion engines for cars and light trucks offer more than one third of the total mitigation potential for road transport while outweighing extra investments. Hybrid powertrains, including plug-in hybrids, offer a similar reduction potential. However, the related extra investments would become cost-effective at a carbon price of around 50 US\$ per tonne $\mathrm{CO}_{2}$ emitted. Hydrogen fuel-cell vehicles have not been considered important by 2020 or 2030 in either study.
For heavy-duty vehicles there is disagreement about the mitigation costs: McKinsey and Co (2009) assume that further improvements are not cost-effective at the projected (relatively low) fuel prices in 2030. Borken-Kleefeld et al. (2009) however identify a significant mitigation potential at negative net extra costs when discounted over the full vehicle life of about 15 years. This finding for trucks is in line with analysis by Bustnes (2006), Frey and Kuo (2007), Greszler (2007), Lutsey (2008), but it contrasts strongly with conventional wisdom that the trucking industry would have already optimised its efficiency potential to the maximum. This may be true when a return-of-investment within only one and a half to three years is required, as is the usual industry perspective; however this is not the perspective of policy making confronted with a global, long-term problem like climate change.

McKinsey and Co (2009) calculate a much large reduction potential than Borken-Kleefeld et al. (2009), for the following reasons: The reduction potential in 2030 must be much larger than in 2020, as twice as much time is available for the introduction of measures. Furthermore, McKinsey and Co (2009) include nonindustrialised countries also, where the reduction potential is relatively large and cheap. In addition, McKinsey and Co (2009) include the mitigation potential by biofuels, that needs to be added to the data from Borken-Kleefeld et al. (2009). Lastly, the baseline emission level in 2030 is higher, hence bigger reductions can be realised at the same costs.

Conclusions from these analyses are:

- Many cost-effective technologies are already on the table and ready for implementation today. Their potential is estimated at about $20-30 \%$ reduction of $\mathrm{CO}_{2}$ emissions below a 2030 baseline projection.

- The extra investments could be returned by fuel savings over the lifetime of many efficient technologies. In fact, total savings balance with extra investments across vehicle categories, both for 2020 and 2030.

- Most important and most cost-effective are improvements of the conventional internal combustion engines in light, medium and heavy trucks as well as in cars. The higher the oil-price or a carbon charge, the larger the cost-effective mitigation potential. This could be an important incentive for a more widespread and earlier application notably of hybrid powertrains.

- Significant mitigation options exist also for heavy-duty vehicle. Over the vehicle lifetime they can have significant cost-savings and even pay for themselves.

- The mitigation potential becomes significantly bigger over time as more efficient technologies penetrate more fully. However, this penetration will only have been effective, when action starts immediately. On the contrary, a delayed application will forego reduction potentials as it starts from a higher level.

- Low-carbon fuels, transportation demand management, buyers' shift to smaller vehicles and/or less travel, as well as improved logistics offer further mitigation potential beyond technological efficiency.

\subsection{Scenarios of future climate impacts and mitigation}

The climate impact of future emissions from (road) transport has, to our knowledge, only been calculated by Skeie et al. (2009). They use the emission scenarios developed within the Quantify project (Borken-Kleefeld et al., forthcoming), discussed above. They calculated the impact in terms of radiative forcing (RF) for all gases and compounds, i.e. including short-lived compounds and cooling 


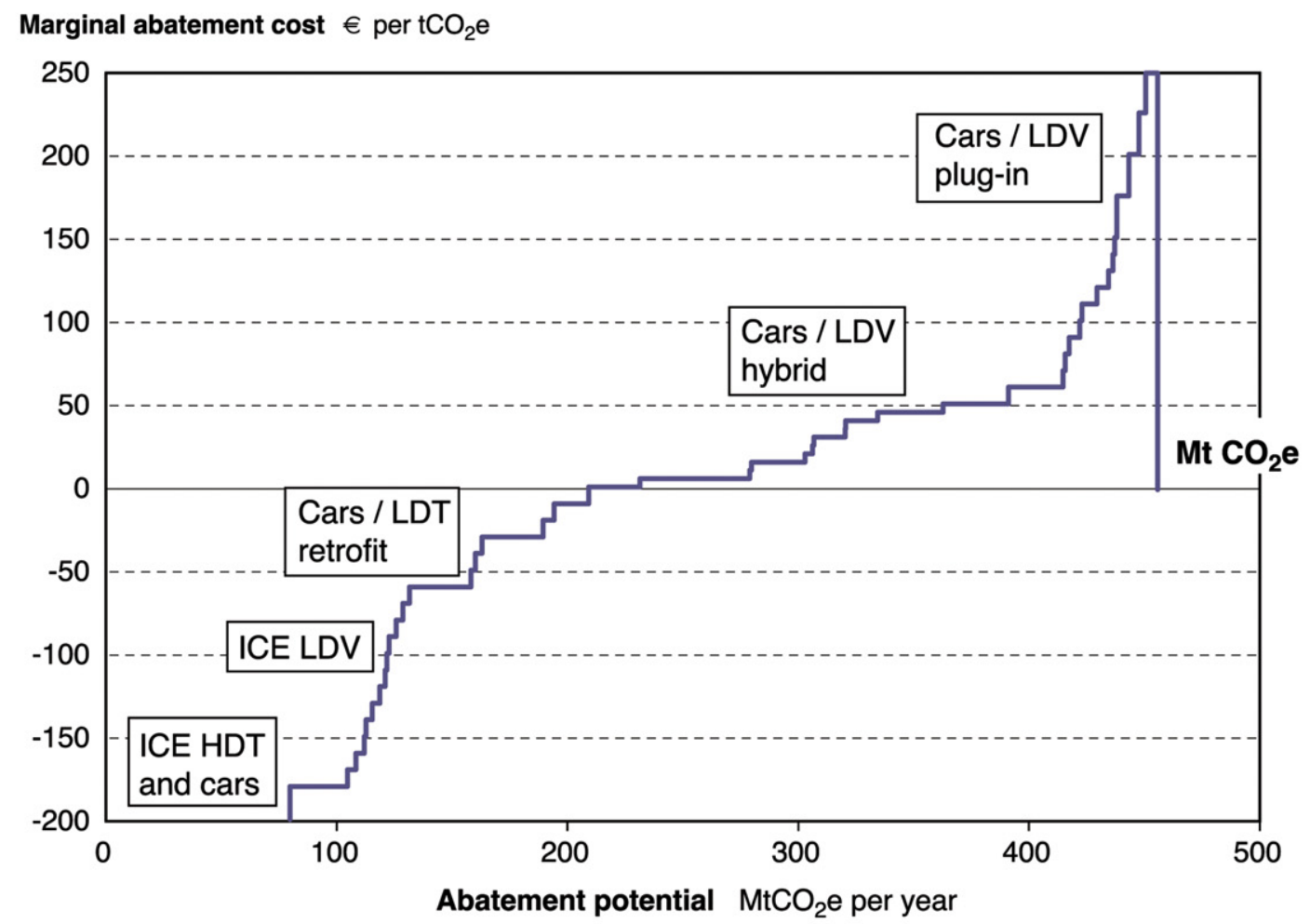

b

worldwide by 2030

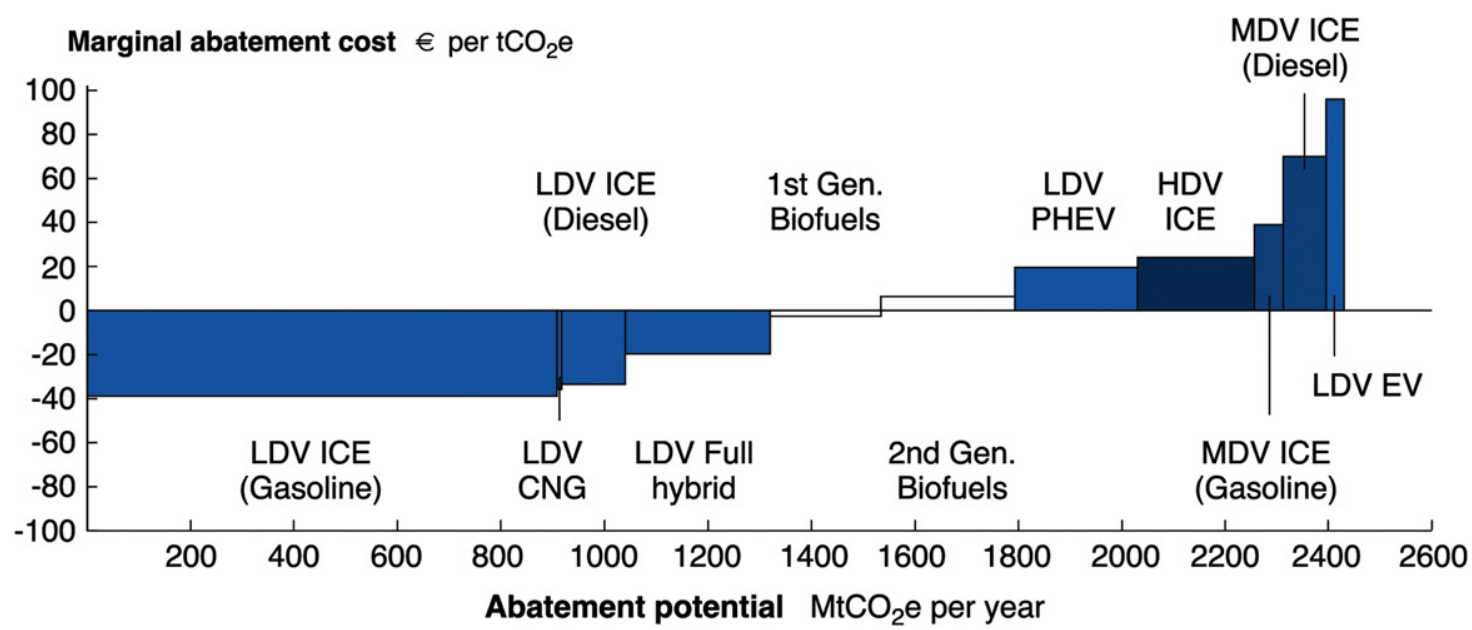

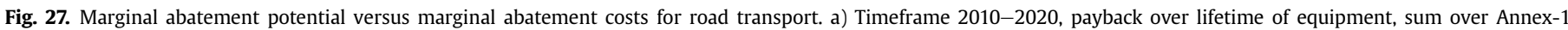
countries (industrialised countries) (Borken-Kleefeld et al., 2009). b) Timeframe 2010-2030, payback over lifetime of equipment, sum over world (McKinsey and Co, 2009).

effects, as well as the resulting temperature change. Key findings for road transport are:

- The radiative forcing in 2050 due to road transport emissions since 1900 is about $450 \mathrm{~mW} \mathrm{~m}^{-2}$ in $\mathrm{A} 1 \mathrm{~B}$, the scenario with highest emission growth, and 325,370 and $360 \mathrm{~mW} \mathrm{~m}^{-2}$ in scenarios A2, B1 and B2 respectively. This is a factor 1.9-2.5 higher than the radiative forcing due to emissions from 1900 to 2000 only (about $170 \mathrm{~mW} \mathrm{~m}^{-2}$ in year 2000). In other words, the climate impact in terms of radiative forcing will accelerate and intensify. Conf Fig. 28, left panel.
- The temperature increase in the year 2000 due to road transport's past emissions has been $0.08{ }^{\circ} \mathrm{C}$, corresponding to about $11 \%$ total anthropogenic temperature change. Future emissions from global road transport lead to an additional temperature increase of $0.15{ }^{\circ} \mathrm{C}-0.11{ }^{\circ} \mathrm{C}$ in the high growth scenarios A1B and $\mathrm{B} 1$ respectively, and to about 0.10 in the low growth scenarios A2 and B2 by 2050. In fact, the same temperature increase as for the past 100 years will be attained within only 30-40 years, due to high growth in road transport. In 2100 road transport's emissions are expected to contribute another $0.30{ }^{\circ} \mathrm{C}-0.23{ }^{\circ} \mathrm{C}$ (scenarios A1B or B1), and $0.15{ }^{\circ} \mathrm{C}$ or $0.20^{\circ} \mathrm{C}$ 
a

Radiative forcing by component from road transport emissions in 2050 by scenario

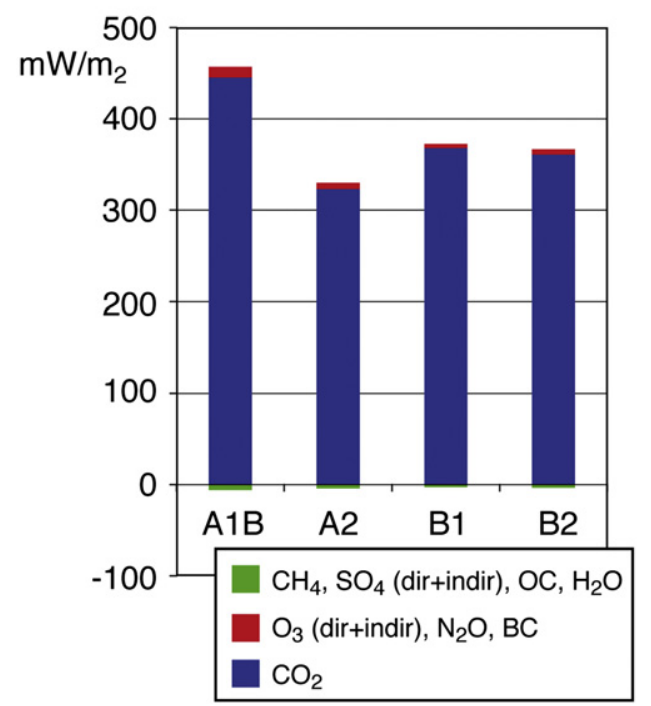

b

Temperature change from road transport emissions from 1900 to 2100

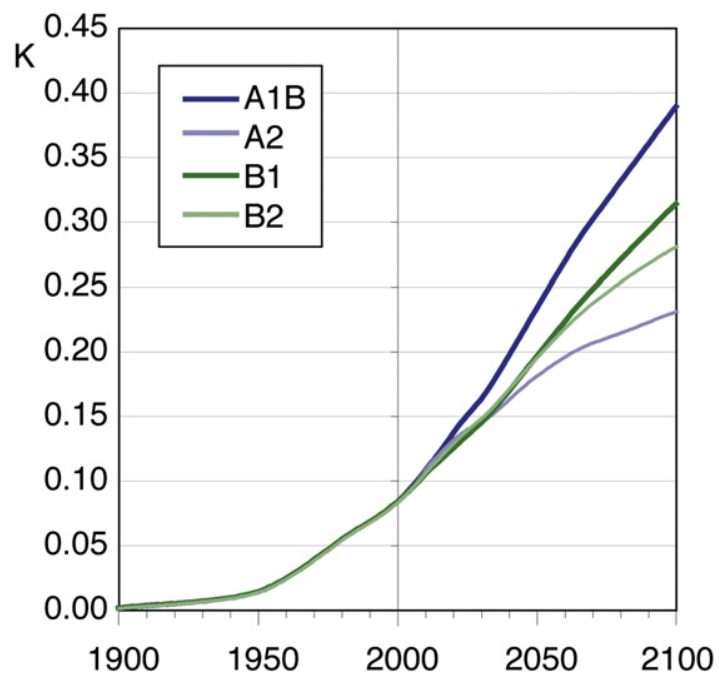

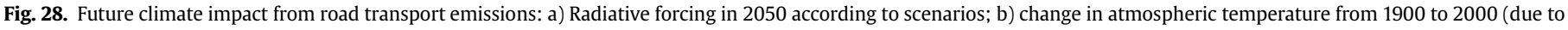
historic emissions) and until 2100 according to scenarios (Data from Skeie et al., 2009).

(scenarios A2 or B2) respectively to global mean temperature. Hence, also for temperature change, the current emissions from transport have the highest impact on the future climate. Conf Fig. 28, right panel.

In all scenarios, road transport's emissions of non- $\mathrm{CO}_{2}$ gases, notably ozone precursors and black carbon, are expected to decline by about one order of magnitude by 2050 . Even if their reductions are $50 \%$ less ("delayed reduction") the future temperature change will only differ by $4 \%$ in 2050 . This once again reinforces that the climate impact beyond 2030 is almost exclusively due to $\mathrm{CO}_{2}$ emissions. Thus, as long as a reduction of non- $\mathrm{CO}_{2}$ gases is ensured, mitigation can only be successful, if emissions of the long-lived gases, and notably $\mathrm{CO}_{2}$, are reduced.

\section{Conclusion}

Emissions from land transport and in particular road vehicles significantly influence the atmospheric composition and the climate. Land transport currently contributes more than one fifth of the total anthropogenic carbon emissions in $\mathrm{CO}_{2}$ equivalents, excluding land use change, about two thirds of which is emitted in OECD countries. The absolute emissions may still increase until the year 2050, with transport emissions from non-OECD countries growing quickly. The impacts on the atmosphere and climate depend on the species emitted and on the time scale considered.

\subsection{Carbon dioxide}

A strong, long-term climate signal comes from increasing $\mathrm{CO}_{2}$ emissions. The impact will last for centuries. Road transport emitted about $4300 \mathrm{Tg}$ carbon dioxide in 2000, corresponding to $72 \%$ of the $\mathrm{CO}_{2}$ emitted by transport and $17 \%$ of the global $25.6 \mathrm{Pg}$ $\mathrm{CO}_{2}$ emitted from fossil fuel combustion and cement manufacture. The cumulative emissions since pre-industrial times translate into a radiative forcing of about $150 \mathrm{~mW} \mathrm{~m}^{-2}$ in 2000 for road traffic, compared to a total anthropogenic $\mathrm{CO}_{2}$ forcing of $1660 \mathrm{~mW} \mathrm{~m}^{-2}$.
Road traffic's contribution is expected to grow significantly until the year 2050 in all forecasting scenarios. The future range of emissions may be between $6000 \mathrm{Tg}$ and $11,300 \mathrm{Tg} \mathrm{CO}_{2}$ per year unless a trend break happens. In the near future road transport will account for more than $20 \%$ of all annual human-induced $\mathrm{CO}_{2}$ emissions. Over a 100-year horizon a one-year pulse of the emissions in 2000 would translate into a time-integrated radiative forcing of about $400 \mathrm{~mW} \mathrm{~m}^{-2} \mathrm{yr}$.

Direct emissions from rail transport are approximately $120 \mathrm{Tg}$ $\mathrm{CO}_{2}$ in 2000 , resulting in $21 \mathrm{~mW} \mathrm{~m}^{-2}$ radiative forcing since preindustrial times. A similar contribution comes from indirect emissions by electricity generation. Emissions from inland shipping are negligible on a global scale.

\subsection{Halogenated compounds}

A mid to long-term impact on radiative forcing comes from halogenated compounds, in particular HFCs and CFCs, released from mobile air conditioners (MAC). Presently, more than $50 \%$ of the worldwide automotive fleet is equipped with MAC. The $700 \mathrm{Tg}$ $\mathrm{CO}_{2}$-equivalents emitted as halocarbons in 2002 equal $17 \%$ of road transport's $\mathrm{CO}_{2}$ emissions in 2000. The radiative forcing will decrease with shrinking banks of CFC-12, but it will remain relevant during the next decades. Existing HFCs and CFCs from MAC will furthermore continue to contribute to the decomposition of the ozone layer in the next decades. Until recently, stratospheric ozone depletion has contributed to a negative radiative forcing of climate (cooling tendency); however, this is expected to reverse in the next decades due to the decreasing chlorine concentration in the stratosphere. Hence, the positive radiative forcing in the troposphere by the growing use of the cooling agent HFC-134a is of higher relevance for the climate system.

\subsection{Short-lived species}

A short to mid-term climate impact comes from emissions of short-lived non- $\mathrm{CO}_{2}$ gases as well as particles and particle 
precursors. These include nitrogen oxides $\left(\mathrm{NO}_{\mathrm{x}}\right)$, carbon monoxide (CO), sulphur dioxide $\left(\mathrm{SO}_{2}\right)$, particles (PMs), black carbon (BC) and fugitive hydrocarbon emissions from fuel. Hydrocarbons and nitrogen oxides affect air quality and climate warming through the formation of the greenhouse gas ozone, of peroxyacetyl nitrate (PAN), and of hydroxyl radicals $(\mathrm{OH})$, which, in turn, affect the equilibrium concentration of the greenhouse gas methane $\left(\mathrm{CH}_{4}\right)$. According to estimates deduced from smaller perturbations in models, emissions of $\mathrm{NO}_{\mathrm{x}}$ and NMVOC from road traffic may contribute zonally averaged $2-6 \%$ to the formation of tropospheric ozone in the Northern Hemisphere during summer. On a regional scale ozone may increase by $3-5$ ppb whereas around urban and industrial areas the impact may be larger. In parallel, $\mathrm{OH}$ can be increased by $2-4 \%$ in dense traffic regions in $\mathrm{NH}$ summer. In winter, the change of ozone and $\mathrm{OH}$ is small. Road traffic induced ozone can mix up to the tropopause in summer. The impact is similar to the one of aviation. On the other hand, since ozone induces also $\mathrm{OH}$ formation, the positive ozone forcing is partially offset by a reduced lifetime of methane.

For the year 2000 an ozone-related radiative forcing in the range of $50-54( \pm 11) \mathrm{mW} \mathrm{m}^{-2}$ has been calculated. A one-year pulse of the year 2000 emissions leads to a time-integrated RF of about $50 \mathrm{~mW} \mathrm{~m}^{-2}$ yr over 100 years.

A small positive radiative forcing comes from aerosols, primarily due to the effect of black carbon $\left(32-44 \mathrm{~mW} \mathrm{~m}^{-2}\right.$ for year 2000 emissions), which is partially counterbalanced by the impact of sulphate ( $-9.4 \mathrm{~mW} \mathrm{~m}^{-2}$ for year 2000 emissions).

In all world regions vehicle emission standards become stricter and fuel quality improves, with respect to sulphur, lead and aromatics contents. This has offset the effect from traffic growth and non- $\mathrm{CO}_{2}$ emissions from road traffic have been declining in OECD countries. Non-OECD countries with high traffic growth might experience increasing emissions in the next two decades. Nonetheless, the global total emissions are assumed to decline significantly in all scenarios. Hence, one might conclude that the radiative forcing from short-lived species may not increase. Conversely, attention on the long-lived climate gases - expected to be increasing anyway - becomes even more important.

Short-lived traffic-related primary and secondary pollutants affect human health substantially. Most important are very fine particles (probably up to $\mathrm{PM}_{1}$ ) and ozone. Increased ozone and fine particulates $\left(\mathrm{PM}_{2.5}\right)$ concentrations increase respiratory and cardiovascular symptoms and thus increase the risk for premature death. Concentrations of both PM and ozone have not declined in Europe since 1997 despite substantial cuts in emissions.

Emissions from road construction and vehicle and fuel production add to climate impact of traffic. In industrialised countries the construction and maintenance of the road infrastructure may contribute up to $20 \%$ of $\mathrm{CO}_{2}$ emissions from the tailpipe. The production of a mid-size car may result in about $12 \%$ of the total $\mathrm{CO}_{2}$ emissions from driving. Production and supply of gasoline and diesel adds about $15 \%$ to tailpipe $\mathrm{CO}_{2}$ emissions from fuel combustion. With increasing diversity in fuels these upstream emissions become more important. Biofuels are available but are also subjects to various objections, for example if the same plant is used for the fuel and food industry. Their emissions strongly depend on the feedstock and its yield, the production process and the previous of alternative land use. The currently best of first generation biofuels have net savings of about $20-30 \% \mathrm{CO}_{2}$ equivalents relative to well-to-wheel emissions from petroleum based fuels. The second generation biofuels are expected to have higher net savings but will not be commercially available before 2020. Emissions for electricity or - in a potential future - hydrogen entirely depend on the primary energy mix and the production efficiency. Only when produced from low-carbon sources, potentially also including nuclear power and gas, or coupled with carbon capture and storage, these fuels offer a $\mathrm{CO}_{2}$ benefit over petroleum based fuels. Reducing the net carbon intensity (per energy contents) of the fuels is one major area for mitigating climate change from the transport sector The risk is however, that growing fuel demand is met with unconventional oil or coal-derived fuels that have much higher upstream $\mathrm{CO}_{2}$ emissions, besides other environmental drawbacks.

Another major area for mitigation is to drastically increase vehicle fuel efficiency. The conventional combustion engine still offers significant efficiency potentials at relatively low prices for both, passenger and freight vehicles. A hybridisation of the powertrain can further increase the efficiency notably under urban driving conditions. If a combination of several existing technologies would be applied in the fleet, savings of $20-30 \%$ of $\mathrm{CO}_{2}$ emissions could be achieved in OECD countries by 2030 without extra costs. However, markets alone will not deliver these reductions. Reducing vehicle power and weight would be straightforward, rather cheap options to downsize energy demand and thus emissions notably from light-duty vehicles. Overall a factor 4 increase in fuel efficiency is technically possible for light-duty vehicles. However, customer acceptance without incentives, penalties or regulations is questionable. The risk is that customers in industrialised countries are unwilling to use smaller vehicles, while customers in growing economies are aspiring bigger cars. Further down the time horizon, yet considered important to both improve efficiency and to allow low-carbon fuels, is electric traction, either powered by a battery or by a fuel cell. This however requires still major improvements of the battery in terms of cost reduction, durability, capacity and weight or major investments in a hydrogen supply infrastructure.

From today's point of view, however, all these technologies can only reduce the expected growth. Depending on which technologies are applied this growth is estimated to range between $40 \%$ and $130 \%$. An absolute reduction of $\mathrm{CO}_{2}$ emissions, the most important climate mitigation measure for the transport sector, will need stronger interventions. Only scenarios that assume less transport arrive at overall emission reductions. Effective mitigation must address the factors for transport growth in order to contain passenger and freight transport volumes.

Thus, if the transport sector shall contribute to meeting climate mitigation objectives a combination of all measures is necessary: strongly increasing the vehicles' fuel efficiency, reducing the carbon contents of the fuels, and reducing total transport volumes.

\section{Acknowledgement}

This work was performed under EC FP6 Specific Supported Action ATTICA (Contract No.: 036746) with significant support of information, data and results from EC FP6 Integrated Project Quantify (Contract No.: 003893). The authors wish to express their thanks to the other sources of support under international and local schemes, like Mathematical modelling of air quality with applications in risk management (1ET400300414) of National Programme on "Information Society", in framework of Research Plan of MSMT under No. MSM 0021620860

\section{Appendix A}

\section{Reports and assessments}

Up to now, there is no comprehensive scientific assessment of ground transport effects on climate change available, including emission inventories, climate impact modelling and mitigation options. Fuglestvedt et al. (2008) present the first comprehensive 
analysis of radiative forcing arising from the different transport modes, for today as well as in an cumulative overview of the past.

The private industry involved in road traffic published the study "Mobility 2030" as final report of the Sustainable Mobility project of the World Business Council for Sustainable Development (http:// www.wbcsd.org/). An overview of land transport challenges is presented and a forecast model has been developed in cooperation with IEA (SMP/IEA transport model, Fulton and Eads, 2004), discussed also in the emission part of this assessment.

IPCC Climate Change (2007a,b,c) does not discuss the role of emitting sectors in detail, but gives an analysis of mitigation options in the transport sector in the WG III report.

Transport issues in Europe are regularly investigated by the European Environment Agency in the EEA transport series (http:// www.eea.europa.eu/themes/transport/), e.g. the recent EEA report No.1-2007 "Transport and environment: on the way to a new common transport policy". EEA observed a general increase in transport in Europe, for passenger transport slightly less than the increase in the gross domestic product GDP, for freight clearly more. Road freight transport growth in the EU is projected to continue, resulting in an increase in energy demand of more than $15 \%$ between 2000 and 2020 (De Ceuster et al., 2005). Therefore, additional policy initiatives and instruments are demanded.

Policy options are discussed in the European Commission's 2001 White Paper on European transport policy (European Commission WP, 2001). This listed around 60 policy initiatives which were later endorsed by subsequent European Council meetings, including not only climate and health impacts, but also traffic management, economic and safety aspects. WP 2001 also links emissions and infrastructure measures and considers political mitigation measures as harmonisation of fuel taxation for commercial users and alignment of the principles for charging for infrastructure use. A mid-term review (MTR) of the White Paper has been presented in 2006 by the European Commission taking stock of what has been achieved over the past five years and proposes a number of new actions to further improve the European transport system.

The EC Impact Assessment of the Thematic Strategy on Air Pollution and the Directive on "Ambient Air Quality and Cleaner Air for Europe" (European Commission, 2005b) include legislative proposals related to transport. In the near future, they shall achieve the reduction of the transboundary component of urban background concentration of $\mathrm{PM}_{2.5}$. These measures include reviewing emissions limits for light- and heavy-duty vehicles (e.g. to go beyond current Euro standards) and revision of the National Emission Ceilings for 2015 or 2020 in order to reduce urban background concentrations of $\mathrm{PM}_{2.5}$.

\section{Recent and ongoing research}

The European Commission supports many activities, programmes and initiatives dealing with air quality and climate change.

A significant improvement in our understanding of transport's impacts on climate and ozone is expected from the EC FP6 integrated project Quantify (www.pa.op.dlr.de/quantify/). This project is dealing with quantifying impacts from individual transportation sectors like aviation, shipping and road transport. It is the first comprehensive attempt not only to quantify these impacts in global climate model (GCM) runs, but to account for the effects of chemical non-linearity in dilution of the emission behind the exhausts as well as to include metrics for simpler emission reduction assessments.

The European "Clean Air for Europe" Programme (CAFE, http://ec.europa.eu/environment/air/cafe) aims to develop a long-term, strategic and integrated policy advice to protect against significant negative effects of air pollution on human health and the environment. A new phase of CAFE, the implementation of the Thematic Strategy on Air Pollution, started in September 2005.

The Cooperative Programme on the Monitoring and Evaluation of Long-range Transmission of Air Pollutants in Europe (EMEP) has already been running for a long time under the Convention on Longrange Transboundary Air Pollution (http://www.unece.org/env/ $\operatorname{lrtap} /)$ in order to support international cooperation to solve transboundary air pollution problems. EMEP includes also Northern America and recently even addresses long-range transport of the whole northern hemisphere through the Hemispheric Transport of Air Pollution (HTAP) Task Force (http://www.htap.org/).

A cluster of European projects focussed on the investigation of vehicles emissions: ARTEMIS (Assessment And Reliability Of Transport Emissions And Inventory Systems), COST 346 (Emissions and Fuel Consumption from Heavy-Duty Vehicles http:// www2.vito.be/cost346/) and PARTICULATES (Characterisation of Exhaust Particulate Emissions from Road Vehicles).

ARTEMIS computes emissions at a low spatial scale and investigates the behaviour of vehicles in driving cycles. The results, which are implemented in a European emission model for light vehicles, tell that different approaches in emissions inventories and the unstable behaviour of vehicles with emission reduction devices (catalytic converters, particles filters) lead to a high uncertainty about what a single car emits. ARTEMIS states for example that there is quite contrasted behaviour between Diesel (rather sensitive to speed and stop parameters) and gasoline cars (rather sensitive to accelerations).

COST 346 focussed on similar work for heavy-duty vehicles. It gave an overview of emission data, developed an engine map database, used the datasets in an emission model and estimates uncertainties. For the EURO 4 and 5 emission standards, COST 346 expects common test bed analysis to become less reliable, since the engine performance depends more and more strongly on the control system of the specific vehicle.

PARTICULATES investigated the progress and potentials in the reduction of particulate matter. A major step forward is seen in the control of automotive particulate emissions is through the application of diesel particulate filters and sulphur-free fuels $\left(10 \mathrm{mg} \mathrm{kg}^{-1}\right.$ max Sulphur content). PARTICULATES focussed mainly on diesel light-duty and heavy-duty vehicles, but emphasises for example also that the role of two wheelers in less developed countries may be underestimated.

The potential use of alternative fuels have been studied in European projects like TRIAS (TRIAS = Sustainability Impact Assessment of Strategies Integrating Transport, Technology and Energy Scenarios http://www.isi.fhg.de/trias/) and HyWays (HyWays A European Hydrogen Energy Roadmap http://www.hyways.de):

TRIAS presents different scenarios of fuel mixes for the future and discusses the potentials in particular of biofuel. HyWays states that strong policy support is needed in order to achieve a fleet of 15 million fuel cell driven vehicles in Europe by 2030, even extreme policy support for the upper limit of 50 million vehicles.

Since such estimates are very uncertain they are at present not yet reflected in climate impact modelling. Therefore, long-term potentials for climate change mitigation thanks to sustainable mobility are still an unknown.

\section{Appendix B}

Major acronyms and abbreviations:

ACEA Association des Constructeurs Européens d'Automobiles ACIA Arctic Climate Impact Assessment

ADMS urban pollution model

AOT Accumulated Ozone exposure Thresholds

ARTEMIS Assessment And Reliability Of Transport Emissions And Inventory System 
ATTICA Assessment of Transport Impacts on Climate Change and Ozone Depletion

BC Black Carbon

BEACON Building Environmental Assessment Consensus on the transeuropean transport network

CAFE Clean Air for Europe programme

CDIAC Carbon Dioxide Information Analysis Center

CER Community of European Railway and Infrastructure Companies

CICERO Centre for International Climate and Environmental Research (Norway)

CNG Compressed Natural Gas

$\mathrm{CO}_{2}$-eq carbon dioxide equivalent

CONCAWE European Oil Company Organisation for Environment, Health and Safety (Belgium)

COPD chronic obstructive pulmonary disease

CORINAIR European Union Emission Inventory Programme

COST 346 Emissions and Fuel Consumption from Heavy-Duty Vehicles

COST 350 Integrated assessment of environmental impact of traffic and transport infrastructure

CRT continuous regeneration diesel particle filters

DG Directorate General

DG TREN Directorate General for Transport and Energy

DLR Deutsches Zentrum für Luft- und Raumfahrt (German Aerospace Center)

DoE US-Department of Energy

DU Dobson Unit

EC European Commission

ECMWF European Centre for Medium-Range Weather Forecasts (Reading, UK)

EDGAR Environmental Database for Global Atmospheric Research

EDC European drive cycle

EEA European Environment Agency

EEV Enhanced Environmentally-friendly Vehicle

EIONET European Environment Information and Observation Network

EMEP European Monitoring and Evaluation Programme

E39C DLR L39 coupled chemistry-climate model

EU European Union

EUCAR European Council for Automotive Research

EPA US-Environmental Protection Agency

FP6 Sixth Framework Programme for Research

GCM General Circulation Model

GDP gross domestic product

GHG Greenhouse Gas

GTL Gas to Liquids

GTP Global Temperature Change Potential

$\mathrm{GTP}_{20}$ Global Temperature Change Potential with a 20-year time horizon

GTP $_{50}$ Global Temperature Change Potential with a 50 year time horizon

GTP 100 Global Temperature Change Potential with a 100-year time horizon

GWP Global Warming Potential

GWP $_{100}$ Global Warming Potential with a 100 -year time horizon

HDV heavy-duty vehicle

HTAP Task Force on Hemispheric Transport of Air Pollution

ICE internal combustion engine

IEA International Energy Agency

IEO International Energy Outlook

IIASA International Institute for Applied Systems Analysis (Austria)

IPCC Intergovernmental Panel on Climate Change
JRC Joint Research Centre

LCA life-cycle analysis

LDV light-duty vehicles

LES Large Eddy Simulation

LMDz Laboratoire de Météorologie Dynamique GCM

LRTAP Long-Range Transboundary Air Pollution

LSCE/IPSL Laboratoire des Sciences du Climat et l'Environnement (France)

MAC mobile air conditioners

MILAGRO Megacity Initiative: Local and Global Research Observations

MOST Mobility Management Strategies for the next decades

MTR mid-term review

NEDC New European Drive Cycle

NG Natural Gas

$\mathrm{NH}$ northern hemisphere

$\mathrm{NiMH}$ nickel metal hydride

NMVOC Non-Methane Volatile Organic Compounds

NPRI National Pollutant Release Inventory

NRC National Research Council

OC Organic Carbon

OECD Organisation for Economic Co-operation and Development

PAH polyaromatic hydrocarbons

PARTICULATES Characterisation of Exhaust Particulate Emissions And Inventory System

PBL planetary boundary layer

PEMFC polymer electrolyte membrane fuel cells

PM Particulate Matter

$\mathrm{PM}_{0.1} \quad$ Particulate Matter (diameter less than $0.1 \mu \mathrm{m}$ )

$\mathrm{PM}_{2.5} \quad$ Particulate Matter (diameter less than $2.5 \mu \mathrm{m}$ )

$\mathrm{PM}_{10} \quad$ Particulate Matter (diameter less than $10 \mu \mathrm{m}$ )

QUANTIFY Quantifying the Climate Impact of Global and European Transport Systems

RF Radiative Forcing

RR relative risk

RSST Rapid Science Synthesis Team

SAE Society of Automotive Engineers

SCR Selective Catalytic Reduction

SEA Strategic Environmental Assessment

SLC Super-Light Car

SOA Secondary Organic Aerosol

SRES Special Report on Emissions Scenarios

SROC Special Report on Safeguarding the Ozone Layer and the Global Climate System

SUTRA Sustainable Urban Transport Project

TERM Transport and Environment Reporting Mechanism (EEA)

TRANSLAND Integration of Transport and Land Use Planning

TRENDS Transport and Environment Database System

TRIAS Sustainability Impact Assessment of Strategies Integrating Transport, Technology and Energy Scenarios

3-D three-dimensional

UIC Union International de Chemins de Fers

UNFCCC United Nations Framework Convention on Climate Change

US United States

US-DoT United States - Department of Transportation

US-DoE United States - Department of Energy

UTLS Upper Troposphere-Lower Stratosphere

VOC Volatile Organic Compound

WBCSD World Business Council for Sustainable Development

WG working group

WMO World Meteorological Organization

WHO World Health Organization

WSDA Washington State Department of Agriculture 


\section{Appendix C}

Units

SI (Systeme Internationale) units:

Special names and symbols for certain SI-derived units:

Special names and symbols for certain SI-derived units:

\begin{tabular}{|c|c|c|c|c|c|}
\hline \multicolumn{3}{|c|}{ Physical quantity } & \multicolumn{2}{|c|}{ Name of unit } & Symbol \\
\hline \multicolumn{3}{|l|}{ length } & \multicolumn{2}{|l|}{ metre } & $\mathrm{m}$ \\
\hline \multicolumn{3}{|l|}{ mass } & \multicolumn{2}{|c|}{ kilogram } & $\mathrm{kg}$ \\
\hline \multicolumn{3}{|l|}{ time } & \multicolumn{2}{|c|}{ second } & $\mathrm{s}$ \\
\hline \multirow{2}{*}{\multicolumn{3}{|c|}{$\begin{array}{l}\text { thermodynamic temperature } \\
\text { amount of substance }\end{array}$}} & \multirow{2}{*}{\multicolumn{2}{|c|}{$\begin{array}{l}\text { kelvin } \\
\text { mole }\end{array}$}} & K \\
\hline & & & & & $\mathrm{mol}$ \\
\hline Fraction & Prefix & Symbol & Multiple & Prefix & Symbol \\
\hline $10^{-1}$ & deci & $\mathrm{d}$ & 10 & deca & $\mathrm{da}$ \\
\hline $10^{-2}$ & centi & $\mathrm{c}$ & $10^{2}$ & hecto & $\mathrm{h}$ \\
\hline $10^{-3}$ & milli & $\mathrm{m}$ & $10^{3}$ & kilo & $\mathrm{k}$ \\
\hline $10^{-6}$ & micro & $\mu$ & $10^{6}$ & mega & M \\
\hline $10^{-9}$ & nano & $\mathrm{n}$ & $10^{9}$ & giga & G \\
\hline $10^{-12}$ & pico & $\mathrm{p}$ & $10^{12}$ & tera & $\mathrm{T}$ \\
\hline $10^{-15}$ & femto & $\mathrm{f}$ & $10^{15}$ & peta & $\mathrm{P}$ \\
\hline
\end{tabular}

\section{Appendix D}

\begin{tabular}{llll}
\hline Physical quantity & Name in SI unit & Symbol for SI unit & Definition of unit \\
\hline force & newton & $\mathrm{N}$ & $\mathrm{kg} \mathrm{m} \mathrm{s}^{-2}$ \\
pressure & pascal & $\mathrm{Pa}$ & $\mathrm{kg} \mathrm{m}^{-1} \mathrm{~s}^{-2}\left(=\mathrm{N} \mathrm{m}^{-2}\right)$ \\
energy & joule & $\mathrm{J}$ & $\mathrm{kg} \mathrm{m}^{2} \mathrm{~s}^{-2}$ \\
power & watt & $\mathrm{W}$ & $\mathrm{kg} \mathrm{m}^{2} \mathrm{~s}^{-3}\left(=\mathrm{J} \mathrm{s}^{-1}\right)$ \\
frequency & hertz & $\mathrm{Hz}$ & $\mathrm{s}^{-1}$ (cycles per second) \\
\hline
\end{tabular}

Some chemical symbols used:

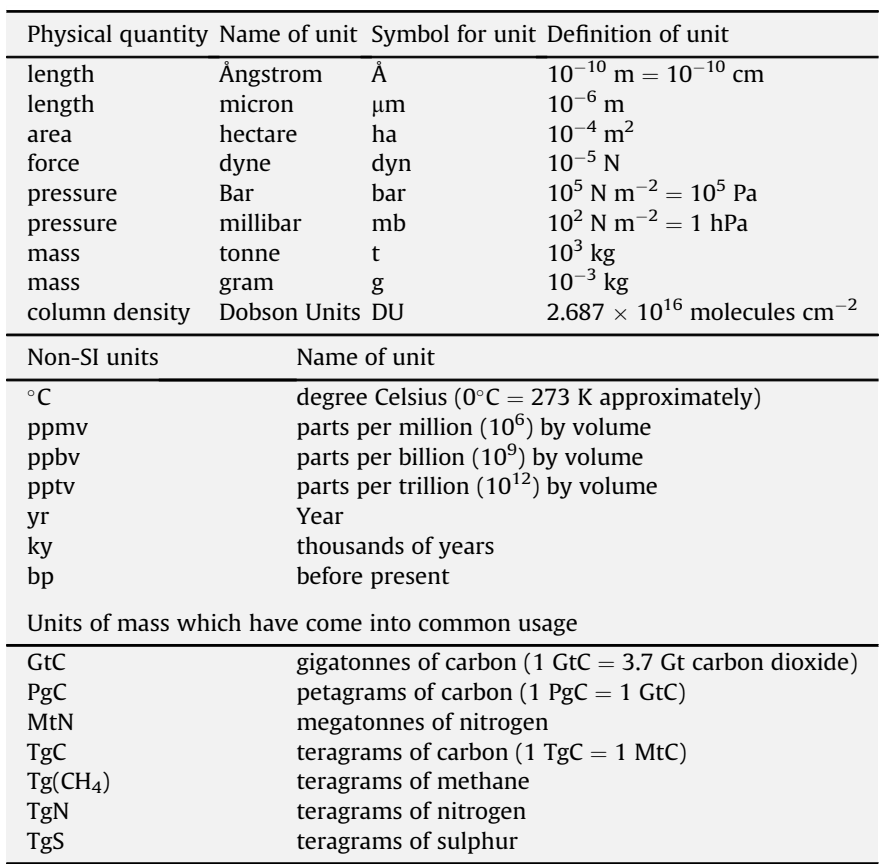

\begin{tabular}{|c|c|}
\hline $\mathrm{Al}$ & aluminium \\
\hline $\mathrm{Ca}$ & calcium \\
\hline $\mathrm{Ca}^{2+}$ & calcium ion \\
\hline CFC & chlorofluorocarbon \\
\hline CFC-12 & dichlorodifluoromethane \\
\hline $\mathrm{Cl}$ & atomic chlorine \\
\hline $\mathrm{Cl}^{-}$ & chlorine ion \\
\hline $\mathrm{ClO}$ & chlorine monoxide \\
\hline $\mathrm{ClONO}_{2}$ & chlorine nitrate \\
\hline $\mathrm{ClOOCl}$ & chlorine peroxide \\
\hline $\mathrm{CH}_{4}$ & methane \\
\hline $\mathrm{CO}$ & carbon monoxide \\
\hline $\mathrm{CO}_{2}$ & carbon dioxide \\
\hline $\mathrm{Cr}$ & chromium \\
\hline $\mathrm{Cu}$ & copper \\
\hline $\mathrm{Fe}$ & iron \\
\hline $\mathrm{H}$ & atomic hydrogen \\
\hline $\mathrm{H}_{2}$ & molecular hydrogen \\
\hline $\mathrm{HC}$ & hydrocarbon \\
\hline $\mathrm{HCHO}$ & formaldehyde \\
\hline HFC & hydrofluorocarbon \\
\hline HFC-134 & $\mathrm{CF}_{3} \mathrm{CH}_{2} \mathrm{~F}$ \\
\hline HFC-152 & $\mathrm{CH}_{3} \mathrm{CHF}_{2}$ \\
\hline $\mathrm{HCl}$ & hydrogen chloride \\
\hline $\mathrm{HO}_{2}$ & hydroperoxyl \\
\hline $\mathrm{H}_{2} \mathrm{O}$ & water \\
\hline $\mathrm{K}$ & potassium \\
\hline $\mathrm{K}^{+}$ & potassium ion \\
\hline $\mathrm{Mg}$ & magnesium \\
\hline $\mathrm{Mg}^{2+}$ & magnesium ion \\
\hline Mn & manganese \\
\hline $\mathrm{Na}^{+}$ & sodium ion \\
\hline $\mathrm{Ni}$ & nickel \\
\hline NO & nitric oxide \\
\hline $\mathrm{NO}_{2}$ & nitrogen dioxide \\
\hline $\mathrm{NO}_{\mathrm{x}}$ & nitrogen oxides $\left(\mathrm{NO}+\mathrm{NO}_{2}\right)$ \\
\hline $\mathrm{N}_{2} \mathrm{O}$ & nitrous oxide \\
\hline $\mathrm{O}\left({ }^{1} \mathrm{D}\right)$ & atomic oxygen (first excited state) \\
\hline $\mathrm{O}_{2}$ & molecular oxygen \\
\hline $\mathrm{O}_{3}$ & ozone \\
\hline $\mathrm{OH}$ & hydroxyl radical \\
\hline$P$ & phosphorus \\
\hline PAN & peroxyacetyl nitrate \\
\hline $\mathrm{Pb}$ & lead \\
\hline $\mathrm{Pb}^{+}$ & lead ion \\
\hline POM & polyoxymethylene \\
\hline S & atomic sulphur \\
\hline $\mathrm{Si}$ & silicon \\
\hline $\mathrm{SO}_{2}$ & sulphur dioxide \\
\hline $\mathrm{Ti}$ & titanium \\
\hline VOC & volatile organic compounds \\
\hline Zn & zinc \\
\hline
\end{tabular}

\section{References}

Aardenne, V., Dentener, J.F., Olivier, J.G.J., Peters, J.A.H.W., 2005. The EDGAR 3.2 Fast Track 2000 Dataset. Netherlands Environmental Assessment Agency, Rijswijk, Netherlands.

Aceves, S.M., Berry, G.D., Martinez-Frias, J., Espinosa-Loza, F., 2006. Vehicular storage of hydrogen in insulated pressure vessels. International Journal of Hydrogen Energy 31, 2274-2283.

Achten, P.A.J., Oever, J.P.J.v.d., Potma, J., Vael, G.E.M., 2000. Horsepower with Brains: the Design of the Chiron Free Piston Engine. SAE Technical Paper Series.

ACIA, 2004. Impacts of a Warming Arctic: Arctic Climate Impact Assessment. Cambridge University Press.

Acid News, 2007. New Emission Standards for Diesel Cars too Weak, Acid News Edition No 1 2007. Air Pollution \& Climate Secretariat, Göteborg, Sweden. 
Almeida, S.M., Pio, C.A., Freitas, M.C., Reis, M.A., Trancoso, M.A., 2005. Source apportionment of fine and coarse particulate matter in a sub-urban area at the Western European Coast. Atmospheric Environment 39, 3127-3138.

Amann, M., Bertok, I., Cofala, J., Gyarfas, F., Heyes, C., Klimont, Z., Schöpp, W., Winiwarter, W., 2004. Baseline Scenarios for the Clean Air For Europe (CAFE) Programme CAFE Report No. 1, IIASA, Laxenburg/Austria.

Amann, M., Bertok, I., Cofala, J., Heyes, C., Klimont, Z., Rafaj, P., Schöpp, W., Wagner, F., 2008. National Emission Ceilings for 2020 Based on the 2008; Climate \& Energy Package. NEC Scenario Analysis Report Nr. 6. IIASA e International Institute for Applied Systems Analysis, IIASA, Laxenburg/Austria.

Amon, T., Amon, B., Kryvoruchko, V., Machmuller, A., Hopfner-Sixt, K., Bodiroza, V., Hrbek, R., Friedel, J., Potsch, E., Wagentristl, H., Schreiner, M. Zollitsch, W., 2007. Methane production through anaerobic digestion of various energy crops grown in sustainable crop rotations. Bioresource Technology 98, 3204-3212.

Anderson, H.R., Atkinson, R.W., Janet, L., Peacock, J.L., Marston, L., Konstantinou, K. 2004. Meta-analysis of Time-series Studies and Panel Studies of Particulate Matter (PM) and Ozone $\left(\mathrm{O}_{3}\right)$. Report of a WHO task group. WHO Regional Office for Europe, Copenhagen.

Atkinson, W., 2000. Review Comments on Draft Report, U.S. High GWP Gas Emissions 1990-2010: Inventories, Projections, and Opportunities for Reductions [Refrigeration and Air-conditioning Chapter]. Sun Test Engineering.

Austin, T.C., Dulla, R.G., Carlson, T.R., 1999. Alternative and Future Technologies for Reducing Greenhouse Gas Emissions from Road Vehicles. Report prepared for the "Transportation Table Subgroup on Road Vehicle Technology and Fuels". Sierra Research Inc., Sacramento, California.

Baba, Y., Ishitani, H., 2003. Well to wheel efficiency of advanced technology vehicles in Japanese conditions. In: Electric Vehicle Symposium, Long Beach, CA.

Baidya, S., Borken-Kleefeld, J., 2009. Atmospheric emissions from road transportation in India. Energy Policy 37, 3812-3822.

Balkanski, Y., Myhre, G., Gauss, M., Rädel, G., Highwood, E.J., Shine, K.P., 2010. Direct radiative effect of aerosols emitted by transport: from road, shipping and aviation, Atmospheric Chemistry and Physics10, 4477-4489. doi:10.5194/acp10-4477-2010.

BEACON, 2005. Building Environmental Assessment Consensus on the Transeuropean Transport Network, Final Report.

Bell, M.L., Dominici, F., Samet, J.M., 2005. A meta-analysis of time-series studies of ozone and mortality with comparison to the national morbidity, mortality, and air pollution study. Epidemiology 16, 436-445.

Bell, M.L., Peng, R.D., Dominici, F., 2006. The exposure-response curve for ozone and risk of mortality and the adequacy of current ozone regulations. Environmental Health Perspectives 114, 532-536.

Bergin, M.H., Cass, G.R., Xu, J., Fang, C., Zeng, L.M., Yu, T., Salmon, L.G., Kiang, C.S., Tang, X.Y., Zhang, Y.H., Chameides, W.L., 2001. Aerosol radiative, physical, and chemical properties in Beijing during June 1999. Journal of Geophysical Research - Atmospheres 106, 17969-17980.

Birmili, W., Alaviippola, B., Hinneburg, D., Knoth, O., Tuch, T., Borken-Kleefeld, J., Schacht, A., 2009. Dispersion of traffic-related exhaust particles near the Berlin urban motorway - estimation of fleet emission factors. Atmospheric Chemistry \& Physics 9, 2355-2374.

Boldo, E., Medina, S., LeTertre, A., Hurley, F., Mucke, H.G., Ballester, F., Aguilera, I., Eilstein, D., 2006. Apheis: health impact assessment of long-term exposure to $\mathrm{PM}_{2.5}$ in 23 European cities. European Journal of Epidemiology 21, 449-458.

Bond, T.C., Streets, D.G., Yarber, K.F., Nelson, S.M., Woo, J.H., Klimont, Z., 2004. A technology-based global inventory of black and organic carbon emissions from combustion. art. no. D14203. Journal of Geophysical Research - Atmospheres 109, 14203.

Borken, J., Steller, H., Meretei, T., Vanhove, F., 2007. Global and country inventory of road passenger and freight transportation: fuel consumption and emissions of air pollutants in the year 2000. Transportation Research Records Journal of the Transportation Research Board 2011, 127-136.

Borken-Kleefeld, J., Steller, H., d. Ceuster, G., Meretei, T., 2008. Global emission scenarios for road transportation until 2050.

Borken-Kleefeld, J., Steller, H., Ceuster, G.D., Vanhove, F., Eide, M., Endresen, O., Behrens, H., Lee, D., Owen, B., Meretei, T., Rypdal, K., Skeie, R.B., v. Aardenne, J., in preparation. OUANTIFY transportation emission scenarios up to 2100.

Borken-Kleefeld, J., Cofala, J., Rafaj, P., 2009. GHG Mitigation Potentials and Costs in the Transport Sector of Annex I Countries: Methodology, Version 2. IIASA Interim Report IR-09-039. IIASA, Laxenburg/Austria.

Borrego, C., Tchepel, O., Barros, N., Miranda, A.I., 2000. Impact of road traffic emissions on air quality of the Lisbon region. Atmospheric Environment 34, 4683-4690.

Borrego, C., Martins, H., Tchepel, O., Salmim, L., Monteiro, A., Miranda, A.I., 2006. How urban structure can affect city sustainability from an air quality perspective. Journal of Environmental Modelling \& Software 21, 461-467.

Boucher, O., Pham, M., Venkataraman, C., 2002, Simulation of the atmospheric sulfur cycle in the Laboratoire de Météorologie Dynamique General Circulation Model. Part I: Model description, Atmos. model evaluation, and European and global budgets, Note scientifique de l'IPSL no 23

Brook, R.D., Franklin, B., Cascio, W., Hong, Y.L., Howard, G., Lipsett, M., Luepker, R. Mittleman, M., Samet, J., Smith, S.C., Tager, I., 2004. Air pollution and cardiovascular disease - a statement for healthcare professionals from the expert panel on population and prevention science of the American Heart Association. Circulation 109, 2655-2671.

Brook, J.R., Graham, L., Charland, J.P., Cheng, Y., Fan, X., Lu, G., Li, S.M., Lillyman, C., MacDonald, P., Caravaggio, G., MacPhee, J.A., 2007. Investigation of the motor vehicle exhaust contribution to primary fine particle organic carbon in urban air. Atmospheric Environment 41, 119-135.

Brunekreef, B., Dockery, D.W., Krzyzanowski, M., 1995. Epidemiologic studies on short-term effects of low levels of major ambient air pollution components. Environmental Health Perspectives 103, 3-13.

Brunekreef, B., Forsberg, B., 2005. Epidemiological evidence of effects of coarse airborne particles on health. European Respiratory Journal 26, 309-318.

Brunekreef, B., Holgate, S.T., 2002. Air pollution and health. Lancet 360 233-1242.

Budd, G., 2006. CUTE. A Fuel Cell Bus Project for Europe. Lessons Learned from a Fuel Cell Perspective CUTE Congress. Ballard Power Systems, Hamburg.

Bustnes, O.-E., 2006. Taking on the Leadership Challenge in Class 8 Trucking. NESCAUM Workshop on "Improving the fuel economy of heavy-duty fleets", San Diego/USA

Cai, H., Xie, S.D., 2007. Estimation of vehicular emission inventories in China from 1980 to 2005. Atmospheric Environment 41, 8963-8979.

Campos, J., de Rus, G., 2009. Some stylized facts about high-speed rail: a review of HSR experiences around the world. Transport Policy 16, 19-28.

Carslaw, D.C., 2005. Evidence of an increasing $\mathrm{NO}_{2} / \mathrm{NO}_{\mathrm{x}}$ emissions ratio from road traffic emissions. Atmospheric Environment 39, 4793-4802.

Chalk, S.G., Miller, J.E., 2006. Key challenges and recent progress in batteries, fuel cells, and hydrogen storage for clean energy systems. Journal of Power Sources 159, 73-80.

Chester, M.V., Horvath, A., 2009. Environmental assessment of passenger transportation should include infrastructure and supply chains. art. no. 024008 Environmental Research Letters 4, 24008.

Choudhury, R., Wurster, R., Weber, T., Schindler, J., Weindorf, W., Miller, M. Brinkman, N., Armstrong, A., Rickeard, D., Jersey, G., Kerby, M., Kheshgi, H. Robbins, J., Cadu, J., Le Breton, D., Dautrebande, O., 2002. Well-to-wheel analysis of energy use and greenhouse gas emissions of advanced fuel/ vehicle systems-a European Study. General Motors \& Ludwig-Bölkow-Systemtechnik $\mathrm{GmbH}$.

Clodic, D., Palandre, L., 2004. Determination of Comparative HCFC and HFC Emission Profiles for the Foam and Refrigeration Sectors Until 2015. Part 1: Refrigerant Emission Profiles. Armines for ADEME and US EPA, Paris, France, 132 pp.

COST 350 Integrated assessment of environmental impact of traffic and transport infrastructure - A strategic approach. WG6 report, 2006. http://www.rws.nl/ rws/dww/home/cost350/.

Crutzen, P.J., Mosier, A.R., Smith, K.A., Winiwarter, W., 2008. $\mathrm{N}_{2} \mathrm{O}$ release from agrobiofuel production negates global warming reduction by replacing fossil fuels. Atmospheric Chemistry \& Physics 8, 389-395.

De Ceuster, G., Herbruggen, B.V., Logghe, S., Franckx, L., Zeebroeck, B.V., Carlier, K. Martens, M., Burgess, A., d. Jong, R., Borst, J., Jansen, B., Snelder, M., Becker, J. Smit, L., Jin, Y., Deane, G., Zhu, Y., Jakimovska, V., Martino, A., Zecca, E., Ponti, M., Fiorello, D., Maffii, S., Schneekloth, N., Bröcker, J., Korzhenevych, A., Bak, M., Pawlowska, B., Burnewicz, J., Nash, C., Menaz, B., Matthew, B., Stipdonk, H., v. Eck, K.R., Vlakveld, W., Mesken, J., v. d. Lans, B., Borken, J., Hedel, R., Gühnemann, A., Grimme, W., Ehmer, H., Scheffer, M., Vance, C., Zeppenfeld, B., Gerçek, H., 2005. ASSESS Final Report, DG TREN, European Commission Report April 2006.

De Rus, G., Nash, C., 2007. In What Cirumstances is Investment in High Speed Rail Worthwile? Institute of Transport Studies, University of Leeds, ITS Working Paper 590.

DeAngelo, B., Beach, R.H., Rose, S., Salas, W., Li, C., et al., 2006. International agriculture: estimates of non-CO2 and soil carbon marginal mitigation costs. Clapp, C. (Ed.)., EPA Report 430-R-06-005. Environmental Protection Agency.

Delucchi, M.A., 2006. Lifecycle Analyses of Biofuels. Institute of Transportation Studies, University of California, Davis.

Despiau, S., Croci, D., 2007. Concentrations and size distributions of fine aeroso particles measured at roof level in urban zone. art. no. D09212. Journal of Geophysical Research - Atmospheres 112, 9212.

DoE, 2007. Hydrogen, Fuel Cells \& Infrastructure Technologies Program. Multi-Yea Research, Development and Demonstration Plan: Planned Program Activities for 2005-2015 Technical Plan Fuel Cells 2007. U.S. Department of Energy.

Dominici, F, Peng, R.D., Bell, M.L, Pham, L, McDermott, A., Zeger, S.L, Samet, J.M., 2006. Fine particulate air pollution and hospital admission for cardiovascular and respiratory diseases. Jama 295, 1127-1134.

Edwards, R., Larivé, J.-F., Mahieu, V., Rouveirolles, P., 2007. Well-to-wheels analysis of future automotive fuels and powertrains in the European context: Well-toTank Report. CONCAWE/EUCAR/JRC, Version 2c, 2007. http://ies.jrc.ec.europa. eu/WTW.

EEA, 2006. Annual European Community LRTAP Convention Emission Inventory 1990-2004. European Environment Agency. Technical Report 8/2006, 60.

EEA, 2007. Transport and Environment: on the Way to a New Common Transport Policy. TERM 2006: Indicators Tracking Transport and Environment in the European Union. European Environment Agency. Report No 1/2007.

EEA TERM, 2003. Transport emissions of air pollutants by mode. Indicator factsheet

Eichlseder, H., Blassnegger, J., 2006. Der zukünftige Ottomotor - überlegener Wettbewerber zum Dieselmotor? Entwicklungstendenzen bei Ottomotoren, Leipzig, Technische Akademie Esslingen.

EIONET, 2003. TRansport and ENvironment Database System (TRENDS). European Topic Centre on Air and Climate Change.

Elvingson, P., 2007. Tougher heavy vehicle emission limits proposed. Acid News 3,12-13. EMEP/CORINAIR, 2006. The Atmospheric Emission Inventory Guidebook, third ed 
Endresen, O., Sorgard, E., Behrens, H.L., Brett, P.O., Isaksen, I.S.A., 2007. A historical reconstruction of ships' fuel consumption and emissions. art. no. D12301. Journal of Geophysical Research - Atmospheres 112, 12301.

Espig, M., Johannaber, M., et al., 2006. Simulation der Verbrauchsverbesserung durch Gewichtsreduzierung in Pkw, Automobiltechnische Zeitschrift, ATZ 108 (12).

EurObserv'ER, 2007. Biofuels Barometer, EurObserv'ER Project: Observ'ER, Eurec Agency, Erec, Jozef Stefan Institute, Eufores, Systèmes Solaires with the financial support of the Ademe and DG Tren "Intelligent Energy-Europe" programme.

European Commission, 1999. Manual on SEA in the Framework of the TransEuropean Transport Network. Commission of the European Communities. Office for Official Publications of the European Communities.

European Commission, 2001. WHITE PAPER - European transport policy for 2010: time to decide.

European Commission, 2004. European Energy and Transport Scenarios on Key Drivers. European Commission, Directorate-General for Energy and Transport, Belgium, $266 \mathrm{pp}$.

European Commission, 2005a. The SEA Manual, A Sourcebook on Strategic Environmental Assessment of Transport Infrastructure Plans and Programmes. A report prepared by BEACON for DG Energy and Transport European Commission, Brussels.

European Commission, 2005b. Impact Assessment of the Thematic Strategy on Air Pollution and the Directive on "Ambient Air Quality and Cleaner Air for Europe", SEC (2005) 1133, Brussels.

European Sustainable Cities Report, 1996. Expert Group on the Urban Environmental European Commission. DG XI Environment, Nuclear Safety and Civil Protection, Brussels.

Ewing, R., Bartholomeu, K., Winkelman, S., Walters, J., Chen, D., 2007. Growing Cooler: The Evidence on Urban Development and Climate Change, Urban Land Institute, Chicago.

Eyers, C.J., Norman, P., Middel, J., Plohr, M., Michot, S., Atkinson, K., Christou, R.A., 2004. AERO2k 2004. Global Aviation Emissions Inventories for 2002 and 2025 (QINETIO/04/01113).

Eyring, V., Kohler, H.W., van Aardenne, J., Lauer, A., 2005. Emissions from international shipping: 1 . The last 50 years. art. no. D17305. Journal of Geophysical Research - Atmospheres 110, 17305.

Eyring, V., Isaksen, I.S.A., Berntsen, T., Collins, W.J., Corbett, J.J., Endresen, O., Grainger, R.G., Moldanova, J., Schlager, H., Stevenson, D.S., 2010. Transport impacts on atmosphere and climate: shipping Atmospheric Environment 40, 4735-4771.

Faiz, A., 1993. Automotive emissions in developing countries-relative implications for global warming. Transportation Research Part A: Policy and Practice 27A, $167-186$

Farrell, A.E., Plevin, R.J., Turner, B.T., Jones, A.D., O'Hare, M., Kammen, D.M., 2006 Ethanol can contribute to energy and environmental goals. Science 311 506-508.

Forster, P., Ramaswamy, V., Artaxo, P., Berntsen, T., Betts, R., Fahey, D.W., Haywood, J., Lean, J., Lowe, D.C., Myhre, G., et al., 2007. In: Solomon, S., Qin, D., Manning M., Chen, Z., Marquis, M., Averyt, K.B., Tignor, M., Miller, H.L. (Eds.), Climate Change 2007: The Physical Science Basis. Contribution of Working Group I to the Fourth Assessment Report of the Intergovernmental Panel on Climate Change. Cambridge Univ. Press, Cambridge and New York.

Fraidl, G.K., Kapus, P.E., et al., 2007. DI Turbo: Die nächsten Schritte. 28. Internationales Wiener Motorensymposium, Wien, VDI

Fraser, M.P., Cass, G.R., 1998. Detection of excess ammonia emissions from in-use vehicles and the implications for fine particle control. Environmental Science \& Technology 32, 1053-1057.

Frey, H.C., Kuo, P.-Y., 2007. Best Practices Guidebook for Greenhouse Gas Reductions in Freight Transportation - Final Report. Center for Transportation and the Environment, Department of Civil, Construction, and Environmental Engineering. North Carolina State University, Raleigh, North Carolina/USA. 267.

Friedrich, H.E., Treffinger, P., et al., 2007. Management von Sekundärenergie und Energiewandlung von Verlustwärmeströmen. Dokumentation $\mathrm{CO}_{2}$-Die Herausforderung für unsere Zukunft. Vieweg/GWV Fachverlage $\mathrm{GmbH}$, München.

Fuglestvedt, J.S., Berntsen, T., Isaksen, I.S.A., Liang, M., Wang, W.-C., 1999. Climatic forcing of nitrogen oxides through changes in tropospheric ozone and methane; global 3-D model studies. Atmospheric Environment 33, 961-977.

Fuglestvedt, J., Berntsen, T., Myhre, G., Rypdal, K., Skeie, R.B., 2008. Climate forcing from the transport sectors. Proceedings of the National Academy of Sciences of the United States of America 105, 454-458.

Fuglestvedt, J.S., Shine, K.P., Berntsen, T., Lee, D.S., Stenke, A., Skeie, R.B., Velders, G.J.M., Waitz, I.A., 2010. Transport impacts on atmosphere and climate: metrics. Atmospheric Environment 40, 4648-4677.

Fulton, L., Eads, G., 2004. IEA/SMP Model Documentation and Reference Case Projections. International Energy Agency (IEA)/World Business Council for Sustainable Development (WBCSD). pp. 1-92.

Granier, C., Brasseur, G.P., 2003. The impact of road traffic on global tropospheric ozone. art. no. 1086. Geophysical Research Letters 30, 1086.

Greenpeace/EREC, 2008. Energy [R]evolution - A Sustainable Global Energy Outlook. Greenpeace/European Renewable Energy Council, Amsterdam. Okt. 2008.

Greszler, A., 2007. US Heavy Duty Vehicle Fleets Technologies for Reducing $\mathrm{CO}_{2}-$ an Industry Perspective. In: Asilomar Conference 2007.
Grewe, V., 2004. Technical note: a diagnostic for ozone contributions of various $\mathrm{NO}_{\mathrm{x}}$ emissions in multi-decadel chemistry-climate model simulations. Atmospheric Chemistry \& Physics 4, 729-736.

Grewe, V., 2007. Impact of climate variability on tropospheric ozone. Science of the Total Environment 374, 167-181.

Grunwald, A., 2002. Technikfolgenabschätzung - eine Einführung. Berlin: Ed. Sigma, 319 S. (ISBN 3-89404-931-6).

Gryparis, A., Forsberg, B., Katsouyanni, K., Analitis, A., Touloumi, G., Schwartz, J., Samoli, E., Medina, S., Anderson, H.R., Niciu, E.M., Wichmann, H.E., Kriz, B. Kosnik, M., Skorkovsky, J., Vonk, J.M., Dortbudak, Z., 2004. Acute effects of ozone on mortality from the "Air pollution and health: a European approach" project. American Journal of Respiratory \& Critical Care Medicine 170, 10801087.

Hansen, J., Sato, M., Ruedy, R., 1997. Radiative forcing and climate response. Journal of Geophysical Research - Atmospheres 102, 6831-6864.

Harrison, R.M., Smith, D.J.T., Luhana, L., 1996. Source apportionment of polycyclic aromatic hydrocarbons collected from an urban location in Birmingham UK. Environmental Science \& Technology 30, 825-832.

Hausberger, S., Engler, D., Ivanisin, M., Rexeis, M., 2003. Update of the Emission Functions for Heavy Duty Vehicles in the Handbook Emission Factors for Road Traffic. Federal Environment Agency, Vienna, Austria.

Hoek, G., Brunekreef, B., Goldbohm, S., Fischer, P., van den Brandt, P.A., 2002. Association between mortality and indicators of traffic-related air pollution in the Netherlands: a cohort study. Lancet 360, 1203-1209.

Hoor, P., Borken-Kleefeld, J., Caro, D., Dessens, O., Endresen, O., Gauss, M., Grewe, V., Hauglustaine, D., Isaksen, I.S.A., Jockel, P., Lelieveld, J., Myhre, G., Meijer, E., Olivie, D., Prather, M., Poberaj, C.S., Shine, K.P., Staehelin, J., Tang, O., van Aardenne, J., van Velthoven, P., Sausen, R., 2009. The impact of traffic emissions on atmospheric ozone and $\mathrm{OH}$ : results from QUANTIFY. Atmospheric Chemistry \& Physics 9, 3113-3136.

Hussein, T., Puustinen, A., Aalto, P.P., Makela, J.M., Hameri, K., Kulmala, M., 2004 Urban aerosol number size distributions. Atmospheric Chemistry \& Physics 4, 391-411.

Ibald-Mulli, A., Wichmann, H.E., Kreyling, W., Peters, A., 2002. Epidemiological evidence on health effects of ultrafine particles. Journal of Aerosol Medicine Deposition Clearance \& Effects in the Lung 15, 189-201.

IEA, 2005a. World Energy Outlook 2005.

IEA, 2005b. Energy statistics of OECD countries - 2002-2003 - Statistiques de l'energie des pays de l'OCDE.

IEA, 2007. World Energy Outlook 2007. International Energy Agency, Paris/France.

IEA, 2008a. World Energy Outlook 2008. International Energy Agency, Paris/France.

IEA, 2008b. Energy Technology Perspectives 2008 - Scenarios \& Strategies to 2050.

IEA/OECD, 2006. Energy Technology Perspectives 2006 - Scenarios \& Strategies to 2050. International Energy Agency (IEA).

IIASA, RAINS, ASIA, 2001. Version 7.52. International Institute for Applied Systems Analysis (IIASA), Laxenburg, Austria.

IIASA, 2007. GAINS Europe - Emissions Aggregated by CORINAIR SNAP1 Sector; Scenario: NEC Report Nr 4 NEC Primescoh_Clev4.

IIASA-GGI, 2007. GGI Scenario Database. International Institute for Applied System Analysis (IIASA). Available at: http://www.iiasa.ac.at/Research/GGI/DB/.

Instanes, A., et al., 2005. Infrastructure: Buildings, Support Systems, and Industrial Facilities. ACIA. Arctic Climate Impact Assessment Cambridge University Press, 934 pp.

IEA, 2004. Energy statistics of non-OECD countries - 2001-2002 - Statistiques de l'energie des pays non-membres, 2004 ed. International Energy Agency (IEA), Paris, France, pp 766.

International Energy Agency, 2006. Energy Technology Perspectives 2006: Scenarios and Strategies to 2050: In Support of the G8 Plan of Action. Organisation for Economic Co-operation and Development, $479 \mathrm{pp}$.

IPCC Second Assessment: Climate Change, 1995. A Report of the Intergovernmental Panel on Climate Change (B. Bolin et al., 1995).

IPCC, 2006. 2006 IPCC Guidelines for National Greenhouse Gas Inventories Prepared by the National Greenhouse Gas Inventories Programme 4-88788032-4, 2006.

IPCC Climate Change, 2007a. IPCC Fourth Assessment Report: The Physical Science Basis, Contribution of the Working Group II to the Fourth Assessment Report of the Intergovernmental Panel on Climate Change.

IPCC Climate Change, 2007b. IPCC Fourth Assessment Report: Impacts, Adaptation and Vulnerability, Contribution of the Working Group II to the Fourth Assessment Report of the Intergovernmental Panel on Climate Change.

IPCC Climate Change, 2007c. IPCC Fourth Assessment Report: Mitigation. Contribution of Working Group III to the Fourth Assessment Report of the Intergovernmental Panel on Climate Change.

ISO 14040, 2006. ISO Report 14040 - Environmental management - Life cycle assessment - Principles and framework. Reports from the International Organization for Standardization.

Ito, K., De Leon, S.F., Lippmann, M., 2005. Associations between ozone and daily mortality - analysis and meta-analysis. Epidemiology 16, 446-457.

Jancovici, J.-M., 2004. Bilan carbone d'une activité industrielle ou tertiaire Description de la méthode: objectifs, résultats exploitables, choix méthodologiques. Rapport réalisé pour le compte de l'ADEME, 223 pp. http://www. ademe.fr/bilan-carbone [avril 2006].

Janic, M., 2003. High-speed rail and air passenger transport: a comparison of the operational environmental performance. Proceedings of the Institution of Mechanical Engineers, Part F: Journal of Rail \& Rapid Transit 217, 259-269. 
Jędrychowski, W., 2000. Environmental respiratory health in central and eastern Europe. Central European Journal of Public Health 8, 33-39.

Jiang, H.L., Feingold, G., 2006. Effect of aerosol on warm convective clouds: aerosol-cloud-surface flux feedbacks in a new coupled large eddy model. art. no. D01202. Journal of Geophysical Research - Atmospheres 111, 1202

Jimenez, M.T.F., Climent-Font, A., Anton, J.L.S., 2003. Long term atmospheric pollution study at Madrid city (Spain). Water Air and Soil Pollution 142, 243-260.

Johansson, C., Norman, M., Gidhagen, L., 2007. Spatial \& temporal variations of $\mathrm{PM}_{10}$ and particle number concentrations in urban air. Environmental Monitoring \& Assessment 127, 477-487.

Johnsen, T., Fet, A., 1999. Screening life cycle assessment of M/V Color Festival, Det Norske Veritas, Technical Report No. 98-2061, Rev. 0.

Joumard, R., 2005. The stakes of air pollution in the transport sector, from the French case. Atmospheric Environment 39, 2491-2497.

JRC/CONCAWE/EUCAR, 2006. Well-to-wheels analysis of future automotive fuels and powertrains in the European context.

Juda-Rezler, K., 2006. Urban air pollution and its health effects. Polish Journal of Environmental Studies 15, 118-122.

Kappos, A.D., Bruckmann, P., Eikmann, T., Englert, N., Heinrich, U., Hoppe, P., Koch, E., Krause, G.H.M., Kreyling, W.G., Rauchfuss, K., Rombout, P., SchulzKlemp, V., Thiel, W.R., Wichmann, H.E., 2004. Health effects of particles in ambient air. International Journal of Hygiene \& Environmental Health 207, 399-407.

Kasseris, E.P., 2006. Comparative analysis of automotive powertrain choices for the near to mid-term future. Massachusetts Institute of Technology, Cambridge, Massachusetts, Master Thesis.

Katsouyanni, K., Touloumi, G., Samoli, E., Gryparis, A., Le Tertre, A., Monopolis, Y., Rossi, G., Zmirou, D., Ballester, F., Boumghar, A., Anderson, H.R., Wojtyniak, B., Paldy, A., Braunstein, R., Pekkanen, J., Schindler, C., Schwartz, J., 2001. Confounding and effect modification in the short-term effects of ambient particles on total mortality: results from 29 European cities within the APHEA2 project. Epidemiology 12, 521-531.

Kemppainen, A.J., Shonnard, D.R., 2005. Comparative life-cycle assessments for biomass-to-ethanol production from different regional feedstocks. Biotechnology Progress 21, 1075-1084.

Ketzel, M., Wahlin, P., Kristensson, A., Swietlicki, E., Berkowicz, R., Nielsen, O.J., Palmgren, F., 2004. Particle size distribution and particle mass measurements at urban, near-city and rural level in the Copenhagen area and Southern Sweden. Atmospheric Chemistry \& Physics 4, 281-292.

Ketzel, M., Omstedt, G., Johansson, C., During, I., Pohjolar, M., Oettl, D., Gidhagen, L., Wahlin, P., Lohmeyer, A., Haakana, M., Berkowicz, R., 2007. Estimation and validation of $\mathrm{PM}_{2.5} / \mathrm{PM}_{10}$ exhaust and non-exhaust emission factors for practical street pollution modelling. Atmospheric Environment 41, 9370-9385.

Köhler, I., Dameris, M., Ackermann, I., Hass, H., 2001. Contribution of road traffic emissions to the atmospheric black carbon burden in the mid-1990s. Journal of Geophysical Research - Atmospheres 106, 17997-18014

Krewitt, W., Teske, S., Simon, S., Pregger, T., Graus, W., Blomen, E., Schmid, S., Schafer, O., 2009. Energy [R] evolution 2008 - a sustainable world energy perspective. Energy Policy 37, 5764-5775.

Krzyzanowski, M., Kuna-Dibbert, B., Schneider, J. (Eds.), 2005. Health Effects of Transport-related Air Pollution. WHO Regional Office for Europe, Copenhagen Available at. http://www.euro.who.int/document/e86650.pdf.

Lacis, A.A., Wuebbles, D.J., Logan, J.A., 1990. Radiative forcing by changes in the vertical distribution of ozone. Journal of Geophysical Research 95, 9971-9981.

Lee, D.S., Pitari, G., Grewe, V., Gierens, K., Penner, J.E., Petzold, A., Prather, M.,Schumann, U., Bais, A., Iachetti, D., Lim, L.L., 2010. Transport impacts on atmosphere and climate: aviation. Atmospheric Environment 40, 4678-4734.

Leikauf, G.D., 2002. Hazardous air pollutants and asthma. Environmental Health Perspectives 110, 505-526.

Lelieveld, J., Peters, W., Dentener, F.J., Krol, M.C., 2002. Stability of tropospheric hydroxyl chemistry. art. no. 4715. Journal of Geophysical Research - Atmospheres 107,4715

Levy, J.I., Chemerynski, S.M., Sarnat, J.A., 2005. Ozone exposure and mortality - an empiric bayes metaregression analysis. Epidemiology 16, 458-468.

Lutsey, N., 2008. Prioritizing Climate Change Mitigation Alternatives: Comparing Transportation Technologies to Options in Other Sectors. University of California, Institute of Transportation Studies, Report UCD-ITS-RR-08-15.

MacLean, H.L., Lave, L.B., 2003. Evaluating automobile fuel/propulsion system technologies. Progress in Energy and Combustion Science 29, 1-69.

Malm, W.C., Day, D.E., Kreidenweis, S.M., 2000a. Light scattering characteristics of aerosols at ambient and as a function of relative humidity: Part II - a comparison of measured scattering and aerosol concentrations using statistical models. Journal of the Air \& Waste Management Association 50, 701-709.

Malm, W.C., Day, D.E., Kreidenweis, S.M., 2000b. Light scattering characteristics of aerosols at ambient and as a function of relative humidity: Part I - a comparison of measured scattering and aerosol concentrations using statistical models. Journal of the Air \& Waste Management Association 50, 686-700.

Manoli, E., Voutsa, D., Samara, C., 2002. Chemical characterization and source identification/apportionment of fine and coarse air particles in Thessaloniki, Greece. Atmospheric Environment 36, 949-961.

Marland, G., Boden, T.A., Andres, R.J., 2007. Global, Regional, and National Fossil Fuel $\mathrm{CO}_{2}$ Emissions. In: Trends: A Compendium of Data on Global Change. Carbon Dioxide Information Analysis Center, Oak Ridge National Laboratory. U.S. Department of Energy, Oak Ridge, Tenn., U.S.A. http://cdiac.ornl.gov.
Marr, L.C., Dzepina, K., Jimenez, J.L., Reisen, F., Bethel, H.L., Arey, J., Gaffney, J.S., Marley, N.A., Molina, L.T., Molina, M.J., 2006. Sources and transformations of particle-bound polycyclic aromatic hydrocarbons in Mexico City. Atmospheric Chemistry \& Physics 6, 1733-1745.

Matthes, S., 2003. Globale Auswirkung des Straßenverkehrs auf die chemische Zusammensetzung der Atmosphäre, Ph.D. thesis, Ludwig-Maximilians Universität München, 2003.

Matthes, S., Grewe, V., Sausen, R., Roelofs, G.J., 2007. Global impact of road traffic emissions on tropospheric ozone. Atmospheric Chemistry \& Physics 7 $1707-1718$

Max, E., 2005. Free Piston Energy Converter. Electric Vehicle Symposium 21 Monaco.

McKinsey \& Co, 2009. Pathways to a Low-Carbon Economy - Version 2 of the Global Greenhouse Gas Abatement Cost Curve. McKinsey \& Company.

Mizuho, 2004. Well-to-Wheel Analysis of Greenhouse Gas Emissions of Automotive Fuels in the Japanese Context - Well-to-Tank Report. Mizuho Information \& Research Institute.

Moeckli, M.A., Fierz, M., Sigrist, M.W., 1996. Emission factors for ethene and ammonia from a tunnel study with a photoacoustic trace gas detection system. Environmental Science \& Technology 30, 2864-2867.

Moffet, R.C., de Foy, B., Molina, L.T., Molina, M.J., Prather, K.A., 2008. Measurement of ambient aerosols in northern Mexico City by single particle mass spectrometry. Atmospheric Chemistry \& Physics 8, 4499-4516.

MOST, 2003. Mobility Management Strategies for the Next Decades Final Report. D9.

Mudway, I.S., Kelly, F.J., 2000. Ozone and the lung: a sensitive issue. Molecular Aspects of Medicine 21, 1-48.

Muezzinoglu, A., Odabasi, M., Onat, L., 2001. Volatile organic compounds in the air of Izmir, Turkey. Atmospheric Environment 35, 753-760.

Myhre, G., Shine, K., Gauss, M., et al. Radiative forcing from the transport sectors, in preparation.

Naess, O., Nafstad, P., Aamodt, G., Claussen, B., Rosland, P., 2007. Relation between concentration of air pollution and cause-specific mortality: four-year exposures to nitrogen dioxide and particulate matter pollutants in 470 neighborhoods in Oslo, Norway. American Journal of Epidemiology 165, 435-443.

Nakicenovic, N., et al., 2000. Special Report on Emissions Scenarios: a Special Report of Working Group III of the Intergovernmental Panel on Climate Change, $599 \mathrm{pp}$.

Neburchilov, V., Martin, J., Wang, H.J., Zhang, J.J., 2007. A review of polymer electrolyte membranes for direct methanol fuel cells. Journal of Power Sources 169 221-238.

Newman, P., Kenworthy, J., 1999. Sustainability and Cities - Overcoming Automobile Dependence. Island Press, Washington, DC.

Nielsen, T., 1996. Traffic contribution of polycyclic aromatic hydrocarbons in the center of a large city. Atmospheric Environment 30, 3481-3490.

Niemeier, U., Granier, C., Kornblueh, L., Walters, S., Brasseur, G.P., 2006. Globa impact of road traffic on atmospheric chemical composition and on ozone climate forcing. art. no. D09301. Journal of Geophysical Research - Atmospheres $111,9301$.

NPRI, 2006. Background Paper on Reporting of Particulate Matters from Road Dust National Pollutant Release Inventory (NPRI) Report, Environment Canada.

NRC, 2002. Effectiveness and Impact of Corporate Average Fuel Economy (CAFE) Standards, Committee on the Effectiveness and Impact of Corporate Average Fuel Economy (CAFE) Standards. National Research Council. National Academy Press, Washington, DC.

Nyberg, F., Gustavsson, P., Jarup, L., Bellander, T., Berglind, N., Jakobsson, R. Pershagen, G., 2000. Urban air pollution and lung cancer in Stockholm. Epidemiology 11, 487-495.

O'Brien, K., Sygna, L., Haugen, J.E., 2004. Vulnerable or resilient? A multi-scale assessment of climate impacts and vulnerability in Norway. Climatic Change $64,193-225$

Ohara, T., Akimoto, H., Kurokawa, J., Horii, N., Yamaji, K., Yan, X., Hayasaka, T., 2007. An Asian emission inventory of anthropogenic emission sources for the period 1980-2020. Atmospheric Chemistry \& Physics 7, 4419-4444.

Olivier, J.G.J., Berdowski, J.J.M., Peters, J.A.H.W., Bakker, J., Visschedijk, A.J.H Bloos, J.P.J., 2001. Applications of EDGAR. Including a description of EDGAR V3.0: Reference database with trend data for 1970-1995. Rep. $773301001 /$ NRP Rep. 410200 051. RIVM, Bilthoven, Netherlands.

Olivier, J., Peters, J., Granier, C., Pétron, G., Müller, J.F., Wallens, S., 2003. Present and future surface emissions of atmospheric compounds, POET Rep. 2, EU Proj. EVK2-1999-00011. Available at: http://www.aero.jussieu.fr/projet/ACCENT POET_metadata.php.

Palmer, M.W., Pimentel, D., Lal, R., Kennedy, D., 2007. Biofuels and the environment Science 317, 897-898.

Palmgren, F., Berkowicz, R., Ketzel, M., Winther, M., 2007. Elevated $\mathrm{NO}_{2}$ pollution in Copenhagen due to direct emission of $\mathrm{NO}_{2}$ from road traffic. Conference Proceedings of the 2nd ACCENT Symposium, Atmospheric Composition Change, Urbino, Italy, July 23-27, 2007.

Perrino, C., Catrambone, M., Di Bucchianico, A.D.M., Allegrini, I., 2002. Gaseous ammonia in the urban area of Rome, Italy and its relationship with traffic emissions. Atmospheric Environment 36, 5385-5394.

Perrino, C., Catrambone, M., Bucchianico, A.D.M.D., 2003. Gaseous ammonia from traffic emissions in the urban area of Rome. In: Advances in air pollution series. Air Pollution XI: International Conference on Modelling, Monitoring and Management of Air Pollution No. 11, vol. 13. pp. 601-609. 
Peters, A., Skorkovsky, J., Kotesovec, F., Brynda, J., Spix, C., Wichmann, H.E., Heinrich, J., 2000. Associations between mortality and air pollution in Central Europe. Environmental Health Perspectives 108, 283-287.

Peters, A., Dockery, D.W., Muller, J.E., Mittleman, M.A., 2001. Increased particulate air pollution and the triggering of myocardial infarction. Circulation 103 2810-2815.

Pfeffer, H.U., 1994. Ambient air concentrations of pollutants at traffic-related sites in urban areas of North-Rhine-Westphalia, Germany. Science of the Total Environment $147,263-273$.

Pohl, S.-E., Gräf, M., 2005. Dynamic simulation of a free piston linear alternator. In: Schmitz, G. (Ed.), Proceedings of the 4th International Modelica Conference, Hamburg, March 7-8.

Pope, C.A., 1989. Respiratory disease associated with community air pollution and a steel mill, Utah Valley. American Journal of Public Health 79, $623-628$.

Pope, C.A., 2000. Epidemiology of fine particulate air pollution and human health biologic mechanisms and who's at risk? Environmental Health Perspectives 108, 713-723.

Pope, C.A., Thun, M.J., Namboodiri, M.M., Dockery, D.W., Evans, J.S., Speizer, F.E., Heath, C.W., 1995. Particulate air pollution as a predictor of mortality in a prospective study of us adults. American Journal of Respiratory \& Critical Care Medicine 151, 669-674.

Pope, C.A., Burnett, R.T., Thun, M.J., Calle, E.E., Krewski, D., Ito, K., Thurston, G.D. 2002. Lung cancer, cardiopulmonary mortality, and long-term exposure to fine particulate air pollution. Jama: Journal of the American Medical Association 287, 1132-1141.

Pope, F.D., Hansen, J.C., Bayes, K.D., Friedl, R.R., Sander, S.P., 2007. Ultraviolet absorption spectrum of chlorine peroxide, ClOOCl. Journal of Physical Chemistry A 111, 4322-4332.

Preisegger, E., 1999: Automotive Air Conditioning Impact of Refrigerant on Global Warming. Joint IPCC/TEAP Expert Meeting on Options for the Limitation of Emissions of HFCs and PFCs, Petten, the Netherlands.

Rappenglück, B., Schmitz, R., Bauerfeind, M., Cereceda-Balic, F., von Baer, D., Jorquera, H., Silva, Y., Oyola, P., 2005. An urban photochemistry study in Santiago de Chile. Atmospheric Environment 39, 2913-2931.

Reis, S., Simpson, D., Friedrich, R., Jonson, J.E., Unger, S., Obermeier, A., 2000. Road traffic emissions - predictions of future contributions to regional ozone levels in Europe. Atmospheric Environment 34, 4701-4710.

Riahi, K., Roehrl, R.A., 2000. Greenhouse gas emissions in a dynamics-as-usua scenario of economic and energy development. Technological Forecasting \& Social Change 63, 175-205.

Riahi, K., Gruebler, A., Nakicenovic, N., 2006. Scenarios of long-term socio-economic and environmental development under climate stabilization. Technological Forecasting \& Social Change. doi:10.1016/j.techfore.2006.05.026.

Rodriguez, S., Van Dingenen, R., Putaud, J.P., Dell'Acqua, A., Pey, J., Querol, X Alastuey, A., Chenery, S., Ho, K.F., Harrison, R., Tardivo, R., Scarnato, B. Gemelli, V., 2007. A study on the relationship between mass concentrations, chemistry and number size distribution of urban fine aerosols in Milan, Barcelona and London. Atmospheric Chemistry \& Physics 7, 2217-2232.

Rose, D., Wehner, B., Ketzel, M., Engler, C., Voigtlander, J., Tuch, T. Wiedensohler, A., 2006. Atmospheric number size distributions of soot particles and estimation of emission factors. Atmospheric Chemistry \& Physics 6, 1021-1031.

Ross, D.K., 2006. Hydrogen storage: the major technological barrier to the development of hydrogen fuel cell cars. Vacuum 80, 1084-1089.

Ryan, L., Convery, F., Ferreira, S., 2006. Stimulating the use of biofuels in the European Union: implications for climate change policy. Energy Policy 34 3184-3194.

SAE, Society of Automotive Engineers 2003, Alternative Refrigerants Assessment Workshop.

Samaras, Z., Ntziachristos, L., Thompson, N., Hall, D., Westerholm, R., Boulter, P., 2005. PARTICULATES - Characterisation of Exhaust Particulate Emissions from Road Vehicles. Final Report to the European Commission, DG TREN, Contract 2000-RD.11091. LAT, Athens, Greece. 114 p.

Samaras, C. Meisterling, K., 2008. Life cycle assessment of greenhouse gas emissions from plug-in hybrid vehicles: implications for policy. Environmental Science \& Technology 42, 3170-3176

Schafer, A., 2000. Regularities in travel demand: an international perspective. Journal of Transportation and Statistics 3,1-31.

Schäfer, A., Heywood, J.B., Weiss, M.A., 2006. Future fuel cell and internal combustion engine automobile technologies: a 25-year life cycle and fleet impact assessment. Energy 31, 2064-2087.

Schedel, R., 2007. Viel Entwicklungspotenzial in der Aerodynamik. ATZ. 01/2007.

Schmid ,V., 2003, Dissertation: Reaktivierte Nebenbahnen und alternative Buskonzepte, Institut für Straßen- und Verkehrswesen Universität Stuttgart, 2003.

Schmid, S.A., 2009. Global scenarios for light duty vehicles to 2050. 7th International Colloquium FUELS Jan 2009

Schmidt, G., 2006. Antriebe für den Europäischen Markt und die Rolle von Hybridkonzepten. 10. Handelsblatt Jahrestagung Automobiltechnologien.

Schultz, M.G., Feichter, J., Leonardi, J., 2004. Climatic Impact of Surface Transport, in Issues in Environmental Science and Technology. Transport and the Environment. R. Soc. of Chem., Cambridge, U.K. pp. 111-127.

Schwartz, J., 2000. Harvesting and long term exposure effects in the relation between air pollution and mortality. American Journal of Epidemiology 151, $440-448$.
Schwarz, J.P., Stark, H., Spackman, J.R., Gao, R., Watts, L.A., Thomson, D.S., Fahey, D.W., 2007. Atmospheric heating of the Houston urban boundary layer by black carbon aerosol absorption of solar radiation, personnal communication, AGU Fall Meeting, A32A Urban Effects on Radiative Forcing by Aerosol and Clouds I.

Shine, K.P., Berntsen, T.K., Fuglestvedt, J.S., Sausen, R., 2005. Scientific issues in the design of metrics for inclusion of oxides of nitrogen in global climate agreements. Proceedings of the National Academy of Sciences United States of America 102, 15768-15773.

Shine, K.P., Berntsen, T.K., Fuglestvedt, J.S., Bieltvedt Skeie, R., Stuber, N., 2007. Comparing the climate effect of emissions of short- and long-lived climate agents. Philosophical Transactions of the Royal Society A, 1903-1914.

Skeie, R.B., et al., 2009. Global temperature change from the transport sectors: Historical development and future scenarios. Atmospheric Environment 43 (39), 6260-6270. doi:10.1016/j.atmosenv.2009.05.025.

SLC, 2007. Sustainable Production Technologies of Emission Reduced Light-weight Car Concepts: SuperLIGHT-CAR/SLC, Collaborative Research \& Development Project Co-funded by the European Commission Under the 6th Framework Programme.

Smokers, R., Vermeulen, R., van Mieghem, R., Gense, R., Skinner, I., Fergusson, M. MacKay, E., ten Brink, P., Fontaras G. and Samaras Z. 2006. Review and analysis of the reduction potential and costs of technological and other measures to reduce $\mathrm{CO}_{2}$ emissions from passenger cars. TNO Report 06.OR.PT.040.2/RSM. Report to the European Commission.

Song, Y., Tang, X.Y., Zhang, Y.H., Hu, M., Fang, C., Zeng, L.M., 2003a. The study of the status and degradation of visibility in Beijing. Research of Environmental Sciences 16, 10-12.

Song, Y., Tang, X.Y., Fang, C., Zhang, Y.H., Hu, M., Zeng, L.M., Li, C.C., Mao, J.T., 2003b. Relationship between the visibility degradation and particle pollution in Beijing. Acta Scientiae Circumstantiae 23, 468-471.

SROC, 2006. In: Metz, B., Kuijpers, L., Solomon, S., Andersen, S.O., Davidson, O. Pons, J., de Jager, D., Kestin, T., Manning, M., Meyer, L. (Eds.), Special Report on Safeguarding the Ozone Layer and the Global Climate System: Issues Related to Hydrofluorocarbons and Perfluorocarbons. Cambridge University Press, UK. pp 478.

Stone, E.A., Snyder, D.C., Sheesley, R.J., Sullivan, A.P., Weber, R.J., Schauer, J.J., 2008. Source apportionment of fine organic aerosol in Mexico City during the MILAGRO experiment 2006. Atmospheric Chemistry \& Physics 8, 1249-1259.

Streets, D.G., Bond, T.C., Carmichael, G.R., Fernandes, S.D., Fu, Q., He, D., Klimont, Z., Nelson, S.M., Tsai, N.Y., Wang, M.Q., Woo, J.H., Yarber, K.F., 2003. An inventory of gaseous and primary aerosol emissions in Asia in the year 2000. art. no. 8809. Journal of Geophysical Research - Atmospheres 108, 8809.

SUTRA, 2003. Sustainable Urban Transport Project. Final Report. Available at: http:// www.ess.co.at/SUTRA/DELIVERABLES/PUBLIC.pdf.

Tarzia, V. (Ed.), 2003. European Common Indicators: Towards a Local Sustainability Profile, ECIP Final Report. Ambiente Italia Research Institute.

Thacher, E.F., Helenbrook, B.T., Karri, M.A., Richter, C.J., 2007. Testing of an automobile exhaust thermoelectric generator in a light truck. Proceedings of the Institution of Mechanical Engineers, Part D, Journal of Automobile Engineering 221, 95-107.

Torney, F., Moeller, L., Scarpa, A., Wang, K., 2007. Genetic engineering approaches to improve bioethanol production from maize. Current Opinion in Biotechnology 18, 193-199.

TRANSLAND, 2000. Integration of Transport and Land Use Planning. Final Summary Report. Available at: http://cordis.europa.eu/transport/src/translandrep.htm.

Treloar, G.J., Love, P.E.D., Crawford, R.H., 2004. Hybrid life-cycle inventory for road construction and use. Journal of Construction Engineering \& Management ASCE 130, 43-49.

Turco, R.P., Yu, F.Q., 1999. Particle size distributions in an expanding plume undergoing simultaneous coagulation and condensation. Journal of Geophysical Research - Atmospheres 104, 19227-19241.

Turton, H., 2006. Sustainable global automobile transport in the 21st century: an integrated scenario analysis. Technological Forecasting \& Social Change 73 $607-629$.

UIC/CER, 2006. Rail Diesel Emissions e Facts and Challenges Community of European Railway and Infrastructure Companies. Available at: www.uic.asso.fr/ download.php/environnement/060912_Rail_Diesel_8aout_06.pdf.

Umierski, M., Rütten, O., et al., 2004. PKW-Erdgasantriebe für hohe Leistungsdichte und niedrigste Abgasemissionen. Gasfahrzeuge: Die passende Antwort auf die CO2-Herausforderung der Zukunft? O. Dingel (ed.), Expert Verlag, Renningen, ISBN-13: 978-3-8169-2439-5.

US-DoE, 2006. International Energy Outlook 2006. U.S. Department of Energy, Energy Information Administration, Washington, DC, USA, 192+X pp.

US-DoE, 2009. International Energy Outlook 2009. U.S. Department of Energy, Energy Information Administration, Washington, DC, USA, 127+X pp.

US-DoT, 2006. National Transportation Statistics 2004. U.S. Department of Transportation, Bureau of Transportation Statistics. Washington, DC, U.S. Government Printing Office, pp. 640.

US-EPA, 2003. User's Guide to MOBILE6.1 and MOBILE6.2 - Mobile Source Emission Factor Model. US-Environmental Protection Agency, Office of Transportation and Air Quality, Washington, D.C., USA.

US-EPA, 2005. National Emissions Inventory (NEI) Air Pollutant Emissions Trends Data. 1970-2002. Average annual emissions, all criteria pollutants in MS Excel - July 2005. US-Environmental Protection Agency, Washington, D.C., USA, Posted August 2005. http://www.epa.gov/ttn/chief/trends/index.html. Accessed April 6, 2006. 
4816

E. Uherek et al. / Atmospheric Environment 44 (2010) 4772-4816

Van Mierlo, J., Magneto, G., Lataire, P., 2006. Which energy source for road transport in the future? A comparison of battery, hybrid and fuel cell vehicles. Energy Conversion \& Management 47, 2748-2760.

Velasco, E., Lamb, B., Westberg, H., Allwine, E., Sosa, G., Arriaga-Colina, J.L., Jobson, B.T., Alexander, M.L., Prazeller, P., Knighton, W.B., Rogers, T.M., Gritter, M., Herndon, S.C., Kob, C.E., Zavala, M., de Fry, B., Volkamer, R., Molina, L.T., Molina, M.J., 2007. Distribution, magnitudes, reactivities, ratios and diurnal patterns of volatile organic compounds in the Valley of Mexico during the MCMA 2002 \& 2003 field campaigns. Atmospheric Chemistry \& Physics 7, 329-353.

vo Helmolt, R., Eberle, U., 2007. Fuel cell vehicles: status 2007. Journal of Power Sources $165,833-843$.

WHO, 2000. Air Quality Guidelines for Europe, Second Edition. WHO, Regional Office for Europe Regional Publications, European Series, No. 91.

WHO, 2002. The World Health Report 2002. Reducing Risks, Promoting Healthy Life. World Health Organization, Geneva. Available at. http://www.who.int/whr/ 2002/en/whr02_en.pdf.

WHO, 2003. Health aspects of air pollution with particulate matter, ozone and nitrogen dioxide. Report on a WHO Working Group. WHO Regional Office for Europe, Copenhagen (document EUR/03/5042688). Available at http://www. euro.who.int/document/e79097.pdf.

WHO, 2005a. WHO air quality guidelines global update 2005. Report on a Working Group Meeting, Bonn, Germany, 18-20 October 2005.

WHO, 2005b. Particulate matter air pollution: how it harms health. WHO, Regional Office for Europe Fact sheet EURO/04/05: Berlin, Copenhagen, Rome, 14 April 2005.

WHO, 2006. Health risks of particulate matter from long-range transboundary air pollution. Joint WHO/Convention Task Force on the Health Aspects of Air
Pollution. European Centre for Environment and Health, Bonn Office. Available at: http://www.euro.who.int/document/E88189.pdf.

Wietschel, M., Hasenauer, U., de Grout, A., 2006. Development of European hydrogen infrastructure scenarios $-\mathrm{CO}_{2}$ reduction potential and infrastructure investment. Energy Policy 34, 1284-1298.

WMO, 1998. Scientific Assessment of Ozone Depletion: 1998, WMO Global Ozone Research and Monitoring Project - Report No. 44, Geneva.

WMO, 2002. The Scientific Assessment of Ozone Depletion, WMO Global Ozone Research and Monitoring Project-Report No. 47, Geneva, Switzerland. ISBN: 92807-2261-1.

Wrobel, A., Rokita, E., Maenhaut, W., 2000. Transport of traffic-related aerosols in urban areas. Science of the Total Environment 257, 199-211.

WSDA, 2007. Renewable Diesel Technology. Renewable Diesel Subcommittee of the Washington State Department of Agriculture. White Paper July 2007.

Zah, R., Böni, H., et al., 2007. Ökobilanzen vo Energieprodukten: Ökologische Bewertung won Biotreibstoffen. Bern, EMPA, Abteilung Technologie and Gesellschaft.

Chang, Y., Zhu, X., Zens, L., Wang, W., 2004. Urbanization, energy, and air pollution in China: the challenges ahead. In: Proceedings of a Symposium, pp. 139-154.

Zhang, J.L., Xe, Z., Zhang, J.J., Tanga, Y.H., Song, C.J., Navessin, T., Si, Z.Q., Song, D.T., Wang, H.J., Wilkinson, D.P., Lu, Z.S., Holdcroft, S., 2006. High temperature PEM fuel cells. Journal of Power Sources 160, 872-891.

Zmirou, D., Schwartz, J., Suez, M., Zanobetti, A., Wojtyniak, B., Touloumi, G., Six, C., Deleon, A.P., Lemoullec, Y., Bacharova, L., Schouten, J., Ponka, A., Katsouyanni, K., 1998. Time-series analysis of air pollution and cause-specific mortality. Epidemisology 9, 495-503. 